Aus der Abteilung Klinische Pharmakologie

(Prof. Dr. med. J. Brockmöller)

im Zentrum Pharmakologie und Toxikologie

der Medizinischen Fakultät der Universität Göttingen

\title{
Variabilität des Therapieansprechens von Gemcitabin bei \\ Pankreaskarzinom: Identifizierung relevanter Genpolymorphismen
}

Retrospektive Studie bei Patienten mit Pankreaskarzinom

\section{INAUGURAL-DISSERTATION}

zur Erlangung des Doktorgrades

der Medizinischen Fakultät

der Georg-August-Universität zu Göttingen

vorgelegt von

Alexander Schaudinn

aus Erfurt

Göttingen 2012 
Dekan:

Prof. Dr. med. M. P. Schön

I. Berichterstatter: Prof. Dr. med. J. Brockmöller

II. Berichterstatter/in: Priv.-Doz. Dr. med. Liersch

III. Berichterstatter/in:

Tag der mündlichen Prüfung: 28.01.2013 


\section{Inhaltsverzeichnis}

ABKÜRZUNGSVERZEICHNIS.........................................................................................................ii

TABELLENVERZEICHNIS...................................................................................................................

ABBILDUNGSVERZEICHNIS......................................................................................................................................viii

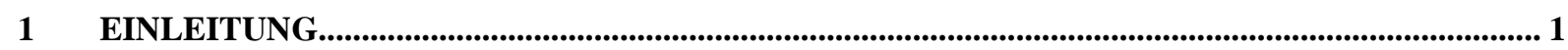

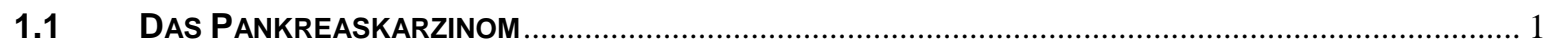

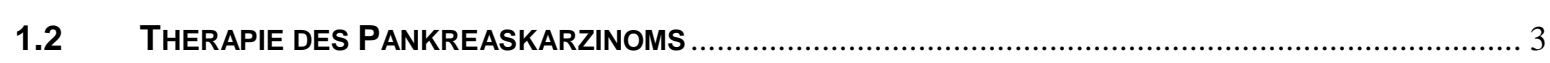

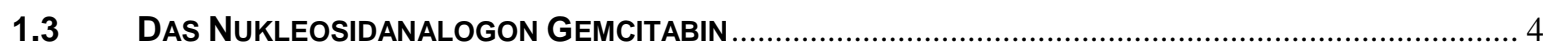

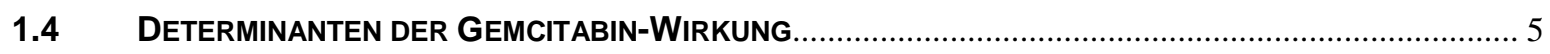

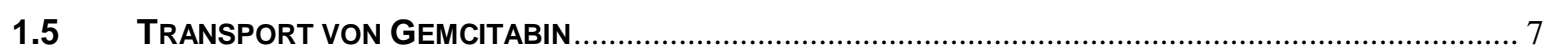

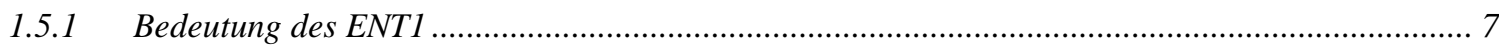

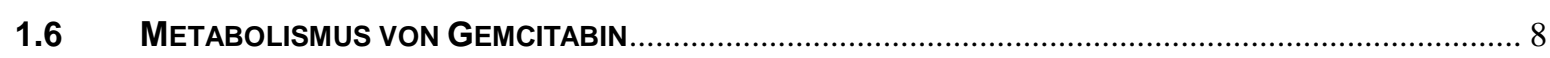

1.7 HedGEHOG-SignalWEg UND WIRKSAMKEIT Von GEMCITABIN .............................................. 9

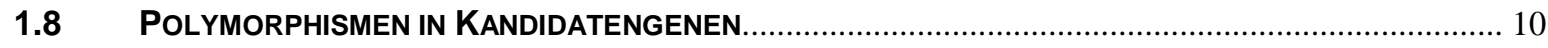

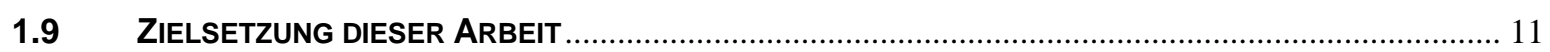

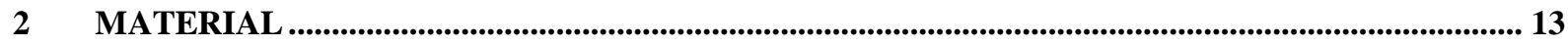

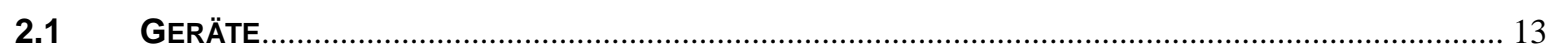

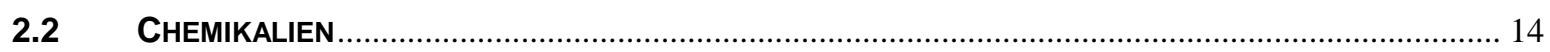

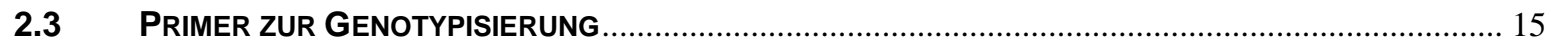

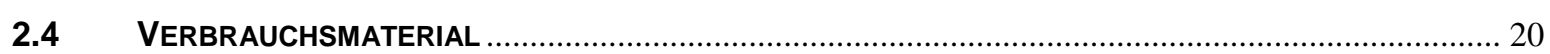

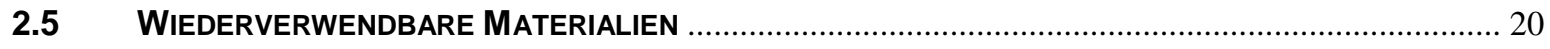

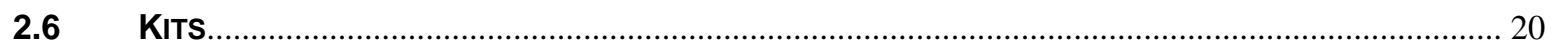

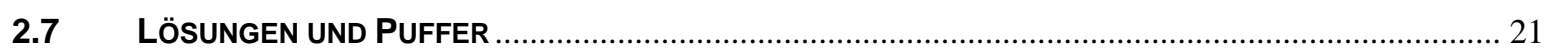

2.8 SOFTWARE

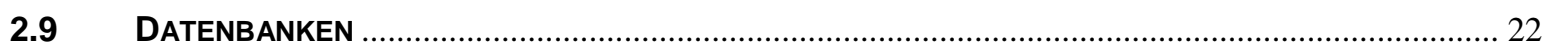

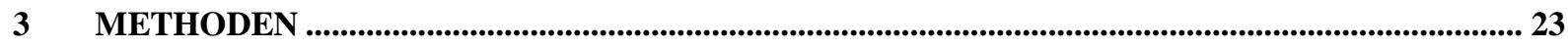

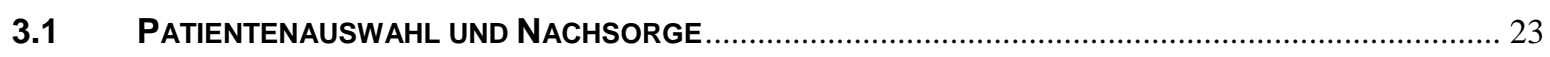

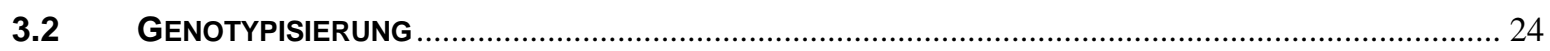

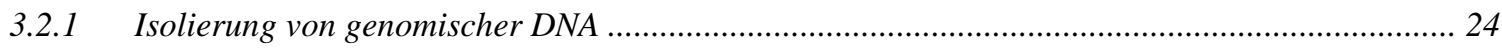

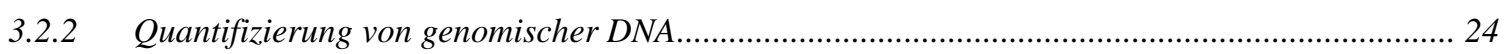

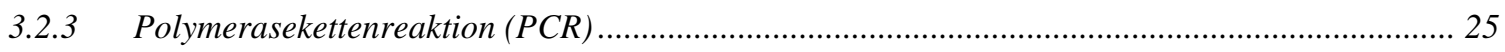

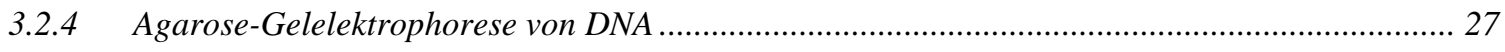

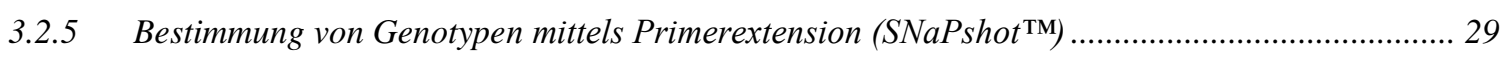

3.2.6 Fragmentlängenanalyse zweier Insertionspolymorphismen ………………….......................... 31

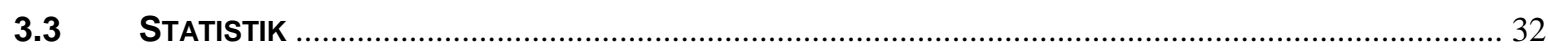

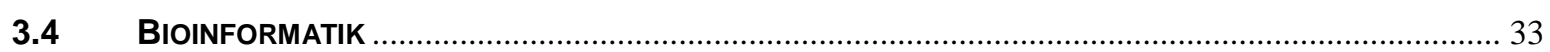




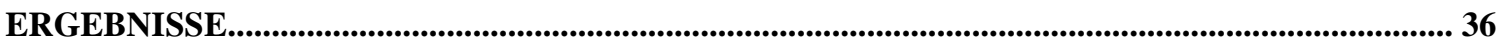

4.1 PatientenKohorte mit VeRTEILUNG DeR ÜBerlebenSZEITEN................................................... 36

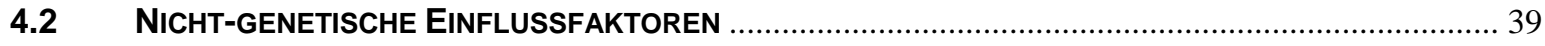

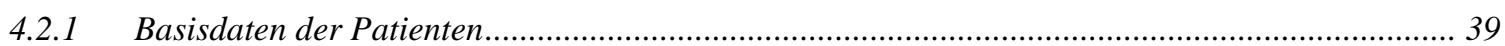

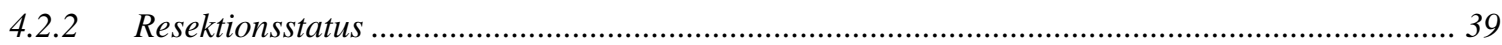

4.2.3 Histopathologisches Grading............................................................................................ 40

4.2.4 Gemcitabin als Mono- oder Kombinationstherapie ..................................................................... 41

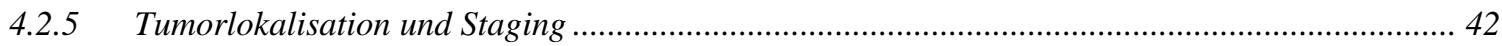

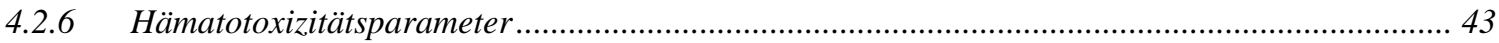

4.3 KeIMBahN-VARIANTEN IN KANDIDATENGENEN FüR GEMCITABIN.............................................. 44

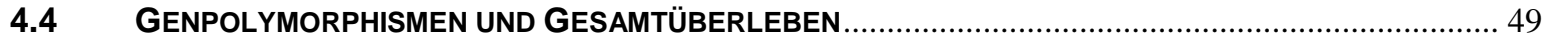

4.4.1 Explorative Analyse mit 109 Kandidatengen-Varianten .............................................................. 50

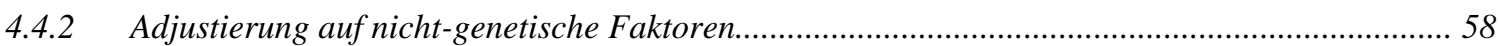

4.4.3 Kombiniertes SNP-Modell............................................................................................. 58

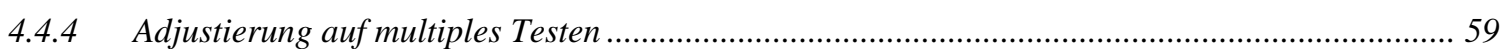

4.4.5 Stärkste Effekte für Varianten im Bereich des ENT1-Gens....................................................... 59

4.4.6 SNP in SHH mit tendenzieller Beeinflussung der Überlebenszeit .............................................. 62

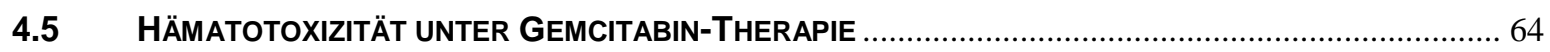

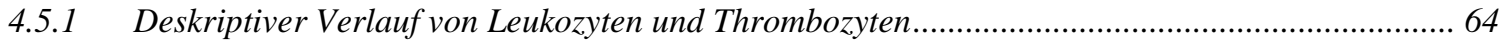

4.5.2 Variabilität in Ausprägung und Zeitdauer des Nadir-Eintritts .................................................... 66

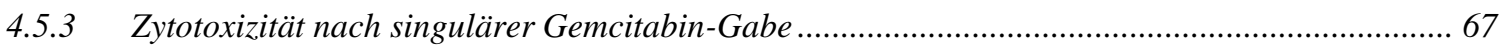

4.5.4 Einfluss von Varianten in Gemcitabin-Kandidatengenen auf Nadir sowie Zytotoxizität nach

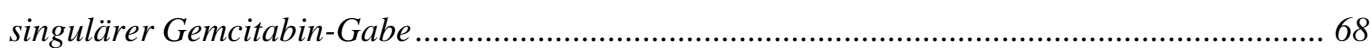

4.5.5 Rs747199 beeinflusst gleichsinnig Überleben und Hämatotoxizität ............................................ 69

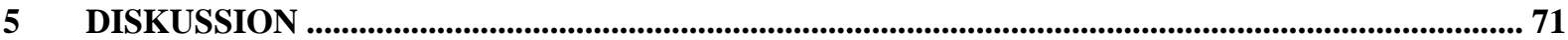

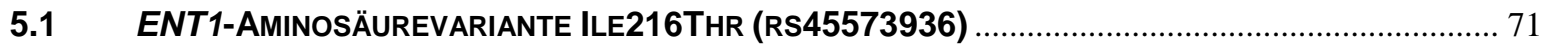

5.2 VARIANTEN IN PROMOTORREGION UND INTRON 1 von ENT1 ................................................... 73

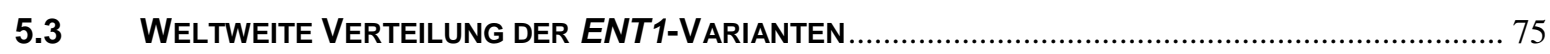

5.4 WEITERE GENVARIANTEN ALS MÖGLICHE BIOMARKER FÜR THERAPIEANSPRECHEN ………......... 76

5.5 DETERMINANTEN DER HÄMATOTOXIZITÄT UNTER GEMCITABIN..................................................... 77

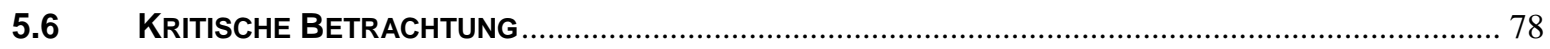

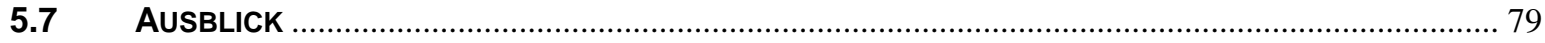

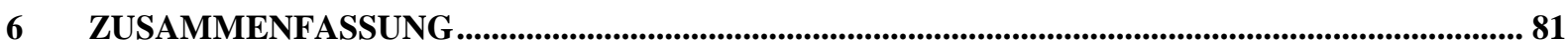

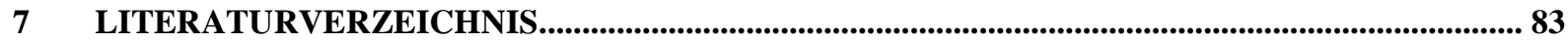




\section{Abkürzungsverzeichnis}

A

Abb.

Ala

ASCO

BMI

bp

bzw.

$\mathrm{C}$

${ }^{\circ} \mathrm{C}$

ca.

CDA

CMPK1

CNT (s)

CTC

dbSNP

(d)CDP

DCK

DCTD

dCTP

$\mathrm{ddH}_{2} \mathrm{O}$

ddNTP

Del

dFdU

dFdUMP

d.h.

DNA

dNTP

EDTA

ENT (s)

et al.

FAM

FDR

FL
Adenin

Abbildung

Alanin

American Society of Clinical Oncology

Body Mass Index

Basenpaare

beziehungsweise

Cytosin

Grad Celsius

circa

Cytidindeaminase

Cytidinmonophosphatkinase 1

konzentrativer Nukleosidtransporter (Plural)

Common Terminology Criteria for Adverse Events, Toxizitätskriterien

database SNP, innerhalb NCBI-Datenbank

(Desoxy-) Cytidindiphosphat

Desoxycytidinkinase

Desoxycytidilat-Deaminase

Desoxycytidintriphosphat

(doppelt destilliertes) Wasser

Didesoxynukleosidtriphosphat

Deletion

2',2'-Difluorodesoxyuridin

Difluorodesoxyuridin-Monophosphat

das heißt

Deoxyribonucleic Acid, Desoxyribonukleinsäure

Desoxynukleosidtriphosphat

Ethylen Diamin Tetraacetic Acid

äquilibrierender Nukleosidtransporter (Plural)

et alii, und andere

6-Carboxyfluorescein

False Discovery Rate

Fragmentlänge 


\begin{tabular}{|c|c|}
\hline $5-\mathrm{FU}$ & 5-Fluorouracil \\
\hline $\mathrm{G}$ & Guanin \\
\hline g & Gramm \\
\hline Gln & Glutamin \\
\hline $\mathrm{h}$ & hour, Stunde \\
\hline Het & Heterozygotie \\
\hline HR & Hazard Ratio \\
\hline HWE & Hardy-Weinberg-Equilibrium \\
\hline Ile & Isoleucin \\
\hline IL17F & Interleukin $17 \mathrm{~F}$ \\
\hline Ins & Insertion \\
\hline IPMN & Intraduktale papillär-muzinöse Neoplasie \\
\hline $\mathrm{k}$ & Kilo \\
\hline $\mathrm{kbp}$ & Kilobasenpaare \\
\hline $\mathrm{kg}$ & Kilogramm \\
\hline KI & Konfidenzintervall \\
\hline $\mathrm{KOF}$ & Körperoberfläche \\
\hline k-ras & Kirsten rat sarcoma viral oncogene homolog \\
\hline LD & linkage disequilibrium, Kopplungsungleichgewicht \\
\hline Lys & Lysin \\
\hline $\mathrm{m} / \mathrm{m}^{2}$ & Meter / Quadratmeter \\
\hline M & Mol \\
\hline MAF & minor allele frequency, Frequenz des selteneren Allels \\
\hline MAPRE2 & Microtubule-associated protein, member 2 \\
\hline $\mathrm{mg}$ & Milligramm \\
\hline $\mathrm{MgCl}_{2}$ & Magnesiumchlorid \\
\hline$\mu \mathrm{g}$ & Mikrogramm \\
\hline$\mu 1$ & Mikroliter \\
\hline $\min$ & Minuten \\
\hline $\mathrm{ml}$ & Milliliter \\
\hline $\mathrm{mM}$ & Millimol \\
\hline mRNA & messenger RNA, Boten-RNA \\
\hline $\mathrm{NaCl}$ & Natriumchlorid \\
\hline NCBI & National Center for Biotechnology Information \\
\hline $\mathrm{NCI}$ & National Cancer Institut \\
\hline ng & Nanogramm \\
\hline
\end{tabular}




\begin{tabular}{|c|c|}
\hline $\mathrm{nm}$ & Nanometer \\
\hline Notch & Notch-Signalweg \\
\hline NOX4 & NADPH Oxidase-4 \\
\hline NSCLC & $\begin{array}{l}\text { Non-small cell lung cancer, nicht-kleinzelliges } \\
\text { Bronchialkarzinom }\end{array}$ \\
\hline NTs & Nukleosid-Transporter (Plural) \\
\hline NT5C/NT5C3 - 5' & Nukleotidase/Isoform 3 \\
\hline OD & optische Dichte \\
\hline$P$ & Signifikanzniveau \\
\hline PBMC & $\begin{array}{l}\text { Peripheral Blood Mononuclear Cells, } \\
\text { mononukleäre Zellen des peripheren Bluts }\end{array}$ \\
\hline PCR & Polymerase Chain Reaction, Polymerasekettenreaktion \\
\hline $\mathrm{pH}$ & pondus Hydrogenii \\
\hline PRB2 & proline-rich protein BstNI subfamily 2 \\
\hline Primer-F & Vorwärts-Primer \\
\hline Primer-R & Rückwärts-Primer \\
\hline PTCH1 & Patched 1 \\
\hline PYCARD & $P Y D$ and $C A R D$ domain containing \\
\hline $\mathrm{r}$ & Korrelationskoeffizient nach Pearson \\
\hline $\mathrm{r}^{2}$ & Bestimmtheitsmaß \\
\hline rho & Spearmans Rangkorrelationskoeffizient \\
\hline RNA & Ribonucleic Acid, Ribonukleinsäure \\
\hline ROX & 6-Carboxy-X-Rhodamin \\
\hline RRM1/RRM2(B) & Unterformen der Ribonukleotid-Reduktase \\
\hline rs-Nummer & Reference SNP-Nummer \\
\hline S. & Seite \\
\hline $\mathrm{s}$ & Sekunde \\
\hline Ser & Serin \\
\hline $\mathrm{SHH}$ & Sonic hedgehog \\
\hline SLC29A1 & $\begin{array}{l}\text { solute carrier family } 29 \text { member } 1 \text { (Nukleosidtransporter); } \\
\text { Synonym zu ENT1-Transporter }\end{array}$ \\
\hline SMO & Smoothened \\
\hline SNP & $\begin{array}{l}\text { Single Nucleotide Polymorphism, Einzelnukleotid- } \\
\text { Polymorphismus }\end{array}$ \\
\hline $\mathrm{T}$ & Thymin \\
\hline Tab. & Tabelle \\
\hline TBE & Tris-Borat-EDTA-Puffer \\
\hline
\end{tabular}


TE

TGF $\beta$

Thr

TNM

Tris

$\mathrm{U}$

u.a.

UICC

UTR

UV

$\mathrm{V}$

v.a.

Var

$\mathrm{v} / \mathrm{v}$

Wnt

$\mathrm{Wt}$

$\chi^{2}$-Test

z.B.
Tris-EDTA-Puffer

Transforming growth factor beta

Threonin

Tumor-Klassifikation nach Tumorausbreitung (T), Lymphknotenbefall (N),Metastasierung (M)

Tris-Hydroxymethyl-Aminomethan

Units (Einheit für Enzymaktivität)

unter anderem $/ \mathrm{n}$

Union internationale contre le cancer

untranslated region, nicht abgelesener Bereich auf der mRNA

Ultraviolett

Volt

vor allem

Varianten-Allel

volume per volume (Volumen pro Volumen)

Wnt-Signalweg (Wingless und Int-1)

Wildtyp-Allel

Chi-Quadrat-Test

zum Beispiel 


\section{Tabellenverzeichnis}

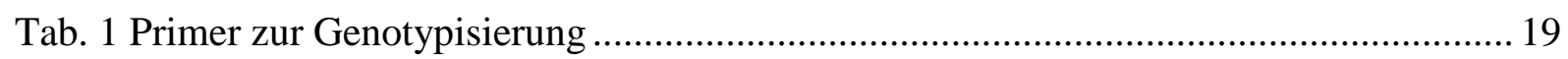

Tab. 2 Standard-Bedingungen für PCR mit Taq-Polymerase .............................................. 25

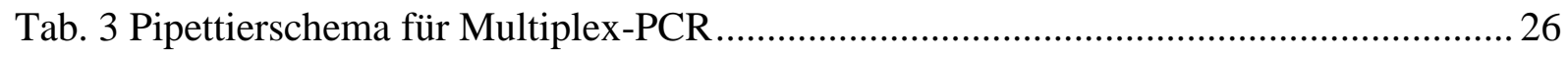

Tab. 4 Pipettierschema für Einzel-PCR im 12- $\mu 1-$ Maßstab ................................................ 27

Tab. 5 Reaktionsansatz und Reaktionsbedingungen für SNaPshot ${ }^{\mathrm{TM}}$-PCR ............................ 30

Tab. 6 Kandidatengene mit Anzahl untersuchter Genvarianten (SNPs) ................................. 34

Tab. 7 Charakteristika auswertbarer Patienten bezüglich Gemcitabin-Therapie ..................... 38

Tab. 8 Korrelation von Hämatotoxizitätsparametern und Gesamtüberleben ........................... 43

Tab. 9 Charakteristika untersuchter Genpolymorphismen geordnet nach Genen ................... 49

Tab. 10 Genpolymorphismen und Gesamtüberleben ........................................................ 57

Tab. 11 Zusammenstellung der mit dem Gesamtïberleben assoziierten SNPs .......................58

Tab. 12 Kombiniertes Cox-Modell der am stärksten mit dem Überleben assoziierten SNPs . 59

Tab. 13 Cox-Regressionsanalyse zur Assoziation von ENT1 rs45573936 und Überleben ..... 60

Tab. 14 ENT1 rs1057985 und nicht-genetische Faktoren im Cox-Modell bezogen auf

Gesamtüberleben 62

Tab. 15 Einfluss von $S H H$ rs 288746 und nicht-genetischer Faktoren auf Gesamtüberleben .. 63

Tab. 16 Verlaufsdaten für Leukozyten während der ersten 42 Tage Gemcitabin-Therapie .... 65

Tab. 17 Verlaufsdaten für Thrombozyten in den ersten 42 Tagen der Gemcitabin-Therapie 65

Tab. 18 SNPs mit Einfluss auf Hämatotoxizität

Tab. 19 Häufigkeit der ENT1-Varianten rs1057985, rs747199 und rs45573936 bezogen auf Ethnizitäten 


\section{Abbildungsverzeichnis}

Abb. 1 Strukturformeln von Desoxy-Cytidin und Gemcitabin ............................................... 4

Abb. 2 Weg des Gemcitabins bis zu seinem Wirkort ............................................................ 6

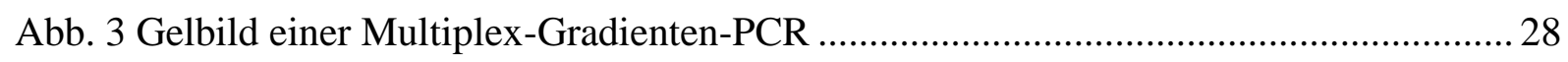

Abb. 4 SNaPshot ${ }^{\mathrm{TM}}$-Elektropherogramm für zehn Polymorphismen des ENT1-Gens ............ 31

Abb. 5 Flussdiagramm zur Auswahl der Patientenkohorte ................................................... 37

Abb. 6 Kaplan-Meier-Kurve zur Überlebenszeit in Abhängigkeit vom Resektionsstatus ...... 40

Abb. 7 Überlebenskurven in Abhängigkeit vom histopathologischen Grading ....................... 41

Abb. 8 Überlebenskurven für Gemcitabin in Mono- und Kombinationstherapie ..................... 42

Abb. 9 Korrelation zwischen Überlebenszeit und Grad der Leukopenie unter Gemcitabin .... 44

Abb. 10 Überlebenskurven in Abhängigkeit des ENT1-SNPs rs45573936 (Ile216Thr) ......... 60

Abb. 11 Architektur des ENT1-Gens und Kopplungsplot der analysierten Varianten ............ 61

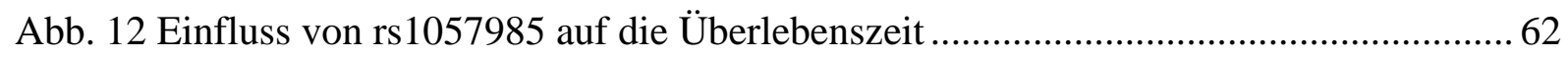

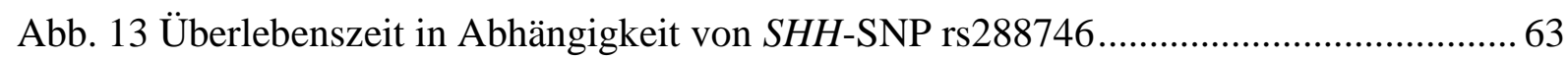

Abb. 14 Häufigkeitsverteilung des Leukozytopeniegrades und des Zeitintervalls bis

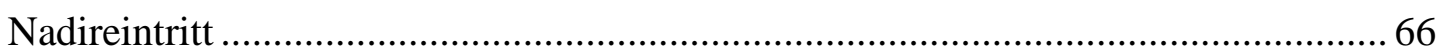

Abb. 15 Häufigkeitsverteilung des Thrombozytopeniegrades und des Zeitintervalls bis

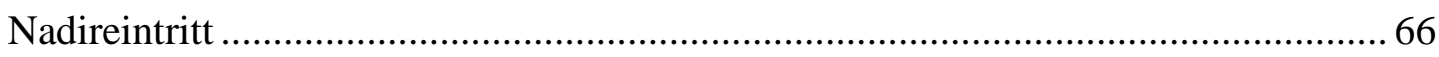

Abb. 16 Verlauf von Leukozyten und Thrombozyten innerhalb der ersten sieben Tage ........ 67

Abb. 17 Effekte von rs747199 auf Hämatotoxizität und Gesamtüberleben ............................ 70

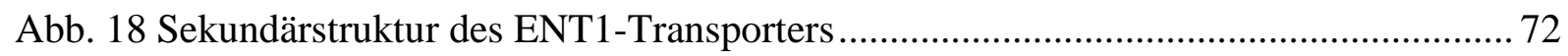

Abb. 19 Gemcitabin-Toxizität in Abhängigkeit von rs45573936 (Ile216Thr). ...................... 73

Abb. 20 Einfluss des Promotor-SNPs rs 1057985 auf die basale ENT1-Transkription ............ 74 


\section{Einleitung}

\subsection{Das Pankreaskarzinom}

Jedes Jahr erkranken in Deutschland etwa 13000 Personen neu an einem Pankreaskarzinom mit stetig steigender Tendenz (Robert Koch-Institut 2011). Für beide Geschlechter besteht in etwa ein gleich hohes Lebenszeitrisiko von 1,4\% zur Entwicklung eines Pankreaskarzinoms (Robert Koch-Institut 2010a). Das durchschnittliche Erkrankungsalter liegt in Deutschland bei 76 Jahren (Frauen) bzw. 69 Jahren (Männer). Innerhalb der Gruppe der GastrointestinalTumore ist das Pankreaskarzinom in Deutschland das dritthäufigste Malignom nach Kolonund Magenkarzinom (in den USA bereits das zweithäufigste). Unter allen neu aufgetretenen malignen Tumoren steht es auf Platz neun (Frauen) bzw. zehn (Männer). Betrachtet man vergleichend die Letalität maligner Tumore in Deutschland, rangiert das Pankreaskarzinom mittlerweile bereits an vierter Stelle (Robert Koch-Institut 2010a). Den beobachteten Effekt von hoher Letalität bei verhältnismäßig niedriger Inzidenz unterstreichen weltweite Zahlen mit einer Letalitätsrate von 3,7/100000 zu einer Inzidenzrate von 3,9/100000 Personen (Ferlay et al. 2010). Die Aggressivität dieses Karzinoms spiegelt sich auch in der sehr niedrigen 5-Jahresüberlebensrate wider (weltweit unter 5\%, Jemal et al. 2010; in Deutschland $8 \%$ bei Frauen und $6 \%$ bei Männern, Robert Koch-Institut 2010b). Betrachtet man die Gesamtüberlebenszeit aller Patienten von durchschnittlich weniger als einem Jahr, so ist das Pankreaskarzinom eine der Tumorentitäten mit der wohl schlechtesten Prognose überhaupt. Auch bei primär mit kurativer Intention resezierten Patienten liegt die mittlere Gesamtüberlebenszeit bei nur 20-25 Monaten und nur 15\% dieser Patienten sind fünf Jahre nach Diagnosestellung noch am Leben (Vincent et al. 2011).

Ein Grund für die schlechte Prognose ist der über lange Zeit klinisch stumme Verlauf. Frühsymptome sind selten und meist unspezifisch im Sinne einer B-Symptomatik (u.a. Gewichtsverlust und Leistungsabfall). Symptome wie Ikterus, Oberbauchbeschwerden mit Schmerzen, Übelkeit, Erbrechen, Verdauungsbeschwerden, Thrombosen oder das Neuauftreten eines Diabetes mellitus Typ II können sich erst spät im Krankheitsverlauf zeigen. $\mathrm{Zu}$ diesem Zeitpunkt hat der Tumor meist bereits angrenzende Gewebe infiltriert. Es besteht eine Tendenz zu früher Metastasierung (lymphogen; hämatogen in Leber, Peritoneum, Lunge und Knochen). Zudem kommt es nach Resektion sehr häufig zu Rezidiven (Vincent et al. 2011).

Ätiologisch wird von einer multifaktoriellen Genese des Pankreaskarzinoms ausgegangen. Evident ist der maßgebliche Einfluss genetischer Disposition. Dabei werden familiäre 
Mutationen hoher Penetranz und angeborene Syndrome (z.B. das Peutz-Jeghers-Syndrom) für 5-10\% der Pankreaskarzinome verantwortlich gemacht. Eine positive Familienanamnese ist in 7-10\% der Fälle bekannt. Zigarettenrauchen verursacht etwa 20-25\% der Pankreaskarzinome (Hassan et al. 2007). Ein weiterer nachgewiesener Risikofaktor ist Diabetes mellitus Typ II (2,6-fach erhöhtes Erkrankungsrisiko). Die Bedeutung der chronischen Pankreatitis für die Karzinogenese wird hingegen aktuell als verhältnismäßig gering betrachtet (Raimondi et al. 2010). Weitere ätiologische Faktoren sind Alter, männliches Geschlecht, Adipositas $\left(\mathrm{BMI}>30 \mathrm{~kg} / \mathrm{m}^{2}\right.$ ), fettreiche Diät, Nickelexposition und Infektionen mit Hepatitis $\mathrm{B}, \mathrm{C}$ oder Helicobacter pylori. Keine Evidenz ließ sich für den exzessiven Konsum von Alkohol (Hart et al. 2008) bzw. Kaffee (Turati et al. 2012) nachweisen. Das „0“-Allel des AB0Blutgruppensystems scheint das Risiko für die Entwicklung eines Pankreaskarzinoms zu reduzieren (Risk Ratio von 0,7 bei Personen mit Homozygotie für dieses Allel; Amundadottir et al. 2009; Wolpin et al. 2010). Protektiv werden außerdem Allergien in der Vorgeschichte bzw. die Einnahme von Acetylsalicylsäure (Aspirin), nicht-steriodalen Antirheumatika (z.B. Ibuprofen) bzw. Metformin erachtet.

Durchschnittlich liegen bei einem Pankreaskarzinom 63 somatische Mutationen vor. Diese befinden sich in einer Reihe unterschiedlicher funktioneller Systeme. Praktisch immer betroffen scheinen Gene für Apoptose, Zellzyklus-Regulation, der Hedgehog-Signalweg sowie die Signalkaskaden über k-ras, TGF $\beta$ und Wnt/Notch zu sein (Jones et al. 2008). Auch für Keimbahn-Polymorphismen wird eine ursächliche Bedeutung für die Entwicklung eines Pankreaskarzinoms vermutet. So wird die oben angeführte Assoziation mit dem AB0-Lokus auch bislang nicht identifizierten, gemeinsam vererbten Markern zugeschrieben (Amundadottir et al. 2009).

Unter den malignen Pankreastumoren bildet das adenoduktale mit über 90\% die mit Abstand größte Gruppe. Dieses geht vom exokrinen Anteil des Pankreas aus und ist zumeist (75\% der Fälle) im Bereich des Pankreaskopfes lokalisiert. Zum Pankreasschwanz hin nimmt die Häufigkeit ab. Tumorentität, Grading und Resektionsstatus werden histologisch anhand einer Tumorprobe aus Biopsie oder OP-Resektion festgestellt. Therapieentscheidungen richten sich neben dem Resektionsstatus insbesondere nach der Stadieneinteilung der UICC (Union internationale contre le cancer). Diese beruht auf der Charakterisierung des Tumors gemäß der TNM-Klassifikation basierend auf der Tumorausbreitung (T), dem Lymphknotenbefall (N) und der Metastasierung (M). Die Einteilung der UICC umfasst fünf Stadien zwischen 0 und 4. 


\subsection{Therapie des Pankreaskarzinoms}

Beim Pankreaskarzinom wird prinzipiell eine Operation im Gesunden angestrebt. Dies ist zum Zeitpunkt der Diagnosestellung jedoch nur bei einer Minderheit der Patienten möglich. Darüber hinaus gelingt häufig zumindest noch eine R1-Resektion (Absetzungsrand nur mikroskopisch noch Tumor-befallen). Bei kurativer Operationsintention (Stadium UICC 0IIB) ist die Prognose besser (Wagner et al. 2004). R0-resezierte Patienten überleben im Mittel 20-25, R1-resezierte hingegen nur 8-18 Monate. Für die Chemotherapie wurde zunächst 5Fluorouracil (5-FU) verwendet. Später wurde dann in der palliativen Situation ein Benefit von Gemcitabin gegenüber 5-FU hinsichtlich des Gesamtüberlebens (5,7 versus 4,4 Monate) nachgewiesen (Burris et al. 1997). Auch in adjuvanter Intention hat sich Gemcitabin als Standardtherapeutikum etabliert (Oettle et al. 2007), wobei hier offenbar kein Überlebensvorteil, wohl aber ein günstigeres Nebenwirkungsprofil gegenüber 5-FU vorliegt (Neoptolemos et al. 2010). Borderline-resektable Patienten (UICC Stadium III) können, unter Abwägung des Zeitverzugs bis zur Operation, von einer neoadjuvanten Radiochemotherapie profitieren. Angestrebt wird in diesen Fällen das Downstaging des Tumors, um eine spätere R0-Resektion möglich zu machen (Gillen et al. 2010).

Mehrere Gemcitabin-basierte Kombinationstherapien wurden auf eine Beeinflussung des Gesamtüberlebens von Patienten mit fortgeschrittenem Pankreaskarzinom getestet. Von diesen ist eine Verlängerung der Überlebenszeit am besten für die Kombination von Gemcitabin mit dem Tyrosinkinase-Inhibitor Erlotinib belegt (Moore et al. 2007). Hierfür ließen sich Vorteile gegenüber der Monotherapie mit Gemcitabin nachweisen (Gesamtüberleben 6,2 versus 5,9 Monate; 1-Jahresüberleben 23\% versus 17\%). Aktuelle Studien prüfen den Benefit weiterer Kinase-Inhibitoren wie Sorafenib oder Masatinib. Letztgenanntes führte im Mausmodell in Kombination mit Gemcitabin zu einer deutlichen Wachstumshemmung des Tumors (Humbert et al. 2010). Der Zusatz des Angiogenesehemmers Bevacizumab zeigte in klinischen Studien jedoch keine Verbesserung des Gesamtüberlebens (Kindler et al. 2010). Eine Kombination mit Capecitabin, einem oral bioverfügbaren Prodrug von 5-FU, scheint Metaanalysen zufolge mit einem leichten Gewinn an Überlebenszeit verbunden (Cunningham et al. 2009). Wurde Gemcitabin zusammen mit Cisplatin gegeben, war zwar ein deutlicher Vorteil in Bezug auf die Progression der Tumorerkrankung erkennbar, der Effekt auf die Überlebenszeit war jedoch nur schwach (Heinemann et al. 2006).

Die Einführung von Folfirinox 2011, einer Kombination der bei Darmkrebs bewährten Substanzen Leucovorin (Fol), 5-FU (F), Irinotecan (Irin) und Oxaliplatin (Ox), wurde als 
Alternative zur Gemcitabin-basierten Chemotherapie bei Pankreaskarzinom geprüft. Für Patienten mit metastasiertem Pankreaskarzinom war Folfirinox gegenüber Gemcitabin mit einem deutlichen Überlensvorteil verbunden (Gesamtüberleben 10,4 versus 6,8 Monate; 1Jahresüberleben 48,4\% versus 20,6; Conroy et al. 2011). Aufgrund der ausgeprägten Toxizität dieser Medikamentenkombination bleibt ihre Anwendbarkeit jedoch auf Patienten mit gutem Allgemeinzustand beschränkt und gilt nur unter diesen Voraussetzungen als First-lineTherapie. Abgesehen davon bleibt Gemcitabin bis auf Weiteres Standard in der Therapie des Pankreaskarzinoms. Insgesamt ist das Therapieansprechen bei den meisten Patienten nur kurzfristig. Von einer Heilbarkeit dieser Erkrankung ist man noch weit entfernt.

\subsection{Das Nukleosidanalogon Gemcitabin}

Gemcitabin ist ein Nukleosid und wirkt als phasenspezifisches Zytostatikum als Antimetabolit während der Nukleinsäure-Synthese. Es ist ein Derivat des natürlichen Desoxy-Cytidins und unterscheidet sich von diesem lediglich in zwei Fluor-Substituenten am C2-Atom des Zuckerrings (siehe Abb. 1). Aus dem Nukleosid wird in der Zelle durch Phosphorylierung das entsprechende Nukleotid, die kleinste Einheit des DNA-Strangs. Es fungiert als falscher Bausteine der DNA-Synthese, verursacht Strangbrüche und hemmt kompetitiv Enzyme der Synthese von Nukleinsäuren. In Folge dessen kommt es zu Störungen der zellulären Funktion und schließlich zur Einleitung des Zelltodes.
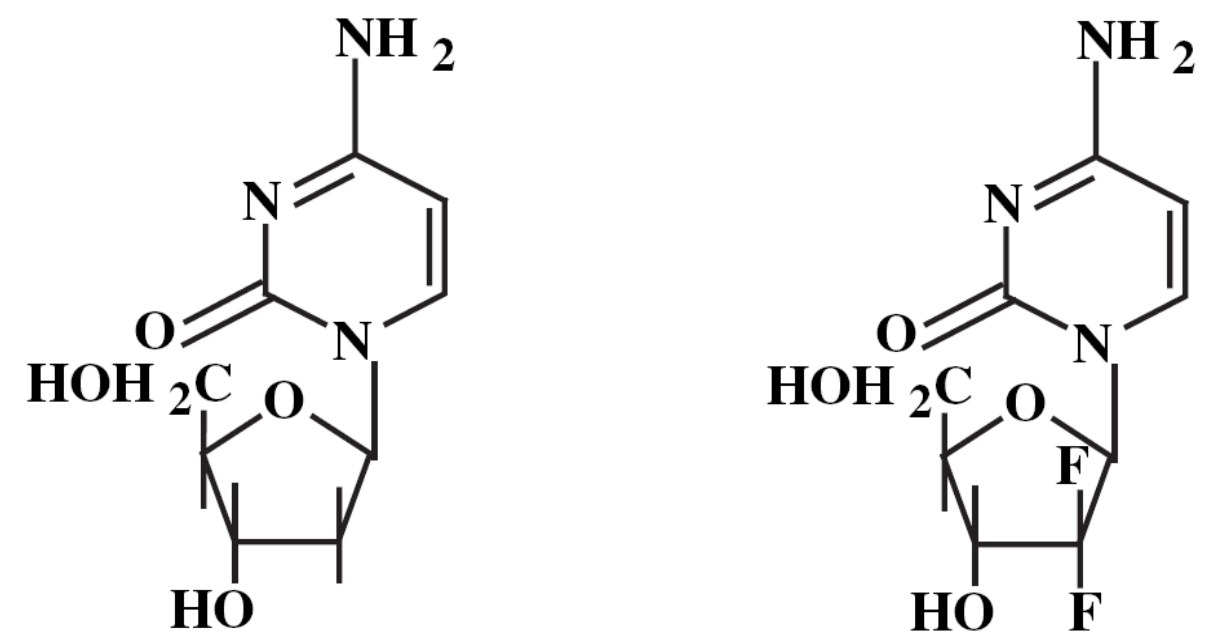

Abb. 1 Strukturformeln von Desoxy-Cytidin (links) und Gemcitabin (2',2'-Difluorodesoxycytidin) (rechts).

Ursprünglich als Virostatikum entwickelt, wird Gemcitabin heute nur zur Therapie solider Malignome eingesetzt. Sowohl an Krebszellinien als auch im Mausmodell war für Gemcitabin ein umfassendes Spektrum antitumoraler Aktivität nachweisbar (Hertel et al. 1990; Braakhuis et al. 1991). Diese Ergebnisse fanden auch in klinischen Studien Bestätigung (Abbruzzese et 
al. 1991). Heute erfährt Gemcitabin als First-line-Therapeutikum Anwendung bei Pankreaskarzinom, nicht-kleinzelligem Bronchialkarzinom (Sandler et al. 2000) und Harnblasenkarzinom (von der Maase et al. 2000). In Kombination mit Paclitaxel wird es ebenfalls bei fortgeschrittenem Mammakarzinom eingesetzt (Albain et al. 2008). Weitere Indikationen stellen Ovarialkarzinom, Gallengangskarzinom, Hodgkin- und Non-HodgkinLymphom dar. Dosislimitierende Nebenwirkung von Gemcitabin ist zumeist die Myelosuppression mit Depletierung aller drei Blutzellreihen. Leukozyto- und Thrombozytopenie stehen jedoch im Vordergrund. Daher ist vor jeder GemcitabinApplikation standardmäßig eine Blutbildkontrolle obligat. Mögliche Optionen im Falle ausgeprägter Zytopenien wären eine Dosisreduktion, der Verzicht der geplanten Einzelgabe oder als ultima ratio der Abbruch der Therapie. Weitere mögliche Nebenwirkungen von Gemcitabin sind Übelkeit, Erbrechen, allergische Reaktionen, Grippe-ähnliche Symptome (Fieber, Kopf-/Muskelschmerz), Hämaturie/Proteinurie, Dyspnoe, periphere Ödeme und Haarausfall.

Es wird angestrebt, soweit möglich und vom Patient vertragen, Gemcitabin in adjuvanter und palliativer Indikation für eine Zeitspanne von mindestens sechs Monaten zu verabreichen. Am häufigsten kommt der 3/4-Takt zur Anwendung. Dabei erfolgt in einem Zyklus eine Gabe an den Therapietagen 1, 8 und 15, worauf sich eine Woche Therapiepause anschließt (Tag 22). Weitere gängige Verabreichungschemata stellen der 2/3- und 6/8-Takt dar. Als Applikation hat sich eine Kurzinfusion über $30 \mathrm{~min}$ mit einer Dosis von $1000-1250 \mathrm{mg} / \mathrm{m}^{2}$ Körperoberfläche (KOF) durchgesetzt (Abbruzzese et al. 1991).

\subsection{Determinanten der Gemcitabin-Wirkung}

Entscheidend für die Wirkung von Gemcitabin ist seine Aufnahme in die Zelle über spezifische Nukleosidtransporter und seine extra- bzw. intrazelluläre enzymatische Metabolisierung. Darüber hinaus sind für den Hedgehog-Signalweg Effekte auf die Wirksamkeit von Gemcitabin beschrieben worden. Für alle diese Determinanten ist denkbar, dass sie eine Variabilität des Ansprechens von Tumorzellen auf Gemcitabin bedingen können. Die genannten Faktoren werden in den folgenden Kapiteln $1.5-1.7$ besprochen und sind zur besseren Übersicht in Abb. 2 schematisch dargestellt. 


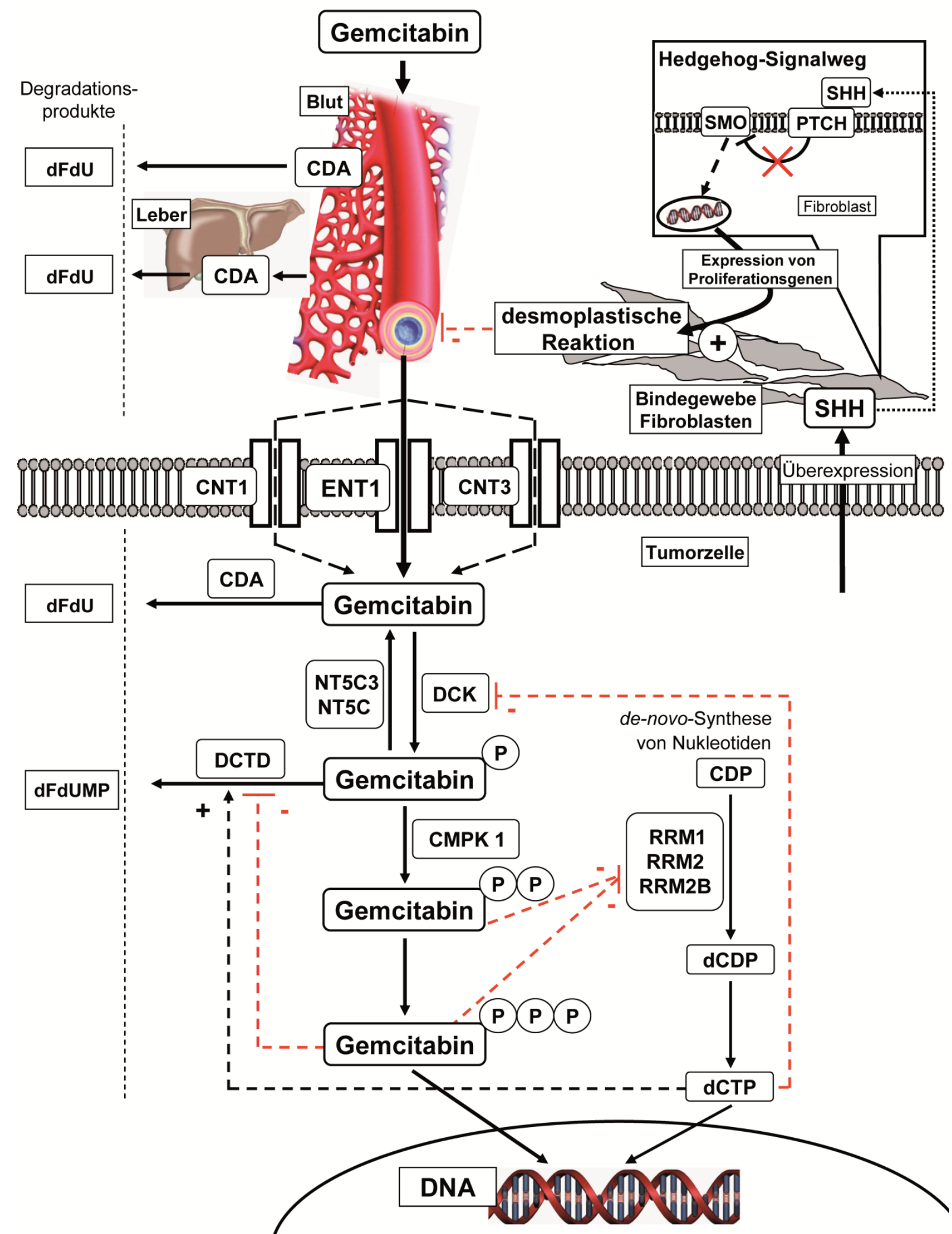

Abb. 2 Weg des Gemcitabins bis zu seinem Wirkort. CDA - Cytidindeaminase, CMPK1 Cytidinmonophosphatkinase 1, CNT1/3 - konzentrative Nukleosidtransporter 1/3, (d)CDP - (Desoxy-) Cytidindiphosphat, DCK - Desoxycytidinkinase, DCTD - Desoxycytidilat-Desaminase, dCTP Desoxycytidintriphosphat, dFdU - 2',2'-Difluorodesoxyuridin, dFdUMP - DifluorodesoxyuridinMonophosphat, ENT1 - äquilibrierender Nukleosidtransporter 1, NT5C/NT5C3-5'-Nukleotidase/ Isoform 3, PTCH1 - Patched 1, RRM1/RRM2(B) - Unterformen der Ribonukleotid-Reduktase, SHH Sonic hedgehog, SMO - Smoothened. 


\subsection{Transport von Gemcitabin}

Zur Aufnahme von Gemcitabin werden spezifische Nukleosid-Transporter (NTs) benötigt (Baldwin et al. 1999). Beim Menschen wurden bislang sieben dieser Transporter beschrieben (Mackey et al. 1998). Drei davon sind konzentrativ (CNTs, Gray et al. 2004) und vier äquilibrierend (ENTs, Baldwin et al. 2004). CNTs sind in polaren Zellen apikal lokalisiert (Hamilton et al. 2001) und finden sich hauptsächlich in Epithelien von Niere, Leber und Gastrointestinaltrakt (Mangravite et al. 2001). ENTs dagegen kommen in polaren Zellen überwiegend basolateral, in geringerem Maße aber auch apikal vor. Sie sind auch in unpolaren Zellen vorhanden, wobei der ENT1 (SLC29A1) ubiquitär - u.a. auch in Blutzellen exprimiert ist (Griffiths et al. 1997).

In-vitro-Studien an Zelllinien aus menschlichem Pankreasgewebe zeigten, dass die Gemcitabin-Aufnahme vorrangig über ENT1, in geringerem Umfang auch über CNT1 und CNT3 erfolgt (siehe Abb. 2; Garcia-Manteiga et al. 2003, Ritzel et al. 2001, Mackey et al. 1999, Mackey et al. 1998).

\subsubsection{Bedeutung des ENT1}

Auf Basis immunhistochemischer Analysen retrospektiver klinischer Studien konnten Assoziationen zwischen der Anwesenheit des ENT1-Transporters und dem Therapieansprechen auf Gemcitabin bei Patienten mit Pankreaskarzinom nachgewiesen werden. Eine hohe ENT1-Expression in den Karzinomzellen war mit einer besseren Prognose verknüpft (Spratlin et al. 2004; Morinaga et al. 2011). Diese Befunde konnten auf mRNAEbene bestätigt werden (Giovannetti et al. 2006). Analoge Effekte für das ebenfalls mit Gemcitabin behandelte nicht-kleinzellige Bronchialkarzinom fanden sich sowohl für mRNAExpression (Achiwa et al. 2004) als auch in immunhistochemischen Analysen (Oguri et al. 2007). Die Bedeutung des ENT1 für die Wirksamkeit von Gemcitabin konnte mittlerweile auch in einer prospektiven Studie bestätigt werden. Eine immmunhistochemisch nachgewiesene hohe Expression von ENT1 im Tumorgewebe war signifikant mit einem längeren Gesamtüberleben korreliert (Farrell et al. 2009). Interessant ist, dass eine hohe ENT1-Expression bei nicht-chemotherapierten Malignomen eher ein prognostisch ungünstiger Faktor zu sein scheint, wie für Karzinome des Magens und der Ampulle gezeigt (Santini et al. 2008; Santini et al. 2010). 


\subsection{Metabolismus von Gemcitabin}

Neben der Route des Gemcitabins und dem Transport ist in Abb.2 auch dessen Metabolismus schematisch dargestellt. Für die rasche Inaktivierung von Gemcitabin nach intravenöser Applikation ist die Cytidindeaminase (CDA) verantwortlich. Diese ist vor allem in Leber, Blutplasma und Niere exprimiert und setzt etwa 90\% der applizierten Substanzmenge in den inaktiven Metaboliten 2',2'-Difluorodesoxyuridin (dFdU) um (Storniolo et al. 1997). Intrazellulär bedarf es einer enzymatischen Phosphorylierung, um Gemcitabin in seine aktive Form, das Gemcitabin-Triphosphat, zu überführen. Die initiale Phosphorylierung zum Monophosphat wird als Geschwindigkeits-bestimmender Schritt des GemcitabinMetabolismus betrachtet und erfolgt durch die Desoxycytidinkinase (DCK) (Shewach et al. 1992). Im phosphorylierten Zustand kann Gemcitabin die Zelle nicht mehr verlassen. Nukleotidasen (NT5C, NT5C3) überführen jedoch einen Teil des Monophosphats wieder in die Ausgangssubstanz und wirken somit antagonistisch zur DCK. Auch intrazellulär kann nicht-phosphoryliertes Gemcitabin durch die CDA degradiert werden. Darüber hinaus kann Gemcitabin-Monophosphat mittels Desoxycytidilat-Desaminase (DCTD) zu dFdUMP inaktiviert werden. Der nächste Phosphorylierungsschritt zum Diphosphat wird durch die Cytidinmonophosphatkinase 1 (CMPK1) bewerkstelligt.

Gemcitabin unterliegt einem intrazellulären Mechanismus der Selbstpotenzierung. Dabei entscheidend ist die Hemmwirkung des Gemcitabin-Diphosphats und -Triphosphats auf die Ribonukleotid-Reduktase und ihrer Unterformen RRM1, RRM2 und RRM2B. Dadurch verkleinert sich der Pool an physiologischem Desoxycytidintriphosphat (dCTP), welches mit Gemcitabin-Triphosphat um den Einbau in DNA konkurriert (Heinemann et al. 1990). Niedrige dCTP-Spiegel führen ihrerseits zu einer Enthemmung der DCK und damit zu einer verstärkten Phosphorylierung von Gemcitabin. Anderseits ist bei niedrigen dCTPKonzentrationen die DCTD weniger aktiv, sodass der Abbau von Gemcitabin-Monophosphat vermindert ist. Hinzu kommt noch, dass Gemcitabin in seiner Triphosphat-Form ebenfalls hemmend auf die DCTD wirkt. Zusammen genommen resultieren aus diesen Effekten höhere Konzentrationen von aktiven Gemcitabinmetaboliten in der Zelle (Plunkett et al. 1996; Heinemann et al. 1992).

Die eigentliche Gemcitabinwirkung besteht zum einen in der kompetitiven Hemmung der DNA-Polymerase durch Gemcitabin-Triphosphat und zum anderen in der als „maskierte Termination“ bezeichneten Initiierung von DNA-Strangabbrüchen (Gandhi und Plunkett 1990). Hierbei wird Gemcitabin-Triphosphat als Substrat der DNA-Polymerase- $\alpha$ in den 
DNA-Strang eingebaut (Huang et al. 1991), worauf genau ein weiteres Desoxynukleotid folgen kann. Gegenüber Reparaturmechanismen und Entfernung aus der DNA ist das Gemcitabin-Triphosphat nach dieser non-terminalen Inkorporierung unempfindlich (Plunkett et al. 1995). Die DNA-Polymerisation stoppt und Apoptose wird induziert (Huang und Plunkett 1995).

\subsection{Hedgehog-Signalweg und Wirksamkeit von Gemcitabin}

Der Hedgehog-Signalweg vermittelt Interaktionen zwischen Zelle und Extrazellulärraum. Benannt ist der Signalweg nach seinem Liganden-Protein Hedgehog (Hh), welches an den Rezeptor Patched bindet, der wiederum eine negative Regulation auf das Smoothened-Protein ausübt (siehe Abb. 2). Ursprünglich wurde dieser Signalweg in Zusammenhang mit der frühen Embryonalentwicklung an D. melanogaster beschrieben, wofür der Nobelpreis verliehen wurde (Nusslein-Volhard und Wieschaus 1980). Mittlerweile wurden je drei Homologe des Hedgehog- und des Patched-Proteins in Vertrebraten identifiziert, wobei beim Menschen Sonic Hedgehog (SHH) und Patched 1 (PTCH1) die größte Rolle spielen.

Für den Hedgehog-Signalweg ist eine Bedeutung für die Entstehung von menschlichen Tumoren nachgewiesen, so etwa für das nicht-kleinzellige Bronchialkarzinom (NSCLC) (Yuan et al. 2007), das Melanom (Stecca et al. 2007) und gastrointestinale Tumore einschließlich des Pankreaskarzinoms (Berman et al. 2003; Thayer et al. 2003). Aufgrund der Überexprimierung von SHH durch Pankreaskarzinomzellen (Berman et al. 2003) kommt es zu einer Verminderung des inhibitorischen Effekts von Patched auf Smoothened. Dies bewirkt eine verstärkte Expression von Genen (Robbins et al. 1997; Nybakken und Perrimon 2002) mit daraus resultierender desmoplastischer Reaktion, einem verstärkten Wachstum des peritumoralen Bindegewebes (Bailey et al. 2008). Die desmoplastische Reaktion wird als Faktor für verminderte Vaskularisierung des Tumors betrachtet. Damit ist es Chemotherapeutika wie Gemcitabin erschwert, in ausreichender Konzentration an ihre Zielzelle zu gelangen. Wurde am Mausmodell der Hedgehog-Signalweg inhibiert, zeigten Pankreastumore eine verstärkte Vaskularisierung, höhere intratumorale Gemcitabinkonzentrationen und einen verminderten Tumorprogress (Olive et al. 2009). Ein weiteres Indiz für die Bedeutung des Hedgehog-Signalwegs beim Pankreaskarzinom war der Nachweis von somatischen Mutationen in diesem System (Jones et al. 2008). 


\subsection{Polymorphismen in Kandidatengenen}

Im Keimbahn-Genom des Menschen finden sich ca. zehn Millionen genetische Varianten, wobei es sich bei den meisten um Einzelbasen-Austausche (engl. single nucleotid polymorphisms, SNPs) handelt. Von einem Polymorphismus in der Allgemeinbevölkerung spricht man dann, wenn die Frequenz des selteneren Allels mindestens $1 \%$ beträgt. Neben den somatischen Mutationen des Tumors können Keimbahn-Polymorphismen einen Einfluss auf Entstehung einer Krebserkrankung sowie auf Ansprechen und Nebenwirkungen haben. Es kann davon ausgegangen werden, dass in einer Tumorzelle in der Regel dieselben Allele der Keimbahn-Polymorphismen vorliegen.

Zu Beginn meiner Dissertation im Jahr 2009 war über einen Einfluss von Polymorphismen auf das Therapieansprechen von Patienten mit Pankreaskarzinom noch kaum etwas bekannt. Lediglich war 2008 auf dem jährlichen Treffen der American Society of Clinical Oncology (ASCO) eine Studie über 17 Keimbahn-Polymorphismen in Kandidatengenen für Gemcitabin im Hinblick auf das Therapieansprechen bei operablem Pankreaskarzinom vorgestellt worden, ein klarer Zusammenhang singulärer Varianten auf die Überlebenszeit fand sich dabei nicht (Tagungsreport von Saif 2008). Diese Daten wurden später auch publiziert (Okazaki et al. 2010). Dieselben Genvarianten wurden anschließend auch noch bei nicht-operablem Pankreas-Karzinom analysiert, wo sich ebenfalls keine klare Assoziation singulärer SNPs mit dem Gesamtüberleben zeigte (Tanaka et al. 2010). Jedoch schien die ENT1-Intronvariante $A 201 G$ (rs760370) das radiologisch erfassbare Therapieansprechen des Tumors zu beeinflussen. Zudem wirkten sich hier vier der 17 SNPs auf die Therapie-bedingte Neutropenie aus. Ein schon mehrfach untersuchtes Kandidatengen für die Hämatotoxizität unter Gemcitabin ist die auch in Blutzellen exprimierte $C D A$. Für den $C D A$-Polymorphismus 79 A $>$ C (Lys27Gln) ist weder klar, ob das Gln27-Variantenallel die Enzymaktivität steigert (Giovannetti et al. 2008) oder senkt (Gilbert et al. 2006), noch ob Gln27 für das Risiko schwerer Neutropenien prädisponiert (Tanaka et al. 2010; Farrell et al. 2011) oder nicht (Sugiyama et al. 2007). In RRM1 waren zwei SNPs mit progressionsfreiem Überleben bei Pankreaskarzinom in der bereits erwähnten Studie assoziiert (Tanaka et al. 2010). Weiterhin gibt es Hinweise auf einen Einfluss der genetischen Variabilität von RRM1, RRM2 bzw. CMPK1 auf das Gesamt- und progressionsfreie Überleben bei nicht-kleinzelligem Bronchialkarzinom (Li et al. 2012; Ryu et al. 2011; Dong et al. 2010) sowie für die Hämatotoxizität bei Mammakarzinom unter Gemcitabin-Therapie (Rha et al. 2007). Im Hedgehog-Signalweg sind bislang keine Genpolymorphismen hinsichtlich einer Assoziation 
mit dem Therapieansprechen auf Gemcitabin von Patienten mit Pankreaskarzinom beschrieben.

Aktuelle genomweite Studien berichten über Assoziationen von Polymorphismen der Gene ILI7F und PRB2 bzw. PYCARD, MAPRE2 und NOX4 mit dem Gesamtüberleben (Innocenti et al. 2012 bzw. ASCO-Report von Xu et al. 2011).

Weiterhin gibt es Untersuchungen, welche für einige SNPs der oben aufgeführten GemcitabinKandidatengene (Transport, Metabolismus, Hedgehog-Signalweg) eine Funktionalität vermuten lassen. Die genetische Variabilität in den kodierenden Bereichen des ENT1 ist sehr gering (Leabman et al. 2003). Eine funktionelle Bedeutung der wenigen seltenen Aminosäurevarianten konnte bei Transportmessungen nicht bestätigt werden (Osato et al. 2003). Polymorphismen im Promotorbereich des ENT1-Gens könnten die Expression dieses Gens modulieren (Myers et al. 2006; Preuß 2009). Für NT5C3-SNPs liegen in vitro Hinweise auf eine Beeinflussung der Expression dieses Gens vor (Aksoy et al. 2009). ReportergenUntersuchungen zu Folge scheint auch die Expression der DCK durch Genpolymorphismen in der Promotorregion (Shi et al. 2004) bzw. die Stabilität des mRNA-Transkripts durch Varianten im 3'-Bereich reguliert (Lamba et al. 2007).

\subsection{Zielsetzung dieser Arbeit}

Patienten mit Pankreaskarzinom haben trotz optimaler Therapie mit Resektion des Tumors und Gemcitabin-basierter Chemotherapie zumeist eine schlechte Prognose. Für nichtgenetische Faktoren wie Resektionsstatus, histopathologisches Grading, Tumorausbreitung und Metastasierung ist der Einfluss auf den Therapieerfolg bekannt. Ein Großteil der interindividuellen Variabilität des Therapieansprechens wird dadurch jedoch nicht erklärt. Als weitere relevante Parameter werden Genvarianten der Keimbahn diskutiert, insbesondere in Genen mit Bezug zur Gemcitabinwirkung. Jedoch gibt es gegenwärtig noch keine Daten dazu, welche überzeugend die Bedeutung eines Genpolymorphismus in diesem Zusammenhang belegen. Bei Kenntnis solcher genetischer Parameter könnten diese - prätherapeutisch bestimmt - als Biomarker für das Therapieansprechen von Patienten mit Pankreaskarzinom unter einer Gemcitabin-Therapie eingesetzt werden. Im Sinne einer personalisierten Medizin wäre es dann möglich, Wirkung und Nebenwirkung einer Gemcitabin-Therapie zu antizipieren. Dem einzelnen Patienten könnte eine nicht Erfolg versprechende, nebenwirkungsreiche Therapie erspart bleiben, sollte dieser nicht die genetischen Voraussetzungen dafür aufweisen. In diesen Fällen könnte auf alternative Therapiemodalitäten zurückgegriffen werden. 
Vor diesem Hintergrund war es Ziel dieser Arbeit, gemäß dem Kandidatengenansatz Gene des Gemcitabin-Metabolismus, des Gemcitabin-Transports und des Hedgehog-Signalwegs auf therapeutisch relevante Varianten zu überprüfen. Als Kandidatengene wurden $C D A, C M P K 1$, DCK, DCTD, ENT1, NT5C3, PTCH1, RRM1, RRM2, SHH und SMO gewählt. Für jedes dieser Gene waren SNPs zu analysieren, welche die genetische Variabilität aller Positionen mit einer Mindestallelfrequenz von 5\% repräsentieren. Die Analysen sollten an DNA von Patienten mit der Diagnose eines duktalen Adenokarzinoms des Pankreas durchgeführt werden, die eine Gemcitabin-basierte Chemotherapie erhalten hatten. Dazu war aus einem Pool von über 500 wegen eines Pankreasprozesses zwischen 2003 und 2010 in der Allgemeinchirugie der Universitätsmedizin Göttingen behandelten Patienten eine möglichst homogene Patientenkohorte in Bezug auf Lokalisation und histologische Entität (adenoduktales Karzinom) zu ermitteln. Für diese Patienten sollte dann das Gesamtüberleben, der Verlauf der Chemotherapie sowie mögliche Hämatotoxizitäten unter Therapie erfasst werden. Die Gegenüberstellung der klinischen Nachsorgedaten und der Genanalysen wurde unter folgenden Fragestellungen vorgenommen:

1. In welchem Ausmaß beeinflussen nicht-genetische Faktoren (Alter, Geschlecht, Resektionsstatus, histologisches Grading, Modalitäten der Gemcitabin-basierten Chemotherapie) das Gesamtüberleben?

2. Wie verhalten sich die Werte der Zellzahlen von Leukozyten und Thrombozyten unter der Gemcitabin-Therapie? Besteht ein Zusammenhang mit dem therapeutischen Outcome?

3. Zeigen die untersuchten Genvarianten Assoziationen zum Gesamtüberleben der Patienten?

4. Zeigen die untersuchten Genvarianten einen Einfluss auf die Hämatotoxizitäten?

5. Lassen sich Effekte von klinisch als relevant identifizierten Genvarianten an funktionellen Daten aus einer ex-vivo-Studie mit Gemcitabin-inkubierten Leukozyten bestätigen? 


\section{Material}

\subsection{Geräte}

Autoklav

Biofuge fresco

Biofuge pico Tischzentrifuge

BioRobot $^{(\mathbb{B}}$ EZ1

Elektrophorese-Kammer (ComPhor L Mini)

Elektrophorese-Netzteil

(Standard Power Pack P25)

Feinwaage BL 610

Fluor-STM MultiImager (für Gelfotografie)

Magnetrührer (IKAMAG RET)

Labofuge $400 \mathrm{R}$

Mehrkanal-Pipette (8er) 0,5 - $10 \mu \mathrm{l}$

Mini-Centrifuge, Model GMC-060

Mikroliter-Küvette für Photometer

(LabelGuard ${ }^{\mathrm{TM}}$ )

Mikrowelle MWS 2820

Multipipette plus

PCR-Gradienten-Cycler (384-Well und 96-Well), Typ Master-Cycler

PCR-Gradienten-Cycler (96-Well),

Typ PTC-200 Peltier

Photometer (Biophotometer 6313)

Pipetten (0,5-10 $\mu 1,10-100 \mu 1,100-1000 \mu 1)$,

Typen Research and Reference

Rahmen und Septen für Sequenzierer

Sequenzierer 3100 Genetic Analyser

Sequenzierplatten

Thermomixer 5436

Tiefkühlschrank VIP Series $-86^{\circ} \mathrm{C}$

UV-Küvetten 50-1000 $\mu 1$

Vertikal-Autoklav KSG 40/60
Tecnorama, Fernwald

Heraeus, Hanau

Heraeus, Hanau

Qiagen, Hilden

Biozym, Hessisch Oldendorf

Biometra, Göttingen

Sartorius, Göttingen

BioRad, Hercules USA

IKA, Staufen

Heraeus, Hanau

Eppendorf, Hamburg

LMS, Tokyo, Japan

Implen, München

Bauknecht, Schorndorf

Eppendorf, Hamburg

Eppendorf, Hamburg

MJ Research/BioRad, Hercules, USA

Eppendorf, Hamburg

Eppendorf, Hamburg

Applied Biosystems, Darmstadt

Applied Biosystems, Darmstadt

Applied Biosystems, Darmstadt

Eppendorf, Hamburg

Sanyo Electric Co Ltd., Japan

Eppendorf, Hamburg

KSG, Olching 
Vertikal-Autoklav: FV für Sterilgut

Vortexer (MS 2 Minishaker)

Wärmeschrank

Zentrifuge 5810R

\subsection{Chemikalien}

Agarose Ultra Pure

Anodenpuffer (für Sequenzierer)

Bromphenolblau

CIAP

DNA-Größenstandard 100 bp

DNA-Größenstandard 1 kb

dNTP-Set

Ethanol

Ethidiumbromid $\left(1 \%\right.$ in $\left.\mathrm{H}_{2} \mathrm{O}\right)$

Exonuklease I

Ficoll-Paque Plus

GeneScan $^{\text {TM }}$ LIZ $^{\circledR} 120$ Size Standard

GeneScan $^{\text {TM }}$ LIZ $^{\circledR} 400$ HD [ROX] Size Standard

HiDi-Lösung (enthält Formamid)

Kalziumchlorid

Magnesiumchlorid (SAP Puffer)

Polymer POP6 (für Sequenzierer)

Polymer POP7 (für Sequenzierer)

Primer (Design nach gewünschter Sequenz, siehe Kapitel 2.3)

Shrimp Alkalische Phosphatase (SAP)

Taq-DNA-Polymerase

Tris

Q-Solution
Tecnorama, Fernwald

IKA, Staufen

Binder, Tuttlingen

Eppendorf, Hamburg

Invitrogen, Karlsruhe

Applied Biosystems, Darmstadt

Roth, Karlsruhe

Fermentas, St. Leon-Rot

Rapidozym, Berlin

Rapidozym, Berlin

ABgene, Epsom

J. T. Baker, Phillipsburg, USA

Merck, Darmstadt

USB, Staufen

GE Healthcare, Uppsala, Schweden

Applied Biosystems, Darmstadt

Applied Biosystems, Darmstadt

Applied Biosystems, Darmstadt

Merck, Darmstadt

Merck, Darmstadt

Applied Biosystems, Darmstadt

Applied Biosystems, Darmstadt

MWG-Biotech, Ebersberg

USB, Staufen

Qiagen

Roth, Karlsruhe

Qiagen 


\subsection{Primer zur Genotypisierung}

\begin{tabular}{|c|c|c|c|c|c|c|}
\hline $\begin{array}{l}\text { Gen } \\
\text { rs-Nummer }\end{array}$ & PCR-Primer, vorwärts $\left(5^{\prime}->3^{\prime}\right)$ & PCR-Primer, rückwärts $\left(5^{\prime}->3^{\prime}\right)$ & $\begin{array}{c}\text { FL } \\
\text { (bp) }\end{array}$ & $\mathrm{PP}$ & SNaPshot ${ }^{\mathrm{TM}}$-Primer $\left(5^{\prime}->3^{\prime}\right)$ & $S$ \\
\hline \multicolumn{7}{|l|}{$\overline{C D A}$} \\
\hline rs 540282 & CCCGGGGATACCACTGGTGATAAGTAG & GGCTCTCATCCATCCCAGAATTCATAG & 128 & 1 & $\left(\right.$ TGAC) ${ }_{5}$ TGGAGGAGCCAGTATAATGGATGG & \\
\hline $\operatorname{rs} 532545$ & TTAATTCTGGGCTAGGGCAAAGAGAAG & GTGACTGTAGGGGCAGTAGGCTGACT & 651 & 1 & GTTCATGCCTCCTGCCT & . \\
\hline $\operatorname{rs} 603412$ & $"$ & $"$ & $"$ & 1 & (TGAC) ${ }_{6}$ TTCAGCAGGTGTGGTGTAAGACA & 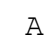 \\
\hline rs 602950 & $"$ & $"$ & $"$ & 1 & CTGCAGGGACACACCCA & . \\
\hline rs2072671 & $"$ & $"$ & $"$ & 1 & GTGACTGTAGGGGCAGTAGGCTGACT & . \\
\hline rs 818202 & CCTGCAACCCTGAAAGGCAGAGAAG & CAGCTTTTGGAGTCAGGGGAAGTCTG & 105 & 1 & $(\mathrm{GACT}){ }_{2} \mathrm{CCAATCCCAGCTCTGTGATTT}$ & 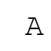 \\
\hline rs10916824 & CCCCTGGTTGTGAGGCTTTAAATGAG & CCTCCACAATCTGCCTCCAGATAATAAG & 151 & 1 & CACAATCTGCCTCCAGATAATAAG & . \\
\hline rs 577042 & AGCTGTGGCACCCAGTAGTGTCTAATG & TGCCCAGCCTACACCTCCTTTTATAAGTC & 252 & 1 & CAACTCTGGACATGAATGCCTG & 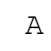 \\
\hline rs 818194 & CCCTGGGATGAGTGCTGAGGATAAG & CGCTTTATGTTTCAATGCTGCCTTTC & 191 & 1 & $\left(\right.$ GACT) ${ }_{5}$ GTGATACAGACTCCTGTCCTACAAGAT & . \\
\hline rs10916827 & GCTCTGGCCCTAGACTCAGTGGTTTC & TCCCATGTCATTTTTCTTGCATCATTAAC & 166 & 1 & TGTGGTTTCAGGATCCAAGCAC & $z$ \\
\hline rs580032 & CCAAGGAGACCCAGCTTAATTTGTTTC & TCTGATGTTAACAAGGGAGCTGGTACTTC & 582 & 1 & $\mathrm{~A}_{4} \mathrm{TGTTCTCAGCACAGCGTC}$ & \\
\hline rs11579252 & " & " & " & 1 & $(\mathrm{CTGA}){ }_{4} \mathrm{CTTCAGGGAAACTGAGCTGAATACC}$ & I \\
\hline rs527912 & $"$ & $"$ & $"$ & 1 & ACTGACTCGCACTCATGATTTGTTAAATTGAGA & 2 \\
\hline rs 1689924 & СTCTCTCTTGGCAGGAACGTTGAGTAAG & TTACATACCCTGTGTCAGGAACTTTACAG & 205 & 1 & $(\mathrm{CTGA}){ }_{2} \mathrm{CTCTGTAACAGACCAGTCTCCTCCA}$ & $I$ \\
\hline rs 12404655 & GCACGGTGGAAATGTCGAAGGTC & TCCCGGGCACACTCAATCTTCTG & 348 & 1 & $(\mathrm{ACTG})_{2}$ ACTTCTTATCATTTGCATTTGGTTTCAGT & $z$ \\
\hline rs12072405 & $"$ & $"$ & & 1 & CTTGACAGGCTGTGCCTAAGGGTAGGTAC & 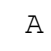 \\
\hline rs1048977 & TGTACATGACCAAGCCGGATGGTAC & GCTGATGGGGAAGCAGTCCAGACTAG & 368 & 1 & $(\mathrm{TGAC})_{4} \mathrm{TGCATTCTCTGGCTGTCACTG}$ & $I$ \\
\hline rs 1614627 & AGTGTGAGGACAGGGAGGGACTGTTTC & TGTTGTGGCAAAGCCATTCTCATCAG & 317 & 1 & TAGGTCAGGACTGAATAAGGAAGGAG & 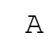 \\
\hline \multicolumn{7}{|l|}{ CMPK1 } \\
\hline rs11211517 & TGGACCTTGGCATCATCAGAAACTC & TGGGGAAAGGGACCAATGTCTTAGAG & 156 & 2 & $\mathrm{~A}_{28} \mathrm{CCACTCAGACCAGCAGCATC}$ & $\mathrm{E}$ \\
\hline rs 7543016 & AGGGCGCAGGATAAAATATCTGCAGTC & FAM-CCAGGACGTGGAGCAGCC [ G/C ] & 314 & $\mathrm{~F}_{\mathrm{LA}}$ & & \\
\hline $\operatorname{rs} 12132521$ & GGGATGCCCATTAAGCAAAAAGTCAC & TACATGGGCCTCTTGGTTCTTGATTAGAG & 173 & 2 & $\mathrm{~A}_{19} \mathrm{TGTCATGACTACACAATAGAAAAAGCACT}$ & . \\
\hline rs35687416 & GTGATGAAAGGAAGAACCCAGATTCACA & GGTTTGAACTGGTTGGCATTCACACTC & 139 & 2 & GTGATGAAAGGAAGAACCCAGATTCACA & \\
\hline
\end{tabular}




\begin{tabular}{|c|c|c|c|c|c|c|}
\hline $\begin{array}{l}\text { Gen } \\
\text { rs-Nummer }\end{array}$ & PCR-Primer, vorwärts $\left(5^{\prime}->3^{\prime}\right)$ & PCR-Primer, rückwärts $\left(5^{\prime}->3^{\prime}\right)$ & $\begin{array}{c}\text { FL } \\
(\mathrm{bp})\end{array}$ & PP & SNaPshot ${ }^{\mathrm{TM}}$-Primer $\left(5^{\prime}->3^{\prime}\right)$ & SP \\
\hline rs6660321 & CCCGATTCCCTGAATCTTCATCCTC & CTCCATCTCCAAACAGGGTCACACAC & 425 & 2 & CTCACCTCTATACAAAGTGTCAATGGAT & B \\
\hline rs7534571 & AAGCCATGAATGTGAGCTTTGGGTATG & GTCCTCAAAGGGCTGCAAAGTCTTAGAC & 198 & 2 & $\mathrm{~A}_{15}$ GGAAGATATGTACTCTCAGTAGCTAT $_{3}$ CTATGAC & B \\
\hline rs 12039726 & CGCCACTGCACTCCTACCTGAGAT & CTGGCACTTAAAATCTAGAGGGGAAATCAAC & 233 & 2 & CGCCACTGCACTCCTACCTGAGAT & B \\
\hline \multicolumn{7}{|l|}{$D C K$} \\
\hline rs 6446982 & GCGCTTGCCTGTTGTCCCAGT & AGAAAACGGGGTACAGAAGCCATCA & 577 & 4 & $(\mathrm{GACT}){ }_{4} \mathrm{CTTTACACACAATAAATGAATAACAG}$ & $\mathrm{C}$ \\
\hline rs2306744 & ACACAGTGCCTTCTCCCCAGATGAG & GACCTGCCGGGTCAGCTAGTGAG & 481 & $\mathrm{E}_{1}$ & $\mathrm{~T}_{3}$ GAGGAGGGCGGGGCCGC & $\mathrm{C}$ \\
\hline rs 12648166 & CAGGATTTCACTCTGTTGCCCAGGTAAAG & CATGTATGCGGGTGAATTTATGTTCACAG & 418 & 3 & GGACAAACAGTGATAGACGAATAAAATTAAATACTA & $\mathrm{D}$ \\
\hline rs 10805074 & GGGGTCAGCTGTCAGTGCAGTTATC & AACGGACCTTAAATGGAGGTCACCTAGTC & 128 & 3 & (CTGA) ${ }_{3}$ CTCTCTGGTTTAATCTGGTTAGTTTCTGTCTAC & $\mathrm{D}$ \\
\hline rs11544786 & ATGGTGGGAATGTTCTTCAGATGATG & ATCCCCAGCTCAGCCATTCATTATTAC & 287 & 4 & $(\text { TGAC })_{4}$ TGGTCTTTTACCTTCCAAACATATGC & $\mathrm{D}$ \\
\hline \multicolumn{7}{|l|}{ DCTD } \\
\hline rs 5016499 & GGCCGGTGCTCTTTCTCTCATGAC & TGAGACCTGTGACTGGGGAAACAGAG & 90 & 2 & $\mathrm{~A}_{11}$ GCCACCTTCCTGACTCCTTG & B \\
\hline rs13111117 & GCATTTTAGGCATCACGTGTGCATTTC & ACCCCTGGTTCTGCCTGTCTTCTCTG & 613 & 2 & $\mathrm{~A}_{16}$ TGGAAATAGCTGTACTGCATCCAC & B \\
\hline rs 10016530 & $"$ & $"$ & $"$ & 2 & $(\mathrm{TGAC}){ }_{2}$ TAAGAAGATGCTTGACTGGTAGGTTG & B \\
\hline rs10520543 & AGGCCCCAGTAGTTCCTGTCACA & TCCATCCCTGGTTAGATTTAAGAGTTCA & 250 & 2 & $\mathrm{~A}_{20}$ TCCCTGGTTAGATTTAAGAGTTCAGC & B \\
\hline rs13148414 & CCCATGCCGTCAGGGTTTATGAG & CTCAGTCCTGCCTAAAACTGAGCAATCTC & 171 & 2 & $(\mathrm{GACT}){ }_{5} \mathrm{GGCATGGCTCTGGTCACT}$ & B \\
\hline rs 6834019 & $"$ & CTCAGTCCTGCCTAAAACTGAGCAATCTC & 171 & 2 & TCACTGACCACAGCCCATCAGAGAAT & B \\
\hline rs 4742 & CACGTGGGCCTCATTTGGTATTCTTAG & GATGATGAGCTTAGCGCATTCATTACAAG & 276 & 2 & $\mathrm{~A}_{23}$ CGATGTGAAAGGCTGTAGTATGTATGT & B \\
\hline rs1960207 & ACTGTAAAGTTTTCCAGCGCTTCATGGT & ATGGGGTGGTGTGGTTTGTATGTTTTC & 571 & 2 & GGTCCCACTGCTGCTGAAC & B \\
\hline rs2515683 & $"$ & $"$ & $"$ & 2 & $\left(\right.$ ACTG) ${ }_{2}$ ACTCTTTTTAATTGTTGTAGAAGAAATGAGGAAC & B \\
\hline rs10017797 & $"$ & $"$ & $"$ & 2 & ACTGACTAGCTGACTTGTTAGAAATCCTTTGACT & B \\
\hline rs 7278 & AGCACTGTTGGTGTTCGGAGCTCTTC & ATCCATAAAGCAGCCCCAGACATCAAC & 423 & 2 & $\mathrm{~A}_{19} \mathrm{CAGCCACACGCTCCCC}$ & B \\
\hline rs3924787 & GAAACCCATCCGATTAGTGGATTTCTTG & CCTGCAGCCTCCTCTATCGAATGTG & 676 & 2 & $\mathrm{~A}_{4}$ GAATGCTTTCTGTTGTAGGAGTTCTGTAT & B \\
\hline rs 4073676 & " & " & $"$ & 2 & $\left(\right.$ TGAC) ${ }_{3}$ TGAAGTTTTTGACAAAACAAGCCTGA & B \\
\hline rs 4073675 & $"$ & $"$ & $"$ & 2 & CAGAAGCCCCAGCAAGTATTCT & B \\
\hline \multicolumn{7}{|l|}{ NT5C3 } \\
\hline rs 6946062 & TGGCTGGATTCCTTGCTTCTGTGTC & GGAGTAGCACCCATCATGTCCATAATCAG & 120 & 4 & ACTGACTAACCCAGTCAACATCATATAGTTGGA & $\mathrm{C}$ \\
\hline rs 7795860 & CAAGTGCTTAGAGGCATCTGGCACATAG & AGGGCCACAAAGGGCTCCATTTC & 510 & 4 & АCTGCTTATTCACCTCTTCTGTATTAGTGAACATTT & D \\
\hline
\end{tabular}




\begin{tabular}{|c|c|c|c|c|c|c|}
\hline $\begin{array}{l}\text { Gen } \\
\text { rs-Nummer }\end{array}$ & PCR-Primer, vorwärts $\left(5^{\prime}->3^{\prime}\right)$ & PCR-Primer, rückwärts $\left(5^{\prime}->3^{\prime}\right)$ & $\begin{array}{l}\text { FL } \\
\text { (bp) }\end{array}$ & PP & SNaPshot ${ }^{\mathrm{TM}}$-Primer $\left(5^{\prime}->3^{\prime}\right)$ & SP \\
\hline rs7792135 & " & " & & 4 & ACACATCAATTTTGTGTCT & $\mathrm{D}$ \\
\hline rs 12668520 & TAATGCACATTGTCGTGCTTCTCAG & AgATTACTGCTCTCATTCAGGGCTATAgA & 599 & 4 & $(\mathrm{GACT})_{2} \mathrm{CAATAACACACTTAAATCGTACAGTGTGAAA}$ & D \\
\hline rs17170218 & $"$ & $"$ & $"$ & 4 & AGATTACTGCTCTCATTCAGGGCTATAGA & C \\
\hline rs3750117 & GAAAGGTAGCTTTTTGCAGGTATATTTGATTAC & : GCAGGACTTTTAATTTATTCCTACTGGACTTC & 514 & 4 & $(\mathrm{GACT}){ }_{3} \mathrm{AAGAACAGGATCAACTTCAATAGCGTA}$ & D \\
\hline rs17170153 & $"$ & $"$ & $"$ & 4 & (TGAC) 2 TAGAGAGATTAGATAATTAGAGCTCATTTTGTTATTC & $\mathrm{D}$ \\
\hline rs 4394301 & TGACATGCCTGTGAGACGTACAAGAGAAG & GGTCAGGCAATTTCTTCCAGCTTACACTG & 152 & 4 & (CTGA) ${ }_{3}$ СTTTCCTGCTCAGATTTCTCCTTTG & C \\
\hline \multicolumn{7}{|l|}{$R R M 1$} \\
\hline rs1561876 & CACCTCTGGGGTTCAGCTTCTGTC & ATCTGAGGCACACATGTCAGAAGCTACTC & 162 & 3 & $\left(\right.$ GACT) ${ }_{4}$ GGTTTCTTGTTTCTGTCTCTTGCTTTC & $\mathrm{C}$ \\
\hline rs1465952 & TCCTTTGCCCAGGGAAAATGAAAC & GGTAACCCTGCCCACAGAGCTTCT & 64 & 3 & $(\mathrm{CTGA}){ }_{4} \mathrm{CTGGAAAATGAAACTTGAATGCACAT}$ & D \\
\hline rs11030918 & GCCACCATCCACTGAAGAACCCTAAAAG & CGGGGTTCGAATGACGTTACTCGAC & 596 & 3 & GACTTGACCCTGCCCTGCTTAAAAT & C \\
\hline rs 12806698 & $"$ & " & $"$ & 3 & GTCGCCTGTCAGTCTGTGAAG & D \\
\hline rs10835613 & CCACCCATAтTTCCGTCTCCTTATTTAG & СTGCAACATTCTTGCGCTCTAAAATGTA & 512 & 3 & CCACCCAтAтTTCCGTCTCCTTAтTTAG & C \\
\hline rs7932702 & $"$ & $"$ & $"$ & 3 & TCTAGGGGAGGACAAAGATC & D \\
\hline rs10498198 & $"$ & " & $"$ & 3 & CTGCAACATTCTTGCGCTCTAAAATGTA & C \\
\hline $\operatorname{rs} 183484$ & TGGGCATTTTTCCAAAGCAGAAGTAG & CCTTGTTCCCACCTTGATCCACATATC & 244 & 3 & CCTTGTTCCCACCTTGATCCACATATC & D \\
\hline rs9937 & GGGTTTGAAGACTGGGATGTATTATTTAAGGAC & GCTGCTGTGTTCCTCTCCTTCTCTTC & 138 & 4 & $(\mathrm{TGAC})_{2} \mathrm{TATTGGATTAGCCGCTGGTCT}$ & D \\
\hline rs1042858 & $"$ & $"$ & $"$ & 4 & $\left(\right.$ ACTG) ${ }_{3}$ ACTTTAGAGTGAACTGGATTGGATTAGC & C \\
\hline rs1042919 & CCTGTTGCAGGCAAAAGGAGTAATTG & СTTACTTAACCACTCCCTGTATGCAAGATGAC & 201 & 4 & GGAGTAATTGATTTAAAGTACTGTTAATGATG & D \\
\hline \multicolumn{7}{|l|}{ RRM2 } \\
\hline rs 7574663 & CAGGGGTCAGGAAAACAAGTTCATTGAC & CTTCTTTTCCCCACGACATTGACTTTGAA & 121 & 3 & $(\mathrm{CTT})_{2}$ TTCCCCACGACATTGACTTTGAA & D \\
\hline rs1130609 & CGGGAGATTTAAAGGCTGCTGGAG & GACACGGAGGGAGAGCATAGTGG & 115 & 4 & GACACGGAGGGAGAGCATAGTGG & D \\
\hline rs6741290 & TTAGGAAATCGAGCGCTCACAAATC & TACTGGCAGCATCGCACTCTTTGTAC & 160 & 4 & TGACTAAGTTGAGCATATGACATAAAATATCAAAGAA & C \\
\hline rs 4668664 & AATGGGACTGAGCTTGCCTTGGT & CTCAGCCATACTGAGAGCACTTGAACTC & 98 & 3 & AATGGGACTGAGCTTGCCTTGGT & C \\
\hline rs1138729 & GGGATTGCAGGCGTGATAAACAAATATTC & GCCTGTACCTCACAATGCAAGACAAAG & 343 & 4 & $(\mathrm{GACT}){ }_{4} \mathrm{CAGTATTTGAACGTCGTCCTGTTT}$ & C \\
\hline \multicolumn{7}{|l|}{ ENT1 } \\
\hline rs9357436 & CAACCCTACAATAGCACATGGTCATC & TAAAGGAAGCAGAAGAGAGGAGCTAGAGAG & 111 & 5 & $\left(\right.$ TGAC) ${ }_{3}$ TTTCCTCTCCTTCCAGTTGCTTC & E \\
\hline rs2297393 & AGGCAAATCCAGCCAGAGACTGATTC & GCTGGCTGAGAATGAACAGCAGACAG & 726 & 5 & ССТАСССССАССААТСC & F \\
\hline
\end{tabular}




\begin{tabular}{|c|c|c|c|c|c|c|}
\hline $\begin{array}{l}\text { Gen } \\
\text { rs-Nummer }\end{array}$ & PCR-Primer, vorwärts $\left(5^{\prime}->3^{\prime}\right)$ & PCR-Primer, rückwärts $\left(5^{\prime}->3^{\prime}\right)$ & $\begin{array}{c}\text { FL } \\
(\mathrm{bp})\end{array}$ & PP & SNaPshot ${ }^{\mathrm{TM}}$-Primer $\left(5^{\prime}->3^{\prime}\right)$ & SP \\
\hline rs3734701 & " & " & " & 5 & $\left(\right.$ GACT) ${ }_{4}$ GCTTCGATTGCTGCTGTCC & F \\
\hline rs1057985 & CCAGTGCTTAACTGAGGGACAAGTG & TGCCAGGCCAGGTTAAACTGTT & 242 & 5 & $(\mathrm{ACTG}){ }_{5} \mathrm{CAGGTCTGCCTCCATA}$ & $\mathrm{E}$ \\
\hline rs 66872347 & CATCGGTTTCCTTCGGGAGTCTTC & GCCCCTAGTTCTCTCCCTCCTCATCTC & 385 & 5 & CTGACTCGCAGCCCGCGCCG & F \\
\hline rs 67057732 & $"$ & $"$ & $"$ & 5 & $(\mathrm{GACT})_{4} \mathrm{CCATAGCCACAGCTGGAGA}$ & F \\
\hline rs6914414 & CACTTGGCATCATGGAGTCTTGATTTG & CAACAGAGCAAGACCTTGTCTGAAAACAC & 445 & 5 & $(\mathrm{TGAC})_{5} \mathrm{TAGGCGTGAGCCACCAC}$ & F \\
\hline rs9462977 & CAATGGCAGGATGATGGCTCACTGA & GGCCTTGTGACAGGGCTGGGACTAG & 354 & 5 & $(\mathrm{CTGA})_{6} \mathrm{CTTAGAGCCCGGGAGGAC}$ & F \\
\hline rs 11274220 & FAM-GATCCCCATCGATCTGGTCGGTATC & CTCCTGGTAAGCAAAGCCGAGGACTG & 271 & $\mathrm{~F}_{\mathrm{LA}}$ & & \\
\hline rs693955 & GACGGGTGATCCCCATCGATC & СTCCTGGTAAGCAAAGCCGAGGACTG & 278 & $\mathrm{E}_{2}$ & $(\mathrm{ACTG}){ }_{5} \mathrm{ACTTAAGCAAAGCCGAGGACTGT}$ & E \\
\hline rs1886884 & GGCTGAGCTGCCTGACACTCAAG & AGAGCTGGTGAGTGGAGGAGCTAGAATC & 195 & 5 & ACTGACTAAGTCAGGCTGGGAATGATCT & F \\
\hline rs747199 & TCTTGGAAAACCGGCCAGCAACTAG & AGGCCCCTCTCTGCAAGTCTGGTCT & 181 & 5 & $(\mathrm{ACTG}){ }_{4}{ }_{4} \mathrm{ACTTGGCTGGAAAGAAAGGTTAAG}$ & E \\
\hline rs9394992 & CCTCCTGTGCCAAAGGCTATGAAAC & TGGGAAATGACTGAGCTGTGCAATAAG & 315 & 5 & GCAGTTCCCTGAAGGCCT & $\mathrm{E}$ \\
\hline rs324148 & TGCCCTGGGTGGTATGAACTACAAAG & TCCCAGACCCAGCATGAAGAAGATAAG & 640 & 5 & GAAGAGAGGGCCTTAGAGCC & E \\
\hline rs324149 & $"$ & $"$ & $"$ & 5 & ACTGACTCCCATAAGAGGACACATGCAAA & $\mathrm{E}$ \\
\hline rs 45573936 & TCAGAAAGTGCCTTCGGCTACTTTATC & CCCAGGTAACAGATGATGGTCAAAATG & 71 & 5 & (TGAC) ${ }_{5}$ TCAGGTAACAGATGATGGTCAAAATG & E \\
\hline rs1128930 & GACCCAGAGAGGGAACCCAAGAAAG & ACGTGTATGGTGGGGTTGTCTTTCACTC & 768 & 5 & $(\mathrm{ACTG}){ }_{4} \mathrm{GGCAGGTATGTGTATATACATATATTCAT}$ & $\mathrm{E}$ \\
\hline rs 760370 & $"$ & $"$ & $"$ & 5 & $\left(\right.$ TGAC) ${ }_{2}$ TGGAGGTGGAGACAGGTTTGC & $\mathrm{E}$ \\
\hline \multicolumn{7}{|l|}{ PTCH1 } \\
\hline rs 71366293 & AGCAGCAGCGGCTGGTCTGTC & FAM-CGTTACCAGCCGAGGCCATGTTG & 190 & $\mathrm{~F}_{\mathrm{LA}}$ & & \\
\hline rs10512249 & CTTTTCTCGTTATGCTTTGGTGGTTGA & GCGGGTGTAACTGCAAAATTATTAGCAC & 306 & 6 & ACTGACTCATGAAGTGAGCCCAGTGAGAG & G \\
\hline rs 473902 & $"$ & $"$ & $"$ & 6 & $(\mathrm{GACT}){ }_{5} \mathrm{TTCCCATGGCAACACGC}$ & G \\
\hline rs574688 & GGCCACACTCTGCCAATCATTGC & GCATTAGACATGCGAGATGCAATTCA & 255 & 6 & TGCATTAGACATGCGAGATGCAATTCA & $\mathrm{H}$ \\
\hline rs2066836 & TGCCACGTATCTGCTCACACAGTC & GTTCAGGATCACCACAGCCTTCATC & 101 & 6 & TCACAGCCTTCTTCATGGC & G \\
\hline rs2236407 & GCACCCCCAACCCAAGACAGTATTAAG & GGACCCTGCAGGAAATTCTCCAC & 247 & 6 & GGACCCTGCAGGAAATTCTCCAC & G \\
\hline rs357564 & ATTGGCTCCCCAGGGTTGACTGAG & CTGGGTTCCGAGGGTTGTGAGAAC & 371 & 6 & GTCTCTGCGCGGTCTGTAG & $\mathrm{H}$ \\
\hline rs357565 & TGGAGCCATCAGAAACTGTTGTTTCATC & TGGCCATATTTTTCTCCATGCCTATGATG & 510 & 6 & $\left(\right.$ CTGA) ${ }_{2}$ CTGCTTTTAGTGTGATCATCACCCAAATA & G \\
\hline rs16909856 & CCCAGGCCAGGAGCTTGACTGTTA & GGGGCTGTCCAATTCTCACTCAGA & 343 & 6 & CCCAGGCCAGGAGCTTGACTGTTA & $\mathrm{H}$ \\
\hline rs357563 & " & " & " & 6 & GGGGCTGTCCAATTCTCACTCAGA & G \\
\hline
\end{tabular}




\begin{tabular}{|c|c|c|c|c|c|c|}
\hline $\begin{array}{l}\text { Gen } \\
\text { rs-Nummer }\end{array}$ & PCR-Primer, vorwärts $\left(5^{\prime}->3^{\prime}\right)$ & PCR-Primer, rückwärts $\left(5^{\prime}->3^{\prime}\right)$ & $\begin{array}{c}\mathrm{FL} \\
(\mathrm{bp})\end{array}$ & PP & SNaPshot ${ }^{\mathrm{TM}}$-Primer $\left(5^{\prime}->3^{\prime}\right)$ & SP \\
\hline \multicolumn{7}{|l|}{$\overline{S H H}$} \\
\hline rs 288746 & CACCGAGTCTTGTTAACGCTCAGCCTCT & GTTTCCAGAAGTTCCCTTTGCAGATCAAC & 122 & 6 & CACCGAGTCTTGTTAACGCTCAGCCTCT & $\mathrm{H}$ \\
\hline rs 872723 & CTCACCCCTGGCTCTGCACTTTG & CCTCTGTGGACCGAGGATAATTATGAGTG & 380 & 6 & ACTGTGCCTTAGAAAAATGTAAAAATACTGCT & G \\
\hline rs 756884 & AATCCCCCTCCCACAAACATGAAG & GCCTCCTGGCTTTTCCAGTTGAG & 180 & 6 & $(\mathrm{ACTG}){ }_{2} \mathrm{ACTCTACGTTCGTTCGTTCGTACAGT}$ & $\mathrm{H}$ \\
\hline rs9333596 & $"$ & $"$ & $"$ & 6 & $(\mathrm{ACTG}){ }_{3} \mathrm{ACTCACCTCCCCACCAAAGAAT}$ & $\mathrm{H}$ \\
\hline rs 1233556 & GCCCTCTGCAGAAGTCACCTTG & GCACTGACTTGCTTCCTGGATGTTTAC & 156 & 6 & $\left(\right.$ TGAC) ${ }_{4}$ TCAGTTCCCCCTCTTTAAATCCC & $\mathrm{H}$ \\
\hline rs 1233571 & GCTGGAGAAACCTCAGCTCTGTTTG & GGCTTACACATCAGGCTTTGCTAGTTAAG & 138 & 6 & (CTGA) ${ }_{3}$ CTGTTTGTATTTATTGTGTGAAGCTCTTTCTAC & G \\
\hline rs 1233560 & CAGGCTTAGGGAACAGGAGTGAACAGAC & AACCATCGCACTTCCTCCGAGATTG & 277 & 6 & GGCTCCAGAGGCCCTGC & G \\
\hline \multicolumn{7}{|l|}{ SMO } \\
\hline rs 6962740 & AACCCTTTAAACAATCCTCGTGAGAACTC & AGGTGGGTTTTGAATCCAGGACTAAAG & 376 & 6 & (CTGA) 5 ATGGTTTAGCACCATCCTCCT & G \\
\hline rs 11762252 & CCAGCTCAAGTCTTCAATTTTGCTTCAG & GAGGGGGATGTGACTAGACAAGACACAG & 191 & 6 & $(\mathrm{GACT}){ }_{4} \mathrm{CATCTGGGTCAATAACTAGACCACAGT}$ & $\mathrm{H}$ \\
\hline rs2718107 & CGCCCAACCAGTACCATGCTCTATAGAC & TGTGTCATCAGGCAATGTCATCTTTGTGT & 398 & 6 & TGTGTCATCAGGCAATGTCATCTTTGTGT & $\mathrm{H}$ \\
\hline rs 4731562 & CGCACTGGACAGAGCCTCTTCTGTTC & ССССТСCTCACTCTGACCCACAGAC & 743 & 6 & $(\mathrm{ACTG}){ }_{3} \mathrm{ACTAGAACCCTTGTTCCTCTTACCAAG}$ & $\mathrm{H}$ \\
\hline rs 2566871 & $"$ & $"$ & $"$ & 6 & TCACTCTGACCCACAGAC & $\mathrm{H}$ \\
\hline rs2228617 & ССTCTCTCGGGCAAGACCTCCTAC & CGGTAGTTCTTGTAGCCCACAAAACAAAT & 234 & 6 & CGGTAGTTCTTGTAGCCCACAAAACAAAT & G \\
\hline
\end{tabular}

Tab. 1 Primer zur Genotypisierung. Die Primer für Polymeraseketten-Reaktion (PCR) und SNaPshot ${ }^{\text {TM}-P C R ~ s i n d ~ m i t ~ i h r e r ~ r s-N u m m e r ~ g e m a ̈ ß ~ d e r ~ N C B I-D a t e n b a n k ~}$ (http://www.ncbi.nlm.nih.gov/SNP/) angegeben und nach Genen geordnet. Zu jedem Primerpaar (vorwärts und rückwärts) ist die entsprechende Fragmentlänge (FL)

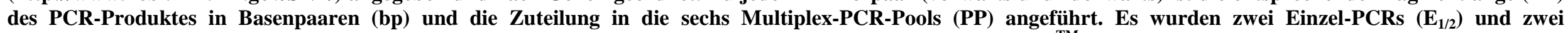
Fragmentlängenanalysen $\left(F_{L A)}\right.$ durchgeführt. Unter "SP" ist die Zugehörigkeit der Primer zu den acht SNaPshot ${ }^{\text {TM }}$-Primerpools (SP) von A bis H aufgelistet. 


\subsection{Verbrauchsmaterial}

2,7-ml-K-EDTA-Röhrchen

Labortücher

Mikroschraubröhrchen (2 ml)

$\mathrm{NaCl}-\mathrm{Lösung}$, isoton $0,9 \%$

PCR-Folien (Adhesive PCR Foil Seals)

Pipettenspitzen $(10 \mu 1)$, extended length

Pipettenspitzen $(10 \mu 1,100 \mu 1,1000 \mu 1)$

Platten, Thermo fast 384-Well

Platten, Thermo fast 96-Well

Reaktionsgefäße (1,5 ml, $2 \mathrm{ml})$

Spitzen für Multipipette plus

(Combitip plus 0,1, 0,2, 0,5, 1,0, 2,5, $5 \mathrm{ml}$ )

Sterile Pipetten $(5 \mathrm{ml}, 10 \mathrm{ml}, 25 \mathrm{ml})$

Streifen, Flat cap strips (8er) für PCR-Platten

\subsection{Wiederverwendbare Materialien}

Rahmen und Septen für Sequenzierer

Sequenzierplatten

\subsection{Kits}

EZ1 DNA Blood Kit zur DNA-Isolierung aus Gesamtblut, vollautomatisch

Multiplex PCR Kit

SNaPshot ${ }^{\mathrm{TM}}$ - Mastermix

Taq-DNA-Polymerase
Sarstedt, Nümbrecht

Kimberly-Clark, Surrey, UK

Sarstedt, Nümbrecht

Braun, Melsungen

Abgene, Epsom

Starlab, Ahrensberg

Sarstedt, Nümbrecht

Abgene, Epsom

Abgene, Epsom

Sarstedt, Nümbrecht

Eppendorf, Hamburg

Sarstedt, Nümbrecht

Abgene, Epsom

Applied Biosystems, Darmstadt

Applied Biosystems, Darmstadt

Qiagen, Hilden

Qiagen, Hilden

Applied Biosystems, Darmstadt

Qiagen, Hilden 


\subsection{Lösungen und Puffer}

$\begin{array}{lll}\text { Probenpuffer für Gelelektrophorese } & \text { Bromphenolblau } & 0,25 \%(\mathrm{v} / \mathrm{v}) \\ & \begin{array}{l}\text { Ficoll Puffer Typ } 400 \\ \text { in 1\% TBE }\end{array} & 15 \%(\mathrm{v} / \mathrm{v}) \\ & \text { Tris } & \\ \text { Restriktionsenzym-Puffer } & \mathrm{MgCl}_{2} & 200 \mathrm{mM} \\ & \text { Tris } & 100 \mathrm{mM} \\ \begin{array}{l}\text { TBE-Puffer (Tris-Borat-EDTA-Puffer), } \\ \text { als 10x konzentriert hergestellt, mit HCl } \\ \text { auf pH 8,3 eingestellt }\end{array} & \begin{array}{l}\text { Borsäure } \\ \text { EDTA }\end{array} & 1 \mathrm{M} \\ \begin{array}{l}\text { TE-Puffer, } \\ \text { pH 7,5, eingestellt mit HCl }\end{array} & \text { Tris } & 30 \mathrm{mM} \\ & \text { EDTA } & 10 \mathrm{mM}\end{array}$

\subsection{Software}

Adobe Illustrator CS3 (Version 13.0.0)

Bildbearbeitung

Adobe Photoshop CS2 (Version 9.0.2)

Bildbearbeitung

3100 Data Collection Software Version 1.0 (Applied Biosystems)

Datenerhebung mit dem 3100 Genetic Analyser Sequenzierer

GeneScan Analysis (Version 3.5.1) (Applied Biosystems)

Auswertung von DNA-Fragment-Analysen im Sequenzierer

HaploView-Software (http://www.broad.mit.edu/mpg/haploview)

Software zur grafischen Aufbereitung von Daten aus den Genotyp-Datenbanken.

$\underline{\text { Microsoft Office }}$

Programme für Textverarbeitung, Präsentationen und Tabellenkalkulation

OLIGO (http://www.oligo.net)

Software zum Primer-Design 
Quantity One S Version 4.2.1 (BioRad)

Grafische Darstellung und Auswertung von Gelbildern unter Bestimmung von Fragmentlängen

SPSS (Version 12.0) und R (Version 2.13.1)

Statistische Testung auf Korrelation und Grafische Darstellung von Messdaten

\subsection{Datenbanken}

$\underline{\operatorname{NCBI}}$ (http://www.nih.gov/)

Aus dieser Datenbank wurden Informationen $\mathrm{zu}$ Genen und deren Poloymorphismen gewonnen (Sub-Datenbank dbSNP, http://www.ncbi.nlm.gov/SNP). Weiterhin fand sich dort die Literatur-Datenbank PubMed (http://www.ncbi.nlm.nih.gov/pubmed).

HapMap-Projekt (http://www.hapmap.org/index.html.en)

Zu Beginn meiner Dissertation war die HapMap-Datenbank die weltweit umfangreichste und detaillierteste zur genetischen Variabilität in unterschiedlichen ethnischen Gruppen. Auf Basis dieser Daten wurde für die Kandidatengene meiner Arbeit über das paarweise Kopplungsungleichgewicht (engl. linkage disequilibrium, $L D$ ) jeweils der Satz an Genpolymorphismen bestimmt, welcher die Variabilität des betrachteten Gens umfassend repräsentiert (so genannte tagging SNPs, mit Algorithmus der Software HaploView).

1000 humane genome-Projekt (http://www.1000genomes.org/)

Zum Ende meiner Dissertation konnten auf Basis der genomweiten Daten des „1000 humane genome-Projekts“ Häufigkeiten einzelner Genvarianten zwischen unterschiedlichen Ethnizitäten verglichen werden. 


\section{Methoden}

Nachfolgend werden zunächst die Auswahl der Patienten, dann die Genotypisierung auf 109 Marker in Kandidatengenen für die Gemcitabin-Empfindlichkeit und schließlich die statistischen Verfahren beschrieben.

\subsection{Patientenauswahl und Nachsorge}

Als Teilnehmer der klinischen Studie kamen 552 Personen in Betracht, die zwischen 2003 und 2010 in der Abteilung für Allgemein- und Viszeralchirurgie der Universitätsmedizin Göttingen wegen des Verdachts eines malignen Pankreasprozesses behandelt wurden. Die Patienten hatten im Rahmen des Therapieaufenthalts in DNA-Analysen eingewilligt. Aus EDTA-Blutproben oder asservierten Leukozyten-Pellets wurde später DNA isoliert.

Für meine Studie kamen schließlich nur histopathologisch gesicherte duktale Adenokarzinome des Pankreas in Frage, bei denen eine Gemcitabin-haltige Chemotherapie durchgeführt wurde. Unter Sichtung von Arztbriefen, OP-Berichten und Pathologiebefunden wurde dies überprüft. Nicht weiter berücksichtigt wurden in diesem Zusammenhang benigne Prozesse des Pankreas (z.B. chronische Pankreatitis, zystische Prozesse), Tumore abweichender Entität wie neuroendokrine Tumore, IPMN (intraduktale papillär-muzinöse Neoplasien), Tumore mit adenosquamösen bzw. zystischen Anteilen sowie alle Tumore, deren Ursprungslokalisation nicht im Pankreas selbst lag (z.B. Karzinome der Papilla Vateri). Aufgrund der per se besseren Prognose von Patienten mit histopathologischem Tumorgrading G1 blieben auch diese Fälle von den weiteren Betrachtungen ausgeschlossen. Patienten, die postoperativ nicht mit Gemcitabin behandelt wurden, sowie Patienten, für die es nicht möglich war, Daten zur Nachsorge zu erheben, blieben ebenfalls unberücksichtigt. Einschränkungen hinsichtlich des Alters der Patienten gab es nicht.

Zur Nachsorge der Therapieverläufe der Studienpatienten wurden ca. 90 Hausarztpraxen und 40 onkologischen Praxen bzw. Ambulanzen im Raum Südniedersachsen und Nordhessen kontaktiert. So konnten Informationen zur Hauptzielgröße Überlebenszeit der Patienten ab Beginn der Gemcitabin-Therapie erfasst werden. Weiterhin wurden Art und Dauer der Chemotherapie dokumentiert. Hierzu gehörten Angaben zu möglichen Kombinationspräparaten, Zyklenzahl und Dosis der einzelnen Gemcitabingaben. Gründe für die Beendigung der Therapie wurden ebenfalls erfragt. Um den Aspekt der Hämatotoxizität der Gemcitabin-Therapie als Nebenzielgröße in die Auswertungen einbeziehen zu können, wurde der Verlauf der hämatologischen Kumulativbefunde für die ersten 42 Therapietage verfolgt. 


\subsection{Genotypisierung}

Als Untersuchungsmaterial diente genomische Keimbahn-DNA aus Zellen des peripheren Blutes. Die gewünschten Genabschnitte wurden mittels Polymerasekettenreaktion (PCR) im Einzel- und Multiplex-PCR-Verfahren vervielfältigt (siehe Kapitel 3.2.3). Hierbei waren Gradienten-PCR und Gelelektrophorese (3.2.4) entscheidend zur Etablierung der Reaktion. Die meisten Genvarianten wurden mit dem Primerextensionsverfahren (SNaPshot ${ }^{\mathrm{TM}}$ ) typisiert (siehe Abschnitt 3.2.5). In zwei Fällen war eine Fragmentlängenanalyse erforderlich (siehe Kapitel 3.2.6).

\subsubsection{Isolierung von genomischer DNA}

Das EDTA-Blut der Studienpatienten hatte zur Konservierung bei $-20^{\circ} \mathrm{C}$ gelagert. Unter Zuhilfenahme des Bio Robots EZ1 (Qiagen) und des EZ1 DNA Blood Kits (Qiagen) konnte aus den zuvor auf Zimmertemperatur gebrachten Blutproben die DNA extrahiert werden. Dabei wurde nach dem Herstellerprotokoll verfahren. Aus $350 \mu 1$ Vollblut eines Patienten wurden $200 \mu 1$ DNA-Eluat gewonnen. Die Konzentrationsbestimmung der DNA erfolgte photometrisch (siehe Abschnitt 3.2.2). In einer Endkonzentration von $10 \mathrm{ng} / \mu \mathrm{l}$ wurden die gewonnenen DNA-Proben in destilliertem Wasser $\left(\mathrm{ddH}_{2} \mathrm{O}\right)$ gelöst und zur Lagerung bei $-20^{\circ} \mathrm{C}$ auf 96-Well-Platten übertragen.

\subsubsection{Quantifizierung von genomischer DNA}

Die Bestimmung der DNA-Menge erfolgte durch Ermittlung der optischen Dichte (OD) im Photometer (Eppendorf) unter Einsatz von UV-durchlässigen Küvetten (UVetten 50-1000 $\mu$ l, Eppendorf). Ein spezieller Adapter der Firma Implen machte die Messung kleiner Mengen unverdünnter Nukleinsäureproben im Mikroliterbereich möglich. So konnte aus jeder isolierten Nukleinsäureprobe jeweils $3 \mu 1$ auf die Messzelle (LabelGuardTM, Firma Implen) aufgetragen werden. War die Messung erfolgt, wurden Messfenster und Deckel des Mikroliteradapters mit Ethanol gereinigt. Als Leerwert wurde $\mathrm{ddH}_{2} \mathrm{O}$ genutzt.

Eine OD von 1, bei einer Wellenlänge von $260 \mathrm{~nm}$, entspricht einer DNA-Konzentration von $50 \mu \mathrm{g} / \mathrm{ml}$. Dabei beruht die Konzentrationsbestimmung von DNA auf dem bekannten Absorptionsmaximum von Nukleinsäuren bei $260 \mathrm{~nm}$. Verunreinigungen der Proben durch Proteine können aufgrund ihres abweichenden Absorptionsmaximums von $280 \mathrm{~nm}$ erkannt werden. Der Quotient aus Extinktion 260 / Extinktion 280 dient als Maßstab für die Reinheit einer Nukleinsäurelösung. Werte zwischen 1,8 und 2,0 lassen auf Proben mit hohem Reinheitsgrad der Nukleinsäure schließen und machen eine Verunreinigung unwahrscheinlich. 


\subsubsection{Polymerasekettenreaktion (PCR)}

Die Polymerasekettenreaktion (PCR) ist eine in-vitro-Methode zur enzymatischen Vervielfältigung von doppelsträngigen Nukleinsäuren. Sie ermöglicht die Amplifikation bestimmter DNA-Fragmente in Größenordnungen bis $\mathrm{zu}>10$ Milliarden. Dabei wird im Optimalfall von einer Verdopplung der kopierten DNA-Stränge während eines Reaktionszyklus ausgegangen. Ein PCR-Zyklus besteht aus den drei Schritten Denaturierung, Hybridisierung (Annealing) und Elongation. Diese sich stetig wiederholende Abfolge (z.B. 35 Mal) stellt das Hauptprinzip der PCR dar. Hierbei kommt es initial zur Trennung der komplementären DNA-Stränge durch Erhitzung des Reaktionsansatzes auf $95^{\circ} \mathrm{C}$ (Denaturierung). Der Reaktionsansatz besteht klassischerweise aus Reaktionspuffer, Nukleotiden mit den vier unterschiedlichen Basen, den beiden spezifischen Oligonukleotidprimern, einer DNA-Polymerase und dem DNA-Template. Zur Verbesserung der Amplifikation von GC-reichen Regionen kann zusätzlich Q-Solution der Firma Qiagen verwendet werden. Während des sich anschließenden Reaktionsschritts der Hybridisierung wird es den Oligonukleotidprimern durch Senkung der Temperatur auf $57-70^{\circ} \mathrm{C}$ ermöglicht sich an die vorliegenden DNA-Einzelstränge anzulagern. Der einmal gebundene Primer dient der DNA-Polymerase als Startpunkt für den Einbau von Nukleotiden (dNTPs). Hierbei erfolgt die Anlagerung der dNTPs in den entstehenden Strang komplementär zum jeweiligen Nukleotid der DNA-Matrize (Elongination). Dieser Vorgang startet stets am 3'-Ende des Primers. Die verwendete Taq-DNA-Polymerase ist thermostabil und kann so die initialen Denaturierungsschritte bis $95^{\circ} \mathrm{C}$ überdauern. Mit der Erhöhung der Reaktionstemperatur auf $72^{\circ} \mathrm{C}$ wird ihr Temperaturoptimun erreicht. Zusätzlich wird ein Bindungsbruch zwischen nicht vollständig komplementären Primer-DNA-Komplexen erzeugt, was die unerwünschte Entstehung von Nebenprodukten vermeidet. Der gesamten Reaktion ist initial ein Denaturierungsschritt bei $95^{\circ} \mathrm{C}$ vorgeschaltet. Zum Ende der Reaktion folgt ein einmaliger, 10-minütiger Elongationsschritt in dem nicht komplett synthetisierte Fragmente vervollständigt werden sollen. Die Standard-PCR-Bedingungen sind in Tab.2 aufgeführt.

\begin{tabular}{llll}
\hline Phase & Temperatur & Zeit & \\
\hline Initiale Denaturierung & $95^{\circ} \mathrm{C}$ & $5 \mathrm{~min}$ & \\
Denaturierung & $95^{\circ} \mathrm{C}$ & $30 \mathrm{~s}$ & 35 Zyklen \\
Anlagerung & $50-70{ }^{\circ} \mathrm{C}$ & $30 \mathrm{~s}$ & \\
Verlängerung & $72^{\circ} \mathrm{C}$ & $1 \mathrm{~min} / \mathrm{kb}$ & \\
Terminale Elongation & $72^{\circ} \mathrm{C}$ & $10 \mathrm{~min}$ & \\
Lagerung & $8^{\circ} \mathrm{C}$ & $\infty$ & \\
\hline
\end{tabular}

Tab. 2 Standard-Bedingungen für PCR mit Taq-Polymerase. 
Entscheidend für die Spezifität der PCR-Reaktion ist die Sequenz der einzelnen Primer, welche die zu amplifizierende Zielregionen der DNA-Matrize flankieren. Für diese Arbeit wurden Primer mit Hilfe des Programms OLIGO ausgewählt. Die Länge der Primer lag meist zwischen 20 und 30 Nukleotiden. Eine Auflistung aller verwendeten PCR-Primer zeigt Tab. 1 im Materialteil dieser Arbeit (siehe Kapitel 2.3).

Zur Etablierung idealer PCR-Bedingungen (optimale Annealing-Temperatur, mit oder ohne Q-Solution) wurde jeweils eine Gradienten-PCR durchgeführt. Damit sollte die Amplifizierung einer möglichst hohen Kopienzahl der gewünschten DNA-Fragmente gewährleistet und das Auftreten von Nebenprodukten minimiert werden. Hierfür wurden stets zwei Reaktionsansätze (mit und ohne Q-Solution) auf eine 96-Well-Platte vorgelegt und mit DNA versetzt. Um mehrere Temperaturen gleichzeitig zu testen, wurden die Proben dann im Heizblock entlang eines Temperaturgradienten $\left(57-70^{\circ} \mathrm{C}\right)$ angeordnet. Der Reaktionsansatz, wie auch die Reaktionsbedingungen im Thermocycler, entsprachen hierbei dem Protokoll des Herstellers. Nach Ablauf der Reaktion konnten die PCR-Produkte auf ein Agarosegel aufgetragen und ausgewertet werden (siehe Kapitel 3.2.4, Abb. 3).

Im Rahmen dieser Arbeit wurde standardmäßig das Multiplex-Verfahren (M-PCR) verwandt. Es ermöglicht die Vervielfältigung von bis zu 25 PCR-Fragmenten gleich mehrerer DNAAbschnitte. Sechs Multiplex-PCR's mit neun bis maximal 18 Fragmenten konnten im Rahmen der Genotypisierung der Kandidatengene CDA, CMPK1, DCK, DCTD, ENT1, NT5C3, PTCH1, RRM1, RRM2, SHH und SMO etabliert werden. Ein Standard-Reaktionsansatz für eine Multiplex-PCR ist in Tab. 3 aufgeführt. Die einzelnen Primer waren in TE-Puffer gelöst und innerhalb der sechs Primer-Pools (siehe Tab. 1 in Kapitel 2.3) auf eine Konzentration von $2 \mu \mathrm{M}$ gebracht worden.

\begin{tabular}{ll}
\hline & Volumen/Reaktion \\
\hline Multiplex-Mastermix (Qiagen) & $6 \mu \mathrm{l}$ \\
Q-Solution (5x) & $1,2 \mu \mathrm{l}$ \\
Primer-Pool & $1,2 \mu \mathrm{l}$ \\
$\mathrm{ddH}_{2} \mathrm{O}$ & $2,8 \mu \mathrm{l}$ \\
\hline
\end{tabular}

Tab. 3 Pipettierschema für Multiplex-PCR.

Ein DNA-Fragment im ENT1-Gen und ein Fragment im DCK-Gen konnten mit der MultiplexMethode nicht zufriedenstellend vervielfältigt werden. In diesen Fällen kam jeweils eine Einzel-PCR zur Anwendung. Das Pipettierschema hierfür findet sich in Tab. 4. Es wurde angestrebt, den Reaktionsansatz auf ein Gesamtvolumen von $12 \mu 1$ je Probe zusammenzustellen. 


\begin{tabular}{lll}
\hline & Volumen/Reaktion & Endkonzentration \\
\hline 10 x PCR Puffer & $1,2 \mu \mathrm{l}$ & $1 \mathrm{x}$ \\
Q-Solution $(5 \mathrm{x})$ (optional) & $2,4 \mu \mathrm{l}$ & $1 \mathrm{x}$ \\
$\mathrm{dNTP}(10 \mathrm{mM}$ each $))$ & $0,24 \mu \mathrm{l}$ & $0,2 \mathrm{mM}$ \\
Primer-F $(100 \mu \mathrm{M})$ & $0,12 \mu \mathrm{l}$ & $1 \mu \mathrm{M}$ \\
Primer-R $(100 \mu \mathrm{M})$ & $0,12 \mu \mathrm{l}$ & $1 \mu \mathrm{M}$ \\
Taq Polymerase $(5 \mathrm{U} / \mu \mathrm{l})$ & $0,06 \mu \mathrm{l}$ & $0,025 \mathrm{U} / \mu \mathrm{l}$ \\
$\mathrm{ddH}_{2} \mathrm{O}$ & $5,86 \mu \mathrm{l}$ & \\
\hline Total & $10 \mu \mathrm{l}$ & \\
Genomische DNA $(10 \mu \mathrm{g} / \mathrm{ml})$ & $2 \mu \mathrm{l}$ & \\
\hline
\end{tabular}

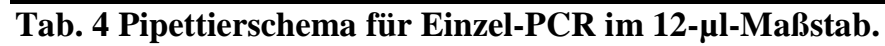

\subsubsection{Agarose-Gelelektrophorese von DNA}

Der Begriff Elektrophorese steht für die Wanderung geladener Teilchen durch ein Trägermaterial in einem elektrischen Feld. Je nach Größe und Ladung besitzen Teilchen eine bestimmte elektrophoretische Beweglichkeit. Substanzgemische lassen sich dahingehend auftrennen. Die Gelelektrophorese mit Agarose bietet die Möglichkeit zur Auftrennung von Nukleinsäuren. Das Bild einer solchen Gelelektrophorese einer Multiplex-Gradienten-PCR zeigt Abb. 3. Unter Einfluss des elektrischen Feldes wandern die negativ geladenen Nukleinsäuren entsprechend ihrer Fragmentlänge unterschiedlich schnell zur Anode.

Bei dem Polysaccharid Agarose handelt es sich um ein Polymer, bestehend aus verschieden gekoppelten Galactoseeinheiten. Die Polymere vernetzen sich proportional zur eingesetzten Menge an Agarose und steigern damit die Geldichte. Diese beeinflusst die Geschwindigkeit, mit der sich die Nukleinsäuren im Trägermedium zur Anode bewegen. Im Rahmen meiner Arbeit wurde dementsprechend die Agarose-Menge zur Herstellung eines Gels in Abhängigkeit der Länge der aufzutrennenden Nukleinsäuren gewählt. Bei kleinen DNAFragmenten, bis maximal $1 \mathrm{~kb}$, lag der Agarosegehalt relativ hoch (2 - 3\%). Zur Auftrennung von größeren DNA-Stücken kamen niedrig-prozentige Agarosegele $(0,8-1 \%)$ zur Anwendung. Ein zwei-prozentiges Agarosegel wurde durch Resuspendierung von $1 \mathrm{~g}$ Agarose in $50 \mathrm{ml}$ TBE-Puffer hergestellt. Das Gemisch wurde so weit aufgekocht, bis sich keine Schlieren mehr zeigten und die Flüssigkeit klar war. Nach leichter Abkühlung und unter stetem Rührvorgang wurde dann $1 \mu \mathrm{l}$ Ethidiumbromid hinzugegeben. Die interkalierende Substanz Ethidiumbromid lagert sich in doppelsträngige DNA ein und bindet zwischen den Nukleinbasen. Fluoreszierend in UV-Licht ermöglicht sie später das Sichtbarwerden der DNA-Banden im Gel. War das Gemisch auf ca. $50-60^{\circ} \mathrm{C}$ abgekühlt, konnte es in einen vorbereiteten Gelträger mit Kamm eingebracht werden. Der Kamm hinterlässt nach 
Abkühlung und Aushärtung des Gels Taschen. Das PCR-Produkt wurde anschließend mit Ladepuffer versehen und in Volumina von $15 \mu 1$ (12 $\mu$ l PCR-Produkt und $3 \mu 1$ Ladepuffer) in diese Taschen hineingegeben. Ein Längenstandard diente jeweils als Referenz. Er wurde unter Berücksichtigung der Länge der aufzutrennenden DNA-Fragmente gewählt und in eine äußere Geltasche eingebracht. Kurze Fragmente (bis 1 kb) liefen zusammen mit einer 100 bp Leiter, längere Fragmente parallel zu einer $1 \mathrm{~kb}$ Leiter.

Die Elektrophorese erfolgte in einer Kammer, die zuvor mit einem Gemisch aus TBE-Puffer und Ethidiumbromid $(0,5 \mu \mathrm{g} / \mathrm{ml})$ befüllt worden war. Bei einer konstanten Spannung von $120 \mathrm{~V}$ variierten die Auftrennungszeiten bedingt durch Unterschiede in den betrachteten Fragmentlängen im Bereich von 50-80 Minuten. Unter Zuhilfenahme des Fluor- $\mathrm{S}^{\mathrm{TM}}$ MultiImagers und der Software Quantity One ${ }^{\circledR} \mathrm{S}$ konnten die DNA-Banden bei einer Wellenlänge von $302 \mathrm{~nm}$ des applizierten UV-Lichts sichtbar gemacht und ausgewertet werden.

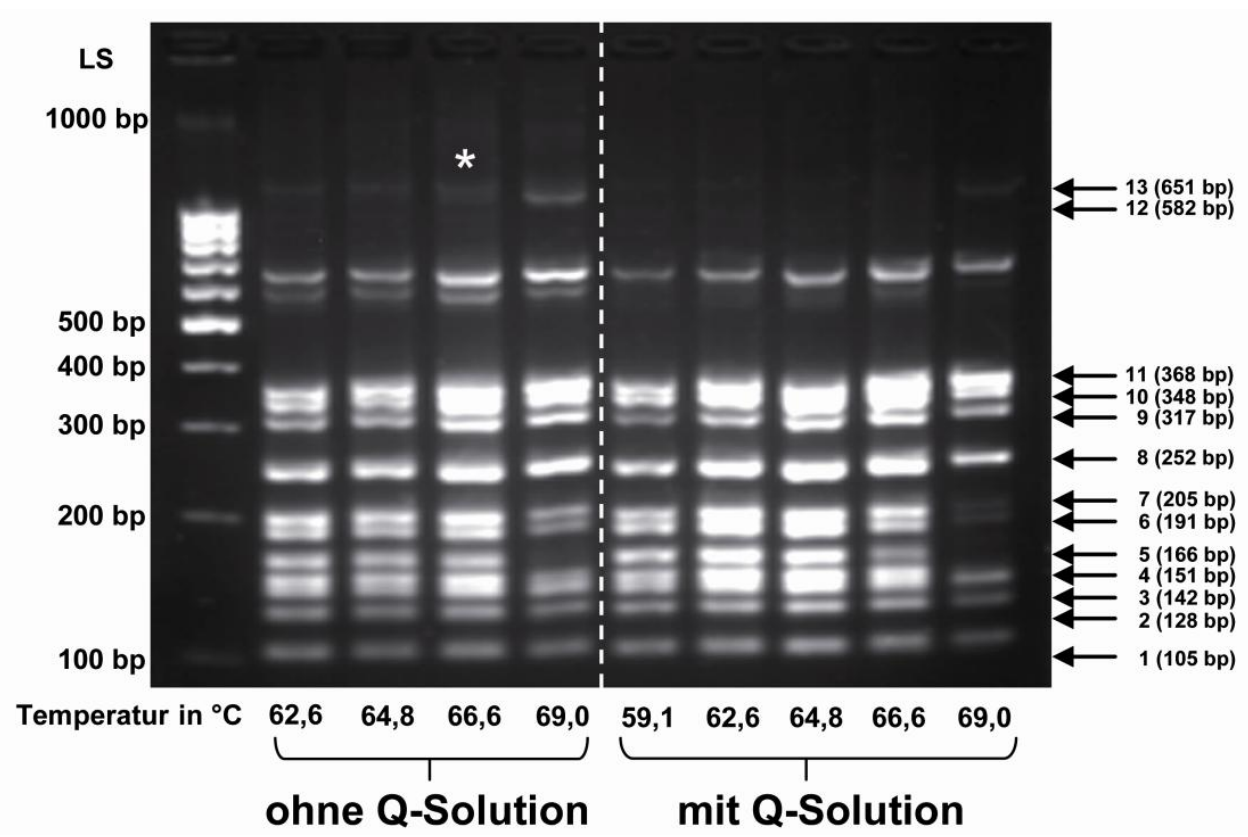

Abb. 3 Gelbild einer Multiplex-Gradienten-PCR. Es wurden fünf Annealing-Temperaturen mit QSolution (rechts) und vier ohne (links) gewählt. Die Temperaturen sind im unteren Teil der Abbildung angegeben. Der Längenstandard (LS) befand sich in der linken äußeren Spur und ist mit der jeweiligen Größe in Basenpaaren (bp) gekennzeichnet. In aufsteigender Fragmentlänge sind am rechten Bildrand die 13 erwarteten PCR-Banden gezeigt. Das Gelfoto entstand im Rahmen der Etablierung der MultiplexPCR zur Genotypisierung des $C D A$-Gens. Optimale Reaktionsbedingungen (markiert mit ,*6) fanden sich bei $66,6^{\circ} \mathrm{C}$, ohne die Verwendung von Q-Solution. 


\subsubsection{Bestimmung von Genotypen mittels Primerextension (SNaPshot ${ }^{\mathrm{TM}}$ )}

Die Methode der Primerextension $\left(\mathrm{SNaPshot}^{\mathrm{TM}}\right.$ ) bietet die Möglichkeit, mehrere genetische Polymorphismen (engl. single nucleotid polymorphismen, SNPs) in einer Reaktion zu bestimmen. Insgesamt 109 SNPs der elf Kandidatengene (CDA, CMPK1, DCK, DCTD, ENT1, NT5C3, PTCH1, RRM1, RRM2, SHH und SMO) wurden im Rahmen dieser Arbeit an 142 Patientenproben mittels SNaPshot ${ }^{\mathrm{TM}}$-Methode bestimmt. Weitere 153 Proben vorangegangener Probandenstudien der Abteilung Klinische Pharmakologie der Universitätsmedizin Göttingen (Preuß 2009; Kuschel 2011) kamen hinzu.

Das Prinzip der Primerextension beruht darauf, dass zunächst der Genombereich, der den gesuchten Polymorphismus flankiert, durch PCR amplifiziert wird. Das PCR-Produkt wird danach durch Zugabe der Restriktionsenzyme Exonuklease 1 (Exo1) und SAP (shrimp alkalic phosphatase) enzymatisch aufgereinigt. Exo1 baut einzelsträngige Primer-DNA ab und verhindert so deren spätere Extension. SAP dephosphoryliert ihrerseits alle nicht gebundenen dNTPs am 5'-Ende, die damit in folgenden Reaktionsschritten nicht mehr als Substrate für weitere Kettenverlängerungen zur Verfügung stehen. Für die Aufreinigung wurden je Probe $5 \mu$ l-Aliquots eines Verdau-Mixes ( $1 \mu$ l SAP-Puffer (10x), 2,82 $\mu 1$ Exo1 und 1,18 $\mu 1$ SAP) auf eine 384-Well-Platte vorgelegt und mit je $10 \mu$ l PCR-Produkt versetzt. Dieser Ansatz kam für $3 \mathrm{~h}$ bei $37^{\circ} \mathrm{C}$ zur Inkubation. Die Enzyme wurden danach bei $80^{\circ} \mathrm{C}$ für 15 min inaktiviert.

Darauf folgte die eigentliche SNaPshot ${ }^{\mathrm{TM}}$-Reaktion. Hierbei findet eine Einzelbasenverlängerung am 3'-Ende eines direkt neben der polymorphen Stelle bindenden spezifischen Primers statt. Am 3'-Ende des Primers lagern sich farbmarkierte Didesoxyribonukleosidtriphosphate (ddNTPs) an. Im Gegensatz zu den Desoxribonukleosidtriphosphaten (dNTPs) der klassischen PCR fehlt ddNTPs eine Hydroxylgruppe an ihrem 3'-Ende. Ein strangverlängernder Einbau weiterer Nukleotidbausteine über das ddNTP hinaus ist somit unmöglich. Die Anlagerung jeweils eines ddNTPs, komplementär zum vorliegenden Allel des Polymorphismus, wird gewährleistet. Die Markierung der ddNTPs mit Fluoreszenzfarbstoff (FS) richtet sich dabei nach der jeweiligen Base: Adenin, grün (FS: dR6G); Thymin, rot (FS: dROX $\left.{ }^{\mathrm{TM}}\right)$; Cytosin, schwarz (FS: dTAMRA ${ }^{\mathrm{TM}}$ ) und Guanin, blau (FS: dR110). Über diese farbliche Markierung kann das vorliegende Allel bei der späteren Auswertung im Elektropherogramm bestimmt werden. Die vorbekannte Länge (Anzahl an Nukleotidbausteinen) der Primer ermöglicht es, mehrere polymorphe Stellen in einer Reaktion nachzuweisen, wenn die zu extendierenden Primer hierdurch mittels Kapillarelektrophorese getrennt werden können. Die für diese Arbeit verwendeten $\mathrm{SNaPshot}^{\mathrm{TM}}$-Primer sind mit ihren 
Sequenzen und in ihrer Zugehörigkeit zu einem der neun Primer-Pools in Tab. 1 (Kapitel 2.3) aufgelistet. Es wurden diejenigen Primer in einem Pool zusammengefasst, die gemeinsam in einem Elektropherogramm analysiert werden sollten. Die Konzentration der Primer innnerhalb der Pools variierte zwischen 2 und $15 \mu \mathrm{M}$ und wurde jeweils der Signalstärke angepasst.

Der Reaktionsansatz der SNaPshot ${ }^{\mathrm{TM}}$-Reaktion beinhaltete den $\mathrm{SNaPshot}^{\mathrm{TM}}-\mathrm{Mastermix}_{\text {(ABI }}$ PRISM SNaPshot ${ }^{\mathrm{TM}}$-Multiplex-Kit), einen gepoolten Primermix (10-fach konzentriert) und $\mathrm{ddH}_{2} \mathrm{O}$ (siehe Tab. 5). Für jede Probe wurden $3 \mu \mathrm{l}$ des Ansatzes auf eine 384-Well-Platte ausgebracht. Waren $2 \mu \mathrm{l}$ PCR-Produkt je Well hinzugegeben, erfolgte die SNaPshot ${ }^{\mathrm{TM}}$ Reaktion gemäß der Angaben des Herstellers in einem 384-Well-Thermocycler. Die Reaktionsbedingungen sind in Tab. 5 veranschaulicht.

\begin{tabular}{ll|lll|l}
\hline Reaktionsansatz & $\mu \mathrm{l}$ & Reaktionsbedingungen & & \\
\hline SNaPshot $^{\mathrm{TM}}$-Mastermix & 0,5 & Phase & Temperatur & Zeit & \\
Primermix & 0,5 & Denaturierung & $96^{\circ} \mathrm{C}$ & $10 \mathrm{~s}$ & \\
$\mathrm{dd}_{2} \mathrm{O}$ & 2,0 & Annealing & $50^{\circ} \mathrm{C}$ & $5 \mathrm{~s}$ & 26 Zyklen \\
aufgereinigtes PCR- & 2,0 & Elongation & $60^{\circ} \mathrm{C}$ & $30 \mathrm{~s}$ & \\
Produkt & & & &
\end{tabular}

Tab. 5 Reaktionsansatz und Reaktionsbedingungen für SNaPshot ${ }^{\text {TM_PCR. }}$

Zur Eliminierung überschüssiger ddNTPs, die bei der späteren Analyse im Sequenzierer durch Bildung von Nebenprodukten zu erheblichen Störsignalen führen könnten, wurde der Reaktionsansatz im Anschluss wiederum mit SAP versetzt. Hierzu wurde je Probe $1 \mu$ einer 1:1-Mischung aus SAP-Puffer (10x) und SAP (1 U/ $\mu$ l) zugegeben und der Ansatz für 30 min bei $37^{\circ} \mathrm{C}$ im Wärmeschrank inkubiert. Auf die Hitzeinaktivierung des Enzyms konnte verzichtet werden, war die Weiternutzung der Proben am gleichen Tag gewährleistet.

Für die anschließende Auftrennung der markierten Primer im Sequenzierer wurde pro Probe $10 \mu 1$ einer 1:100-Mischung aus Gene-Scan-120-Längenstandard und HIDI-Formamid auf eine 96-Well-Sequenzierplatte vorgelegt. Anschließend wurde $1 \mu 1$ des aufgereinigten SNaPshot ${ }^{\mathrm{TM}}$-PCR-Produkts hinzugegeben und der Ansatz gut durchmischt. Schließlich erfolgte die Denaturierung der extendierten Primer durch Erhitzung des Reaktionsansatzes auf $95^{\circ} \mathrm{C}$ für $10 \mathrm{~min}$ im 96-Well-Thermocycler. Die Renaturierung der Primer sollte durch die Zugabe von Formamid vermieden werden. Zusätzlich wurden die Proben sofort nach Beendigung der Inkubationszeit auf Eis überführt. Einer 10-minütigen Abkühlung folgte das Einfügen der 96-Well-Platte in einen Sequenzierplattenträger. Die so stabilisierte Platte konnte in den Sequenzierer verbracht und mittels GeneScan Analysis Software (Version 3.5.1) analysiert werden. Ein Beispiel für ein Elektropherogramm ist in Abb. 4 illustriert. 


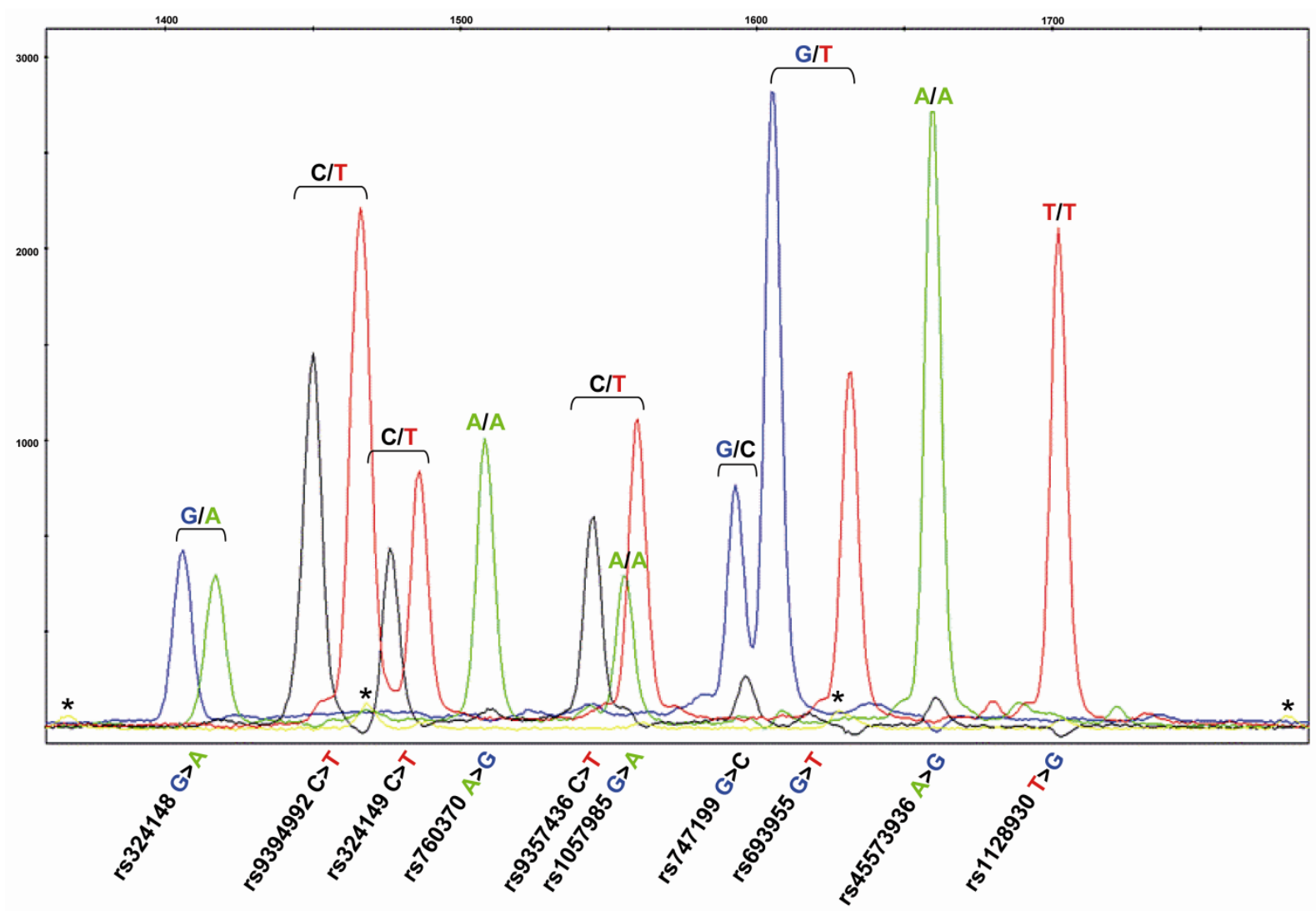

Abb. 4 SNaPshot ${ }^{\text {TM}}$-Elektropherogramm für zehn Polymorphismen des ENT1-Gens. Zu allen Polymorphismen sind rs-Nummer und Basenaustausch unterhalb der Abbildung aufgeführt. Die Genotypenkonfiguration der gezeigten Probe ist oberhalb des jeweiligen Signalpeaks angegeben. Hinsichtlich der Peakfarbe entspricht blau - Guanin (G), schwarz - Cytosin (C), grün - Adenin (A) und rot - Thymin (T). Homozygote Allelausprägung besteht bei singulärem Signalpeak, Heterozygotie bei zwei zusammenhängenden Peaks unterschiedlicher Farbe. Der Längenstandard ist mit „ *“ gekennzeichnet.

\subsubsection{Fragmentlängenanalyse zweier Insertionspolymorphismen}

Für zwei Insertionspolymorphismen der Gene ENT1 und PTCH1 war es mittels SNaPshot ${ }^{\text {TM }}$ Methode nicht möglich gewesen, die jeweiligen Allelkonfigurationen exakt zu differenzieren. In diesen Fällen wurde jeweils eine Fragmentlängenanalyse durchgeführt. Bei dem ENT1-SNP rs11274220, lokalisiert auf Intron 1, handelt es sich um eine 20 Basenpaar-messende Insertionsvariante (Del > Ins 20bp). Der PTCH1-SNP rs71366293 ist seinerseits ein drei Basenpaar messender Insertionspolymorphismus und befindet sich im 5'UTR-Bereich des Gens (Del > Ins CGG). Ausgangspunkt der Reaktion war die PCR-basierte Amplifizierung der DNA-Fragmente von Chromosom 6 (ENT1) bzw. 9 (PTCH1), welche die Insertionen flankierten. Die Etablierung von optimalen Reaktionsbedingungen erfolgte mit je einer Gradienten-PCR analog zum Vorgehen bei der PCR (siehe Kapitel 3.2.3). Auch Reaktionsbedingungen und Reaktionsansatz entsprachen dem der Einzel-PCR (siehe Tab. 2 und Tab. 4 in Kapitel 3.2.3). Entscheidender Unterschied zur Einzel-PCR-Reaktion war, dass der Vorwärtsprimer an seinem 5'-Ende mit einer Fluoreszenz-Markierung (6- 
Carboxyfluorescein/FAM) versehen wurde. Damit sollte in der späteren Auswertung die Unterscheidung der jeweiligen Allelkonfigurationen gewährleistet sein. Zur Vorbereitung des PCR-Produkts auf die folgende Kapillarelektrophorese im Sequenziergerät wurde eine 1:200Verdünnung des ROX-400HD-Längenstandards in Formamid (HIDI) hergestellt und je Probe $10 \mu 1$ des Ansatzes auf eine 96-Well-Sequenzierplatte vorgelegt. Dieser Ansatz wurde dann mit $1 \mu \mathrm{l}$ des PCR-Produkts versetzt. Das Ganze kam zur Denaturierung für 5 min bei $95^{\circ} \mathrm{C}$ in den Thermocycler, um im Anschluss direkt für 10 min auf Eis überführt zu werden. Danach wurde die Platte mit einem Rahmen fixiert und zur Kapillarelektrophorese in den Sequenzierer verbracht. Die Auswertung erfolgte mit der Software GeneScan Analysis (Version 3.5.1).

\subsection{Statistik}

Zur Auswertung der erhobenen Daten wurden deskriptive und analytische statistische Verfahren verwandt.

\section{Deskriptive Statistik}

Die deskriptive Statistik ermöglicht die ordnende und zusammenfassende Darstellung von Messdaten. Anhand grafischer Umsetzung und tabellarischer Auflistung sowie der Berechnung ihrer zentralen Tendenz (Lagemaß) und Streuung lassen sich Daten bezüglich ihrer Verteilung charakterisieren. Verteilungen, welche durch einen mathematischen Parameter dargestellt werden können, werden als parametrisch bezeichnet; zumeist sind das normal verteilte Datensätze. Nicht-parametrische Verteilungen hingegen erfüllen diese Vorgabe nicht. Im Rahmen dieser Arbeit wurden Histogramme zur Verdeutlichung von bibzw. multimodalen Häufigkeitsverteilungen genutzt. Zur Zusammenfassung des Lage- bzw. Streuungsmaßes eines Messparameters dienten Boxplots als nicht-parametrische Darstellungsform. Mit Kaplan-Meier-Plots wurden Überlebensraten in Abhängigkeit von genetischen und nicht-genetischen Faktoren veranschaulicht.

\section{Analytische Statistik}

Die Testverfahren der analytischen Statistik vergleichen zwei oder mehrere Datensätze bezüglich signifikanter Unterschiede. Die Auswahl des adäquaten Tests richtet sich nach der Art der Daten. In meiner Arbeit standen Überlebenszeitanalysen in Abhängigkeit zumeist kategorieller Faktoren (Genotypen, Resektionsstatus, Grading, Alter, Geschlecht) im Vordergrund. Hierfür wurde - bei Betrachtung eines singulären Faktors - der Log-rank-Test verwendet. Dabei wurde bei den Genotypen auch ein Alleldosis-abhängiger Effekt berücksichtigt. Mit dem Cox-proportional-hazard-Modell wurde für jede Genvariante das 
über die Zeit konstante Sterberisiko der heterozygoten und - wenn möglich - der homozygoten Variantenallel-Konfiguration bestimmt. Mit einem Cox-Regressionsmodell wurde der Einfluss mehrerer Faktoren als unanhängige Variablen analysiert.

Für die kontinuierlichen Variablen der Hämatotoxizität orientierte sich die Auswahl des statistischen Testverfahrens daran, ob es sich um verbundene (abhängige) oder unverbundene (unabhängige) Stichproben handelt und welcher Verteilungstyp (normal oder nicht-normal) vorlag. Ein möglicher Zusammenhang zwischen Ausprägung des Nadirs und der Zeitdauer bis $\mathrm{zu}$ dessen Eintreten wurde mit dem nicht-parametrischen SpearmanRangkorrelationskoeffizient (unverbundene Variablen) durchgeführt; dieser Test fand Anwendung auch bei der Prüfung eines möglichen Einflusses der Hämatotoxizitätsparameter auf das Gesamtïberleben. Für Entwicklung der Leukozyten und Thrombozyten innerhalb der ersten sieben Tage der Therapie wurde jeweils der paarweise Wilcoxon-Rangsummentest für verbundene Stichproben angewandt. Eine Abhängigkeit der Hämatotoxizität von den untersuchten Genvarianten wurde mit dem Mann-Whitney-U-Test bei zwei bzw. dem Jonkheere-Terpstra-Test bei drei Genotyp-Konfigurationen geprüft. Letzterer berücksichtigt auch die so genannte Alleldosis, d.h. ob das Variantenallel einmal (heterozygot) oder zweimal vorlag. Hier liegt die Annahme zu Grunde, dass ein relevanter Effekt einer Genvariante bei homozygotem Variantenallel-Status mindestens so stark sein sollte wie bei heterozygoter Ausprägung.

Als nominal statistisch signifikant galten Analyseergebnisse mit einem $P$-Wert $<0,05$. Multiples Testen wurde berrücksichtigt. Sämtliche Analysen und Berechnungen erfolgten mit der SPSS-Software (Version 12.0), ausgenommen das Cox-proportional-hazard-Modell und die Berechung der False Discovery Rate, welche mit dem Statistik-Paket R durchgeführt wurden (R Version 2.13.1).

\subsection{Bioinformatik}

Das humane Keimbahn-Genom birgt nach Schätzungen ca. zehn Millionen genetische Varianten. Die meisten dieser Varianten (>90\%) sind Einzelbasen-Austausche (engl. single nucleotid polymorphisms, SNPs). Diese sind durch eine Mindestfrequenz des selteneren Allels von $>1 \%$ in der Normalbevölkerung definiert. Im Rahmen dieser Arbeit sollte mit Hilfe des Kandidatengen-Ansatzes die Bedeutung von SNPs für das Therapieansprechen von Gemcitabin bei Pankreaskarzinom untersucht werden. 


\section{Auswahl der Kandidatengene}

Als Kandidaten wurden Gene ausgewählt, für die auf Grund von Literaturdaten und funktionellen Überlegungen ein Zusammenhang mit der Wirksamkeit von Gemcitabin belegt oder sehr wahrscheinlich ist. Dies schloss Gene für Metabolismus und Transport von Gemcitabin sowie den Hedgehog-Signalweg ein; letzterer hat - wie in der Einleitung (Kapitel 1.7) dargelegt - Einfluss darauf, ob Gemcitabin durch das umgebende Stroma an die Tumorzellen gelangt. Insgesamt wurden elf Gene ausgewählt, in denen zusammen 109 Polymorphismen bestimmt wurden. Die elf Kandidatengene mit der Anzahl der jeweils untersuchten Varianten sind in Tab. 6 aufgelistet.

\begin{tabular}{lc}
\hline Gen & Anzahl der Genvarianten (SNPs) \\
\hline Gemcitabin-Metabolismus & 18 \\
CDA & 7 \\
CMPK1 & 5 \\
DCK & 14 \\
DCTD & 8 \\
NT5C3 & 11 \\
RRM1 & 5 \\
RRM2 & \\
Gemcitabin-Transport & 18 \\
ENT1 & \\
Hedegehog-Signalweg & 10 \\
PTCH1 & 7 \\
SHH & 6 \\
SMO & 109 \\
\hline Gesamt & \\
\hline
\end{tabular}

Tab. 6 Kandidatengene mit Anzahl untersuchter Genvarianten (SNPs).

\section{Analysierte Genvarianten}

Für die Auswahl der 109 Polymorphismen zur umfassenden Darstellung der Variabilität in den elf genannten Genen kamen folgende Kriterien zur Anwendung:

1. Alle Varianten mit einer in der Literatur beschriebenen funktionellen Bedeutung mit einer Frequenz des selteneren Allels $(\mathrm{MAF}) \geq 2 \%, 2$. alle kodierenden Varianten mit einer MAF $\geq$ $5 \%$, 3. alle übrigen Genvarianten aus der HapMap-Datenbank für die kaukasische Bevölkerung mit einer MAF $\geq 5 \%$, welche zur vollständigen Repräsentation der genetischen Variabilität des betreffenden Gens $\pm 5 \mathrm{~kb}$ auf Grund der Analyse des Linkage disequilibrium (LD) nötig waren. Das sogenannte LD beschreibt das Kopplungsungleichgewicht, in dem zwei Genpolymorphismen zueinander stehen. Je höher dieses ist, desto weniger unabhängig sind zwei genetische Varianten. Für meine Studie wurde eine Stringenz von $r^{2}=0,8$ festgelegt. 
Hatten zwei Varianten zueinander ein LD von $\mathrm{r}^{2}>0,8$, war nur eine der beiden $\mathrm{zu}$ genotypisieren, da diese den Informationsgehalt der anderen hinreichend abdeckte. Diejenigen Genvarianten, die unter diesem Kriterium zur Repräsentation der Variabilität eines betreffenden Gens erforderlich waren, werden als tagging SNPs bezeichnet. Die visuelle Darstellung des LD und die Berechnung der tagging SNPs erfolgten mit der Software HaploView.

Die zur Genotypisierung erforderlichen Primer für PCR- und SNaPshot ${ }^{\mathrm{TM}}$-Reaktionen wurden unter Verwendung der Software OLIGO ausgewählt. 


\section{Ergebnisse}

Ziel dieser Arbeit war, zu untersuchen, ob vererbte Polymorphismen in den Genen des Gemcitabin-Transports, des Gemcitabin-Metabolismus und des Hedgehog-Signalwegs den Therapieerfolg von Gemcitabin bei Patienten mit Pankreaskarzinom beeinflussen. Dazu waren die Überlebenszeiten, gerechnet vom Beginn der Therapie mit Gemcitabin, zu ermitteln. Zunächst wurden allgemeine Parameter wie Alter und Geschlecht der Patienten, Resektionsstatus und histopathologisches Grading im Hinblick auf eine Beeinflussung des Überlebens untersucht; anschließend dann in einer explorativen Weise insgesamt 109 Genpolymorphismen in den oben genannten Gruppen an Kandidatengenen. Diese Genvarianten wurden auch in Bezug zu den erhobenen Hämatotoxizitätsparametern Leukound Thrombozytopenie während der Chemotherapie gesetzt. In dieser Reihenfolge sind die nachfolgenden Abschnitte gegliedert.

\subsection{Patientenkohorte mit Verteilung der Überlebenszeiten}

Zunächst war es meine Aufgabe, aus dem ursprünglichen Pool von 552 mit Verdacht auf einen malignen Pankreas-Prozess behandelten Patienten eine nach Tumorentität und Behandlung möglichst homogene Kohorte zu ermitteln. Dazu habe ich eine sorgfältige Überprüfung des histopathologischen Befundes und der durchgeführten Chemotherapie vorgenommen. Die methodischen Details sind in Kapitel 3.1 (S. 23) beschrieben. Infrage kamen nur Patienten mit einem histologisch gesicherten duktalen Adenokarzinom des Pankreas. Aufgrund der per se besseren Prognose von Patienten mit histopathologischem Tumorgrading G1 wurden diese Fälle von den Betrachtungen ausgeschlossen. Darüber hinaus nicht weiter berücksichtigt werden konnten Patienten, die postoperativ keine Gemcitabin-Therapie erhalten hatten sowie Patienten, für die eine Erhebung von Daten zur Nachsorge unmöglich war. Schließlich resultierte eine Gruppe von 142 Patienten, die bezüglich der Hauptzielgröße Überlebenszeit ausgewertet wurde (siehe Flussdiagramm in Abb. 5). Die Nebenzielgröße Hämatotoxizität ist im Abschnitt 4.5 beschrieben. 


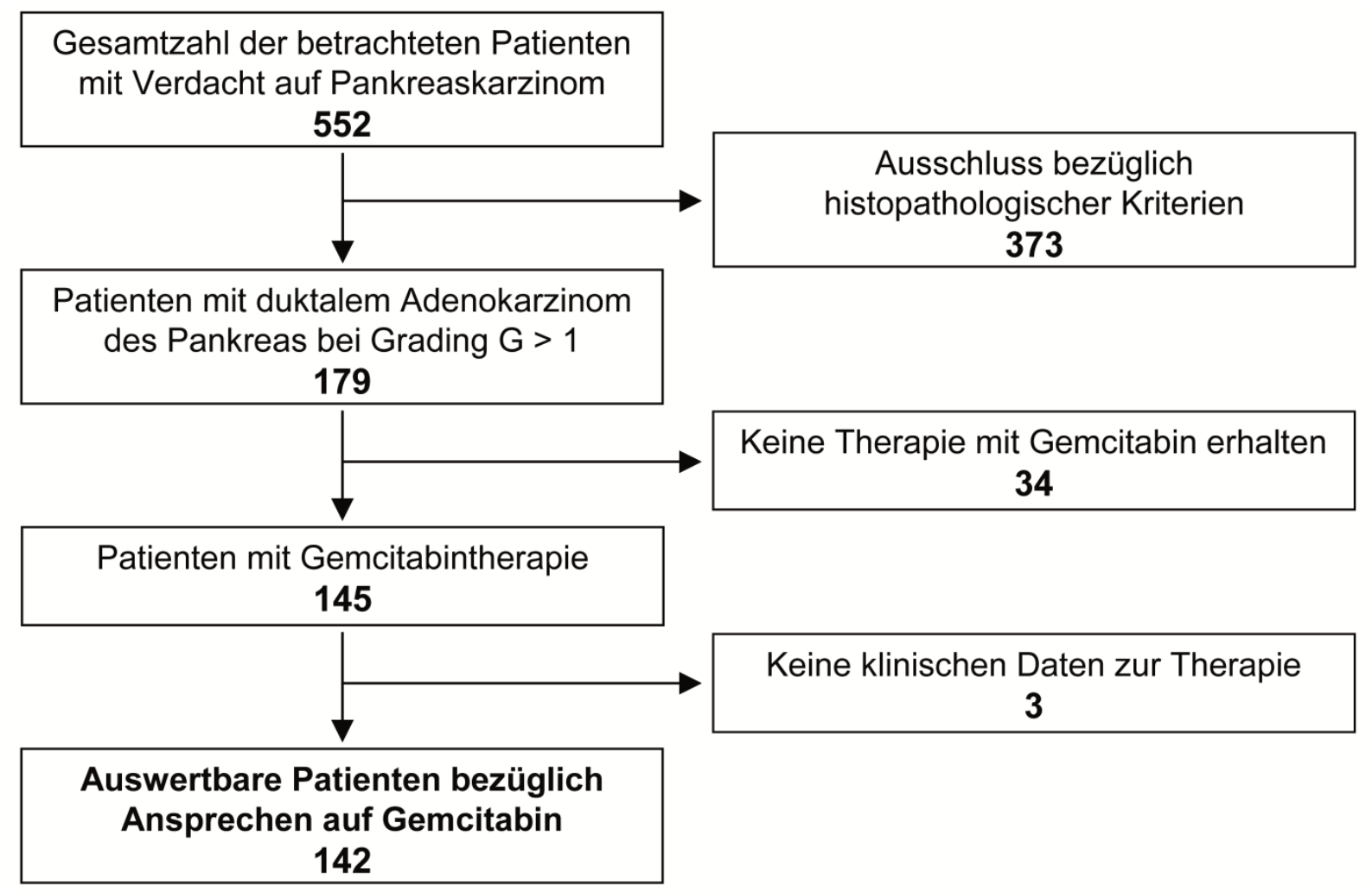

Abb. 5 Flussdiagramm zur Auswahl der Patientenkohorte. Hinsichtlich histologischer Kriterien wurden ausgeschlossen: Benigne Prozesse des Pankreas (z.B. chronische Pankreatitis, zystische Prozesse), abweichende Tumorentität (z.B. Adenome des Pankreas, Neuroendokrine Tumore), abweichende Tumorlokalisation (z.B. Papilla Vateri des Duodenum) und Pankreaskarzinome mit einem niedrigen, d.h. weitgehend differenzierten Grading von G1.

Die basalen Charakteristika zu den 142 Patienten sind in Tab. 7 zusammengestellt. Innerhalb der Patientenkohorte waren Frauen und Männer zu gleichen Teilen repräsentiert. Das Alter bei Beginn der Gemcitabin-Therapie betrug im Median 68 Jahre. Bei 99 Patienten war im Vorfeld der Chemotherapie eine Resektion des Tumors möglich. Von diesen entfielen jeweils etwa die Hälfte auf R0- und R1-Resektionsstatus.

Im Rahmen des Tumorstaging zum Zeitpunkt der Diagnosestellung war anhand der TNMKlassifikation jeder Tumor hinsichtlich Ausbreitung (T-Stadium), Lymphknotenbefall (NStadium) und Metastasierung (M-Stadium) eingestuft worden. Die Klassifikation erfolgte nach der für Pankreaskarzinome üblichen Einteilung. Zum Zeitpunkt der Diagnosestellung war bei der Mehrheit der Patienten der Tumor bereits über die Organgrenzen hinaus gewachsen $(\mathrm{T} 3+\mathrm{T} 4, \mathrm{n}=129$ von 138 klassifizierten) und hatte lymphogen gestreut $(\mathrm{N}>0$, $\mathrm{n}=107$ von 128). Eine Fernmetastasierung war im Rahmen des Primärstagings bereits in 46 Fällen (von 73) sicher nachweisbar. Der Primärtumor war wie folgt lokalisiert: nur Pankreaskopf $(\mathrm{n}=108)$, nur -korpus $(\mathrm{n}=14)$, nur -schwanz $(\mathrm{n}=11)$. In neun Fällen fand sich eine über zwei der drei anatomischen Regionen erstreckende Lokalisation. Bezüglich des 
histopathologischen Gradings musste als Einschlusskriterium mindestens ein G2-Anteil vorhanden sein. Die größte Gruppe bildeten hier die als ausschließlich G2 klassifizierten Tumore. Die meisten Patienten $(n=90)$ erhielten Gemcitabin als Monotherapie. Die mediane Gesamtdauer der Gemcitabin-Therapie betrug 5,5 Monate. Die mediane Gesamtüberlebenszeit nach Therapiebeginn belief sich auf elf Monate. Der Beobachtungszeitraum der einzelnen Patienten lag im Median bei 41 und betrug im Maximum 127 Monate.

\section{Geschlecht [Zahl der Patienten]}

$\begin{array}{lc}\text { Weiblich } & 68 \\ \text { Männlich } & 74 \\ \text { Alter bei Beginn der Gemcitabin-Therapie [Jahre] } & 68 \\ \text { Median } & 61-73 \\ \text { Interquartilabstand } & 44-88 \\ \text { Bereich } & 4\end{array}$

\section{Resektionsstatus}

$\begin{array}{lr}\text { Reseziert } & 99\end{array}$

R0 45

R1 52

R2 2

nicht reseziert $(\mathrm{RN}) \quad 43$

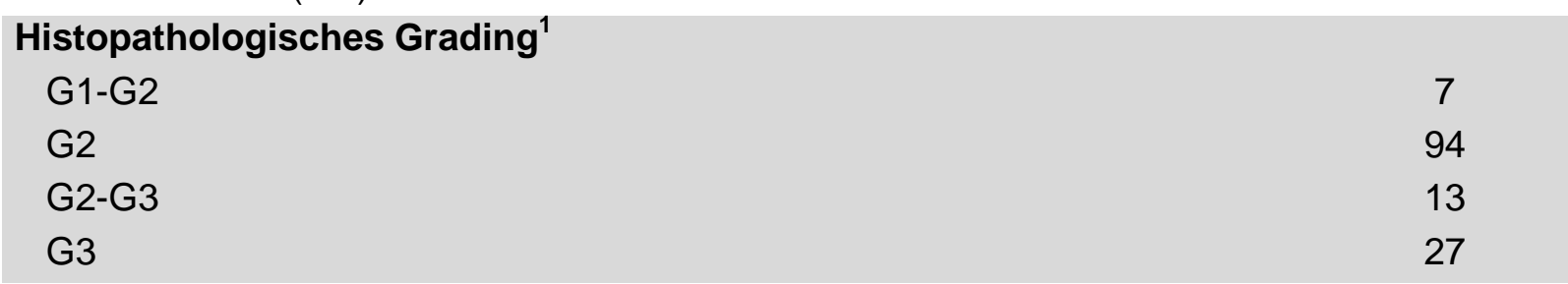

Art der Gemcitabin-Therapie [Zahl der Patienten]
Gemcitabin-Monotherapie

Gemcitabin-Kombinationstherapie $^{2} \quad 52$

\begin{tabular}{|c|c|}
\hline \multicolumn{2}{|c|}{ Gesamtdauer der Gemcitabin-Therapie [Monate] ${ }^{3}$} \\
\hline Median & 5,5 \\
\hline Interquartilabstand & $3,3-8,8$ \\
\hline Bereich & $1-49$ \\
\hline
\end{tabular}

$\begin{array}{lc}\text { Überlebenszeit von Beginn der Gemcitabin-Therapie an [Monate] } \\ \text { Median } & 10,9 \\ \text { Interquartilabstand } & 6,0-17,0 \\ \text { Bereich } & 1-114,0\end{array}$

Nachbeobachtungszeit von Beginn der Gemcitabin-Therapie an [Monate]

Median

$\begin{array}{lr}\text { Interquartilabstand } & 23-64\end{array}$

$\begin{array}{lr}\text { Bereich } & 2-127\end{array}$

Tab. 7 Charakteristika auswertbarer Patienten bezüglich Gemcitabin-Therapie. ${ }^{1}$ Einer Probe konnte kein Grading zugeordnet werden. ${ }^{2}$ Als Kombinationspräparat erhielten 23 Patienten Sorafenib, 13 Erlotinib, elf Patienten 5-Fluorouracil bzw. Capecitabin und fünf Platinverbindungen (Oxali-/Cisplatin). ${ }^{3}$ Die Gesamtdauer der Gemcitabin-Therapie bezieht sich auf den Zeitraum von der ersten bis zur letztmaligen Gabe von Gemcitabin, gleich ob als Mono- oder Kombinationstherapie verabreicht. 


\subsection{Nicht-genetische Einflussfaktoren}

Im Folgenden sollte geprüft werden, inwiefern nicht genetische Faktoren wie Geschlecht, Alter, Resektionsstatus, histopathologisches Tumorgrading, Art der GemcitabinChemotherapie und Hämatotoxizitätsparameter Auswirkungen auf das Gesamtüberleben der 142 Pankreaskarzinompatienten hatten.

\subsubsection{Basisdaten der Patienten}

Als Basisdaten der Patienten wurden Geschlecht und Alter bei Therapiebeginn der Patienten hinsichtlich eines möglichen Einflusses auf das Gesamtüberleben untersucht.

Eine Abhängigkeit des Gesamtüberlebens vom Geschlecht der Patienten ließ sich nicht nachweisen. Unter Log-rank-Testung zeigte sich mit $P=0,4$ keine statistische Signifikanz. Eine nicht-parametrische Korrelationsanalyse ergab auch keine Abhängigkeit vom Alter der Patienten (rho $=-0,06$, bei $P=0,8)$.

\subsubsection{Resektionsstatus}

Eine nach Diagnosestellung zeitnah durchgeführte Resektion des Primarius bringt, wie in der Literatur beschrieben (Wagner et al. 2004), im Gegensatz zu abwartendem Verhalten und/oder alleiniger Chemotherapie einen nachweisbaren Überlebensvorteil mit sich.

Innerhalb meiner untersuchten Kohorte mit 142 Patienten konnte diese Annahme bestätigt werden (siehe Abb. 6). Die histopathologischen Diagnosen zum Resektionsstatus wurden von der kooperierenden Abteilung Pathologie der Universitätsmedizin Göttingen zur Verfügung gestellt. Ein Überlebensvorteil war hier insbesondere für resezierte Patienten im Vergleich zu den nicht-resezierten Patienten nachweisbar. Auch innerhalb der Gruppe der resezierten Patienten zeigten sich, mit der Güte der Resektion korrelierend, Unterschiede im Gesamtüberleben. Mit der Güte der Resektion besserte sich auch die Prognose.

Die statistische Testung dieser Befunde wurde mit dem Log-rank-Test durchgeführt. Der Einfluss des Resektionsstatus auf das Gesamtüberleben war unter Berücksichtigung aller in Abb. 6 genannten Ausprägungen mit $P=0,0002$ hoch signifikant. Wurden zwei Gruppen (reseziert versus nicht-reseziert) gebildet, ergab sich nach Log-rank-Test ein $P$-Wert von 0,001. Auch zwischen R0- und R1-resezierten Patienten war eine Tendenz zu Gunsten von R0 erkennbar, jedoch wurde keine statistische Signifikanz erreicht. Aufgrund der deutlichen Auswirkungen des Resektionsstatus auf das Gesamtüberleben wurden für die Testung des 
Gesamtüberlebens in Abhängigkeit von Genvarianten (siehe Kapitel 4.4) nur R0- und R1resezierte Patienten berücksichtigt $(n=97)$.

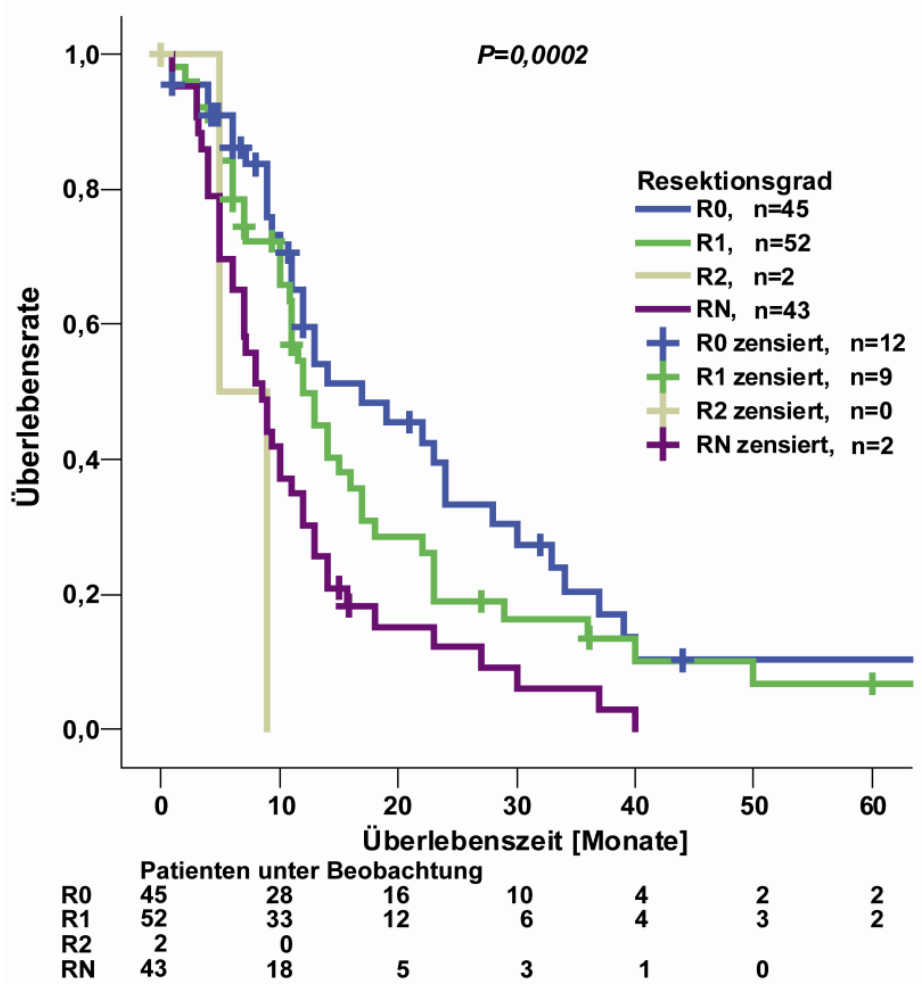

Abb. 6 Kaplan-Meier-Kurve zur Überlebenszeit in Abhängigkeit vom Resektionsstatus. Es sind für vier Resektionsgrade die Überlebenskurven von Beginn der Gemcitabin-Therapie dargestellt. Unterhalb des Graphen sind für Zeitpunkte im 10-Monats-Intervall die Anzahl der verbliebenen Patienten unter Beobachtung aufgelistet. Die Überprüfung der statistischen Signifikanz erfolgte mit dem Log-rankTest, wobei ein linearer Trend zwischen den Resektionsgraden Ro (Absetzungsränder mikroskopisch tumorfrei), R1 (Absetzungsränder mikroskopisch nicht, aber makroskopisch tumorfrei), R2 (Absetzungsränder makroskopisch nicht tumorfrei) sowie $\mathrm{RN}$ (=nicht reseziert) angenommen wurde. Der Befund zeigte sich mit $P=0,0002$ deutlich statistisch signifikant.

\subsubsection{Histopathologisches Grading}

Mittels der G-Klassifizierung wird histopathologisch die Differenzierung der Tumorzellen beschrieben. Gut differenzierte Tumore haben in der Regel eine bessere Prognose als weniger differenzierte. Unterschieden werden G1-Tumore (gut differenziert), G2-Tumore (mäßig differenziert), G3-Tumore (schlecht differenziert) und G4-Tumore (undifferenziert/anaplastisch). In der vorliegenden Arbeit wurden die wenigen Patienten $(n=5)$ mit G1-Tumoren aufgrund der per se weitaus besseren Prognose von vornherein aus den Betrachtungen ausgeschlossen und waren nicht in dem 142 Personen umfassenden Kollektiv enthalten. Eingeschlossen wurden alle Tumore, in denen sich mindestens Anteile eines G2-Status fanden, somit die Grade G1-2, G2, G2-3 und G3. G4-Tumore waren innerhalb des Studienkollektivs nicht zu verzeichnen. Die Diagnosen wurden in der kooperierenden Abteilung der Pathologie des Universitätsklinikum Göttingen gestellt und standen dieser Arbeit zur Verfügung.

Im Rahmen dieser Arbeit sollte überprüft werden, ob zwischen Gesamtüberleben und dem beschriebenen, histopathologischen Grading ein Zusammenhang besteht. Dies ist in Abb. 7 in einer Kaplan-Meier-Grafik dargestellt. Das Grading wirkte sich gemäß der Reihenfolge seiner 
Einteilung auf das Überleben der Patienten aus: Patienten mit gut bis mäßig differenzierten Tumoren (G1-2) hatten einen deutlichen Überlebensvorteil im Vergleich zu den übrigen; eine statistische Signifikanz wurde hier aber nicht erreicht $(P=0,2$ nach Log-rank-Test). G2differenzierte Tumore wiesen eine etwas bessere Prognose als solche mit G3 auf $(P=0,02)$. Das Grading (linearer Trend zwischen den vier betrachteten Stufen) hatte einen statistisch signifikanten Einfluss auf die Überlebensrate $(P=0,002$ nach Log-rank-Test). In der Untergruppe der R0-R1-Resezierten wies das Grading weiterhin eine statistische Signifikanz in Bezug zum Gesamtüberleben auf $(P=0,001)$.

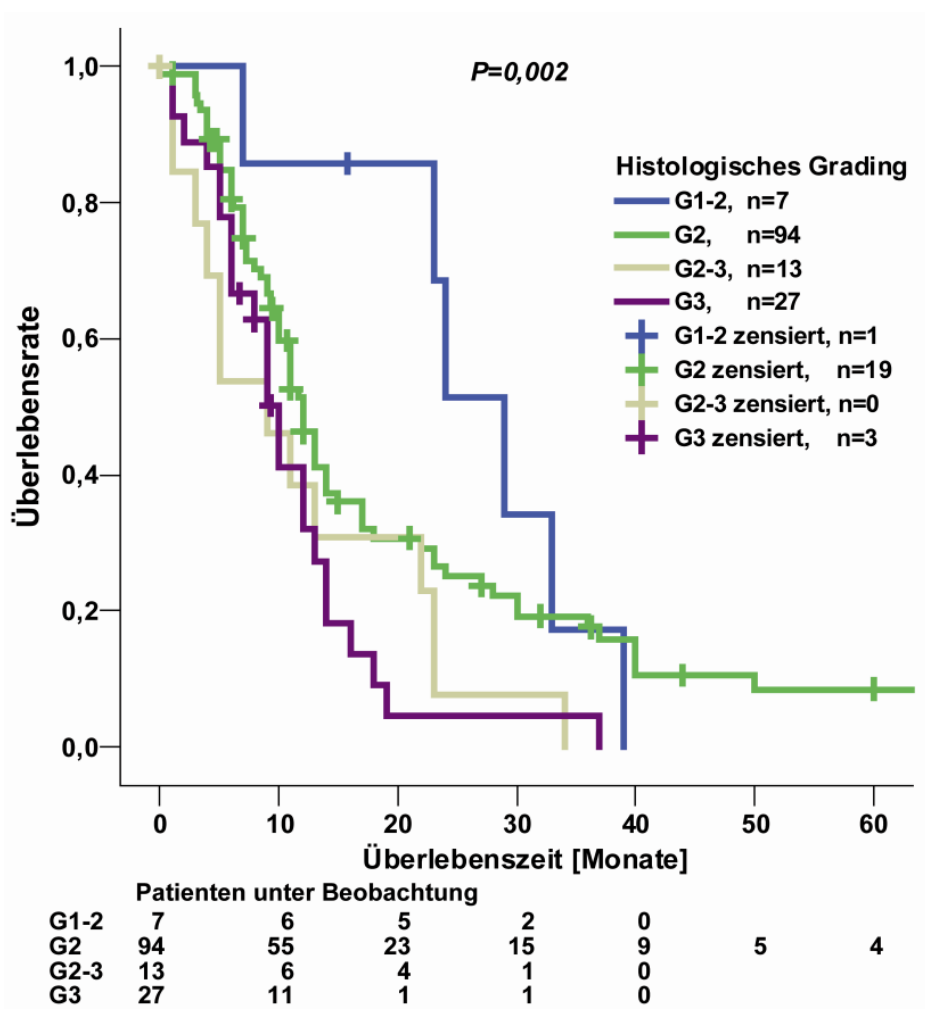

Abb. 7 Überlebenskurven in Abhängigkeit vom histopathologischen Grading. Es sind für die Differenzierungsgrade G1-2, G2, G2-3 und $\mathrm{G3}$ die Überlebensraten nach Beginn der Gemcitabin-Therapie dargestellt. Die jeweiligen Anzahlen der Patienten unter Beobachtung sind in 10-MonatsAbständen unterhalb des Graphen aufgeführt. Die Überprüfung der statistischen Signifikanz erfolgte mit dem Log-rank-Test. Dabei wurde ein linearer Trend innerhalb der unabhängigen Variablen „Grading“ angenommen. Der Befund zeigte sich mit $P=0,002$ statistisch signifikant. In einem Fall konnte kein Grading-Status zugeordnet werden.

\subsubsection{Gemcitabin als Mono- oder Kombinationstherapie}

Die Mehrzahl der in dieser Arbeit untersuchten 142 Patienten war mit Gemcitabin als Monotherapie behandelt worden $(n=90)$. Eine Kombinationstherapie erhielten 52 Patienten. Die häufigsten Kombinationspartner waren Tyrosinkinaseinhibitoren wie Erlotinib oder Sorafenib. Als weitere Kombinationspräparate wurden 5-Fluorouracil bzw. Capecitabin und Platinverbindungen (Oxaliplatin, Cisplatin) eingesetzt. In Abb. 8 ist das Gesamtüberleben der Studienpatienten in Abhängigkeit des Therapieregimes (Mono- versus Kombinationstherapie) in einer Kaplan-Meier-Grafik dargestellt, wobei kein statistisch signifikanter Unterschied nachgewiesen werden konnte $(P=0,2$ nach Log-rank-Test). 
Es wurde weiterhin geprüft, ob eine Korrelation zwischen der Dauer der Gemcitabin-Therapie und dem Überleben vorlag. Hier ergab sich unter non-parametrischer Testung mit dem Spearman-Rangkorrelationskoeffizienten ein statistisch signifikanter Einfluss auf das Überleben mit rho =0,64 $(P=0,01)$. Dies ist jedoch nicht verwunderlich, da etliche Patienten noch vor Beendigung der vorgesehenen Chemotherapiezyklen verstarben. Neben dem Versterben unter Therapie war für die Beendigung der Therapie zumeist eine Verschlechterung des Allgemeinzustandes mit Tumorprogress oder Metastasierung verantwortlich. Nicht selten wurde auch dem Patientenwunsch auf Therapieabbruch entsprochen.

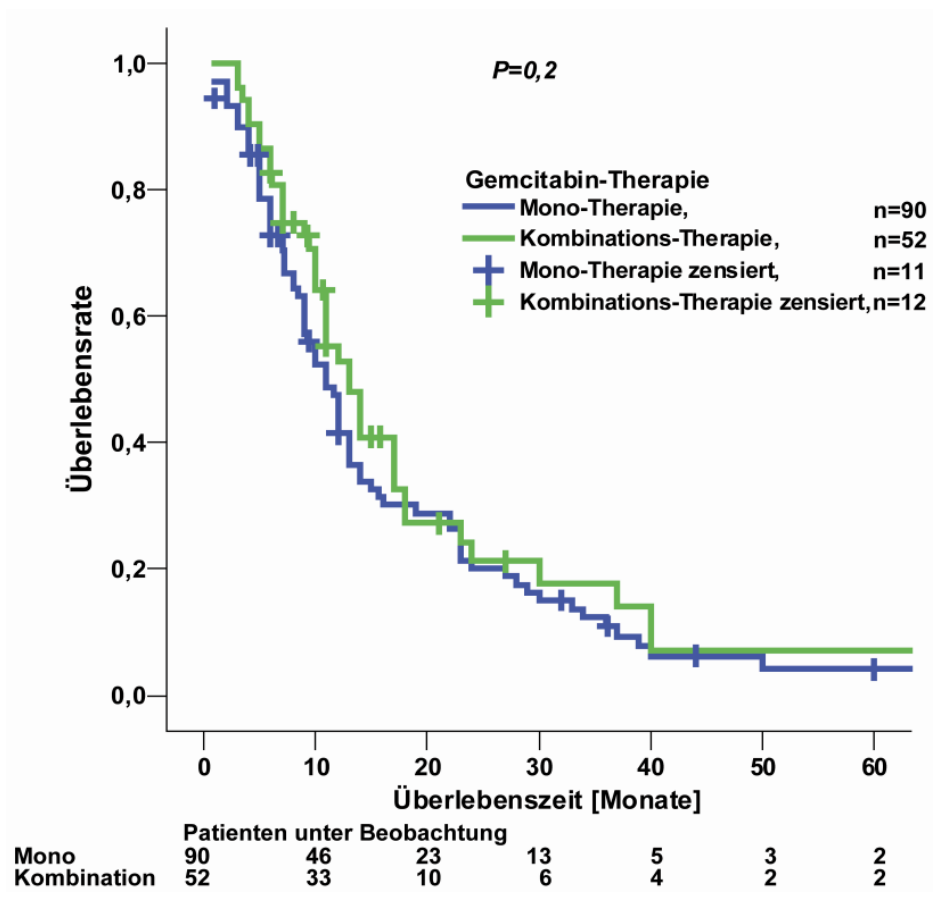

Abb. 8 Überlebenskurven für Gemcitabin in Mono- und Kombinationstherapie. Darstellungsweise analog zu Abb. 6 und Abb. 7.

\subsubsection{Tumorlokalisation und Staging}

Für den Einfluss der Tumorlokalisation (Pankreas-kopf, -korpus und -schwanz) ließ sich kein Einfluss auf die Überlebenszeit $(P=0,4)$ feststellen. Ein höheres T-Stadium ging erwartungsgemäß mit einer schlechteren Prognose einher. Dieser Effekt war jedoch nur mäßig ausgeprägt $(P=0,05)$. Nodal-positive Patienten hatten tendenziell eine kürzere Überlebenszeit $(P=0,08)$, wobei der Unterschied sich erst nach etwa zwei Jahren bemerkbar machte. Dahingegen zeigte sich im Kaplan-Meier-Plot (nicht gezeigt) von Beginn an ein Vorteil für Patienten ohne Fernmetastasen $(P=0,03)$. 


\subsubsection{Hämatotoxizitätsparameter}

Bei einer Zytostatikatherapie profitieren häufig diejenigen Patienten, die besonders schwere Nebenwirkungen erfahren. Es sollte überprüft werden, ob ein Zusammenhang zwischen Veränderungen im Blutbild während der Gemcitabin-Therapie und der Überlebenszeit der Patienten besteht. Von den 142 Patienten mit Daten zur Überlebenszeit konnten für 116 die Blutbildverläufe für Leukozyten und Thrombozyten innerhalb der ersten 42 Tage erfasst werden. Es wurde jeweils der Wert des Nadirs sowie die Zeitdauer bis zu dessen Eintreten bestimmt. Der Nadirwert wurde sowohl als Intervall-skalierte Variable, wie auch als diskrete entsprechend den CTC-Toxizitätsgraden bewertet. Diese Common Terminology Criteria for Adverse Events (CTC) beschreiben den Grad der (Hämato-) Toxizität einer Therapie auf einer Skala von 1 (leicht) bis 4 (schwer). Weiterhin wurde die Gemcitabin-Intensität vor Nadir und die prozentuale Veränderung der Absolutwerte vom prätherapeutischen Ausgangswert bis zum Therapietag 7 betrachtet. Der Grund für die Erhebung des letztgenannten Parameters besteht darin, dass nach sieben Tagen die beste Vergleichbarkeit der in-vivo-Reaktion des Blutbildes besteht. Praktisch alle Patienten waren während der ersten Woche derselben Gemcitabin-Dosis unabhängig der Chemotherapie-Taktung exponiert. Die Verwendung des Nadirwertes würde außer Acht lassen, dass diesem inter-individuell unterschiedliche Gemcitabin-Dosen vorangegangen sind. Tab. 8 fasst die Beziehung zwischen diesen fünf Parametern und der Überlebenszeit zusammen.

\begin{tabular}{|c|c|c|c|}
\hline $\begin{array}{l}\text { Hämatotoxizitäts- } \\
\text { parameter }\end{array}$ & $\begin{array}{l}\text { Statistischer } \\
\text { Test }\end{array}$ & Leukozyten & Thrombozyten \\
\hline Absoluter Nadir & $\begin{array}{l}\text { Spearman- } \\
\text { Rangkorrelation }\end{array}$ & rho $=-0,3 ; P=0,8$ & rho $=0,02 ; P=0,9$ \\
\hline Toxizitätsgrad (CTC) & Log-rank & $P=0,9$ & $P=0,7$ \\
\hline Zeit bis Nadir & $\begin{array}{l}\text { Spearman- } \\
\text { Rangkorrelation }\end{array}$ & rho $=0,07 ; P=0,5$ & rho $=0,19 ; P=0,05$ \\
\hline Intensität bei Nadir & $\begin{array}{l}\text { Spearman- } \\
\text { Rangkorrelation }\end{array}$ & rho $=0,07 ; P=0,4$ & rho $=0,22 ; P=0,02$ \\
\hline $\begin{array}{l}\text { \% Blutzellen Therapietag } 7 \\
\text { bezogen auf Tag } 0\end{array}$ & $\begin{array}{l}\text { Spearman- } \\
\text { Rangkorrelation }\end{array}$ & rho $=0,04 ; P=0,7$ & rho $=0,03 ; P=0,75$ \\
\hline $\begin{array}{l}\text { Tab. } 8 \text { Korrelation von Hämat } \\
\text { Patienten. Die mit dem Überlebe } \\
\text { Spalte aufgelistet. Die Charakte } \\
\text { kalierte unabhängige Variablen } \\
\text { rank-Test verwendet. Beziehunge } \\
\text { gedruckt. }\end{array}$ & otoxizitätsparameter & prechen denen aus & $\begin{array}{l}\text { Betrachtet wurden } 110 \\
\text { ameter sind in der linken } \\
\text { apitel 4.5. Für Intervall } \\
\text { ient, für diskrete der Log }\end{array}$ \\
\hline
\end{tabular}

Zwischen den aufgeführten Hämatotoxizitätsparametern und dem Gesamtüberleben ließen sich für Leukozyten keinerlei Beziehungen darstellen. Beispielhaft ist in Abb. 9 die 
Überlebenszeit in Abhängigkeit des Leukozyten-Nadirs - eingeteilt in Grade nach CTC veranschaulicht. Hinsichtlich Thrombozyten war lediglich für die Zeit bis Nadir und Gemcitabin-Intensität bei Nadir ein leichter Bezug zum Gesamtüberleben erkennbar: Je länger die Zeit bzw. je größer die Gemcitabin-Intensität bis zum Thrombozyten-Nadir, desto länger war tendenziell das Überleben. Diese Befunde entsprechen nicht der eingangs formulierten Hypothese.

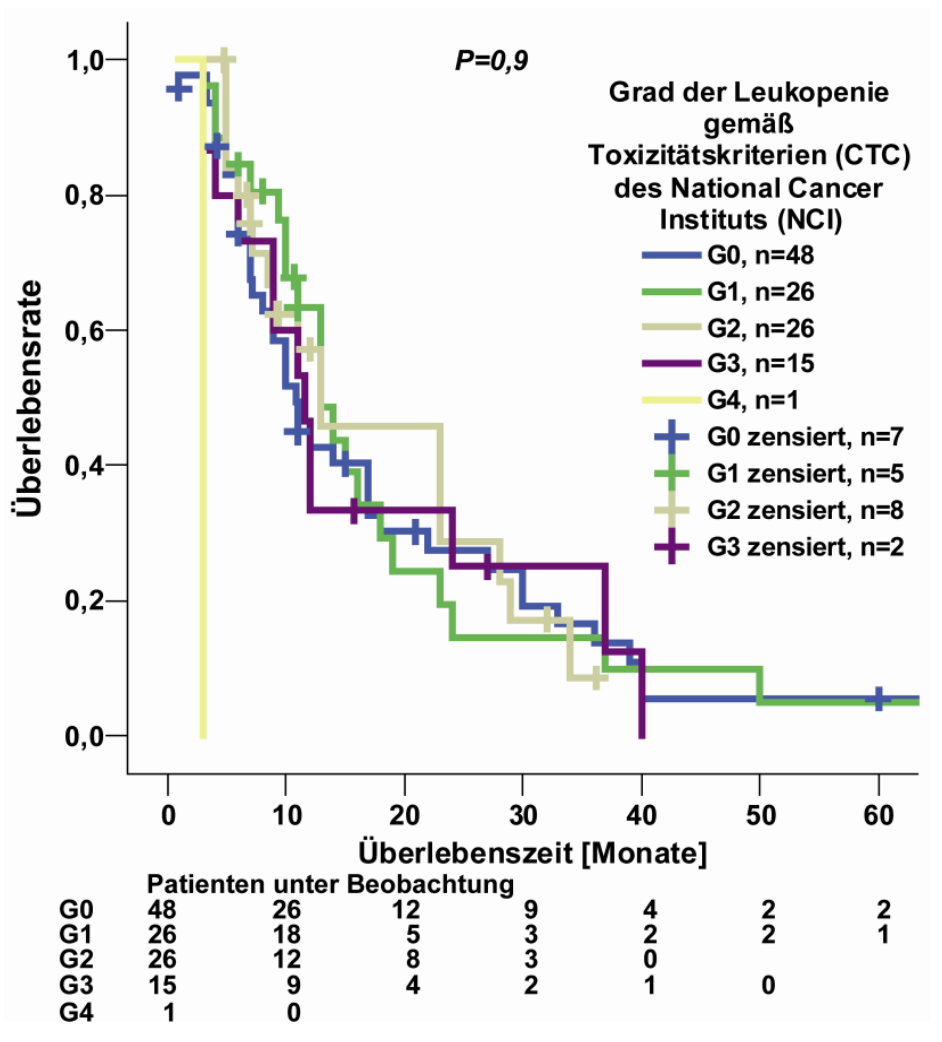

Abb. 9 Korrelation zwischen Überlebenszeit und Grad der Leukopenie unter Gemcitabin. Die Gradeinteilung der Leukopenie wurde entsprechend dem CTC-Score anhand des beobachteten Nadirwerts (innerhalb der ersten 42 Tage der Chemotherapie) vorgenommen. Die Darstellungsweise entspricht Abb. 6 und Abb. 7

\subsection{Keimbahn-Varianten in Kandidatengenen für Gemcitabin}

Wie oben dargelegt, zeigten sich der Resektionsstatus und das Grading als Prädiktoren für die Überlebenszeit, eine Add-on-Chemotherapie jedoch nicht. Weitere Marker, welche eine prognostische Aussage über den Therapieverlauf erlauben, wären klinisch sehr wertvoll, insbesondere wenn diese schon vor Beginn der Behandlung bestimmbar sind. Als solche kommen Keimbahn-Polymorphismen in Betracht. In dieser Arbeit wurde der KandidatengenAnsatz verfolgt. Die analysierten Genotypen wurden hinsichtlich eines Einflusses auf Wirkung (Gesamtüberleben) und Nebenwirkung (Hämatotoxizität) von Gemcitabin bei Pankreaskarzinom-Patienten untersucht.

Die Auswahl der Kandidatengene mit den untersuchten Polymorphismen ist im Methodenteil unter Kapitel 3.4 beschrieben. Einen Überblick der Ergebnisse der Genotypisierung zeigt Tab. 9. Über alle Polymorphismen gemittelt konnten $98 \%$ aller Genotypen bestimmt werden. Das 
Hardy-Weinberg-Gleichgewicht (engl. Hardy-Weinberg equilibrium, HWE), welches die Häufigkeit von erwarteten mit beobachteten Genotypen auf Basis der Allelfrequenzen vergleicht, war für alle SNPs mit einer Ausnahme erfüllt $\left(P>0,05\right.$ nach $\chi^{2}$-Test). Lediglich der Polymorphismus rs13148414 im DCTD-Gen wies hier einen $P$-Wert von 0,003 auf, was jedoch in Anbetracht der Anzahl der untersuchten Varianten $(n=109)$ akzeptabel erscheint. Als weiteres Kriterium für die Qualität der Genotypisierung wurden die Analysen in 14\% der Proben wiederholt. Dabei fand sich keine Abweichung.

\begin{tabular}{|c|c|c|c|c|c|c|c|c|c|}
\hline Gen $^{1}$ & SNP & $\begin{array}{l}\text { Genetisches } \\
\text { Element }^{2}\end{array}$ & $\begin{array}{c}\text { Chromosomale } \\
\text { Lokalisation }^{3}\end{array}$ & $\begin{array}{c}\text { Basen- } \\
\text { aus- } \\
\text { tausch }^{4}\end{array}$ & $\begin{array}{c}W t / W t^{5} \\
(\%)\end{array}$ & $\begin{array}{c}\text { Wt/Var } \\
(\%)\end{array}$ & $\begin{array}{c}\operatorname{Var} / \operatorname{Var}^{5} \\
(\%)\end{array}$ & $\begin{array}{c}\text { MAF }^{6} \\
(\%)\end{array}$ & $\begin{array}{l}\text { Chi- } \\
\text { Test } \\
\text { (HWE }\end{array}$ \\
\hline \multicolumn{10}{|c|}{ Gemcitabin-Metabolismus } \\
\hline \multirow[t]{18}{*}{$C D A$} & rs540282 & $\begin{array}{l}\text { Promotor } \\
-3572\end{array}$ & 1:20911872 & $A>G$ & 78,0 & 21,3 & 0,7 & 11,3 & 0,6 \\
\hline & rs532545 & $\begin{array}{l}\text { Promotor } \\
-272\end{array}$ & $1: 20915172$ & $\mathrm{C}>\mathrm{T}$ & 46,1 & 43,7 & 10,2 & 32,0 & 1 \\
\hline & rs603412 & $\begin{array}{l}\text { Promotor } \\
-26\end{array}$ & $1: 20915418$ & $\mathrm{G}>\mathrm{C}$ & 31,9 & 54,2 & 13,9 & 41,0 & 0,1 \\
\hline & rs602950 & 5'UTR & $1: 20915531$ & $A>G$ & 45,8 & 44,4 & 9.8 & 32,0 & 0,9 \\
\hline & rs2072671 & Exon 1 & $1: 20915701$ & $\mathrm{~T}>\mathrm{G}$ & 45,6 & 46,3 & 8,1 & 31,3 & 0,4 \\
\hline & rs818202 & Intron 1 & $1: 20916791$ & $\mathrm{C}>\mathrm{T}$ & 34,1 & 51,7 & 14,2 & 40,0 & 0,4 \\
\hline & rs10916824 & Intron 1 & 1:20918912 & $A>G$ & 83,8 & 15,5 & 0,7 & 8,4 & 1 \\
\hline & rs577042 & Intron 1 & $1: 20928154$ & $\mathrm{~T}>\mathrm{C}$ & 68,6 & 27,7 & 3,7 & 17,6 & 0,8 \\
\hline & rs818194 & Intron 2 & 1:20931828 & $\mathrm{T}>\mathrm{A}$ & 58,4 & 33,8 & 7,8 & 24,7 & 0,3 \\
\hline & rs10916827 & Intron 2 & 1:20933341 & $\mathrm{G}>\mathrm{A}$ & 36,2 & 46,6 & 17,2 & 40,5 & 0,9 \\
\hline & rs580032 & Intron 2 & 1:20933893 & $A>C$ & 88,7 & 10.3 & 1,0 & 6,2 & 0,2 \\
\hline & rs11579252 & Intron 2 & $1: 20934213$ & $\mathrm{~T}>\mathrm{C}$ & 77,0 & 21,0 & 2,0 & 12,5 & 0,8 \\
\hline & rs527912 & Intron 2 & 1:20934283 & $G>A$ & 46,0 & 41,6 & 12,4 & 33,2 & 0,6 \\
\hline & rs1689924 & Intron 2 & 1:20934796 & $\mathrm{T}>\mathrm{C}$ & 23,1 & 46,8 & 30,2 & 46,4 & 0,6 \\
\hline & rs12404655 & Intron 3 & 1:20943195 & $\mathrm{T}>\mathrm{C}$ & 56,3 & 36,3 & 7,4 & 25,6 & 0,7 \\
\hline & rs12072405 & Intron 3 & 1:20943281 & $A>G$ & 64,7 & 31,9 & 3,4 & 19,3 & 0,9 \\
\hline & rs1048977 & Exon 4 & 1:20945055 & $\mathrm{G}>\mathrm{A}$ & 45,7 & 41,2 & 13,1 & 33,7 & 0,4 \\
\hline & rs1614627 & $\begin{array}{l}\text { Upstream } \\
+1355\end{array}$ & 1:20946756 & $\mathrm{C}>\mathrm{A}$ & 82,7 & 15,9 & 1,4 & 9,3 & 0,6 \\
\hline \multirow[t]{3}{*}{ CMPK } & rs11211517 & $\begin{array}{l}\text { Promotor } \\
-1338\end{array}$ & 1: 47798131 & $C>T$ & 29,7 & 48,6 & 21,7 & 46,0 & 0,9 \\
\hline & rs7543016 & Exon 1 & 1: 47799639 & $C>G$ & 27,5 & 47,5 & 25,0 & 48,8 & 0,7 \\
\hline & rs12132521 & Intron 1 & 1: 47818324 & $\mathrm{G}>\mathrm{A}$ & 51,4 & 39,9 & 8,7 & 28,7 & 0,9 \\
\hline
\end{tabular}




\begin{tabular}{|c|c|c|c|c|c|c|c|c|c|}
\hline Gen $^{1}$ & SNP & $\begin{array}{c}\text { Genetisches } \\
\text { Element }^{2}\end{array}$ & $\begin{array}{c}\text { Chromosomale } \\
\text { Lokalisation }^{3}\end{array}$ & $\begin{array}{c}\text { Basen- } \\
\text { aus- } \\
\text { tausch }^{4}\end{array}$ & $\begin{array}{c}\mathrm{Wt} / \mathrm{Wt}^{5} \\
(\%)\end{array}$ & $\begin{array}{c}\text { Wt/Var } \\
\text { (\%) }\end{array}$ & $\begin{array}{c}\operatorname{Var} / \operatorname{Var}^{5} \\
(\%)\end{array}$ & $\begin{array}{c}\text { MAF }^{6} \\
(\%)\end{array}$ & $\begin{array}{l}\text { Chi- } \\
\text { Test }^{7} \\
\text { (HWE) }\end{array}$ \\
\hline & rs35687416 & Exon 2 & 1: 47834209 & $\mathrm{G}>\mathrm{T}$ & 85,3 & 14,0 & 0,7 & 7,7 & 1 \\
\hline & rs6660321 & Intron 4 & $1: 47841627$ & $T>G$ & 71,0 & 26,9 & 2,1 & 15,6 & 0,9 \\
\hline & rs7534571 & $\begin{array}{l}\text { Upstream } \\
+2768\end{array}$ & 1: 47847279 & $A>G$ & 79,4 & 20,3 & 0,3 & 10,5 & 0,4 \\
\hline & rs12039726 & $\begin{array}{l}\text { Upstream } \\
+5168\end{array}$ & 1: 47849679 & $\mathrm{G}>\mathrm{A}$ & 71,0 & 26,9 & 2,1 & 15,6 & 0,9 \\
\hline \multirow[t]{5}{*}{$D C K$} & rs6446982 & $\begin{array}{l}\text { Promotor } \\
-4122\end{array}$ & $4: 71855143$ & $\mathrm{G}>\mathrm{A}$ & 94,1 & 5,9 & 0 & 2,9 & 0,9 \\
\hline & rs2306744 & 5'UTR & 4: 71859352 & $C>T$ & 97,3 & 2,7 & 0 & 1,4 & 1 \\
\hline & rs12648166 & Intron 2 & 4: 71873745 & $\mathrm{C}>\mathrm{T}$ & 32,3 & 47,1 & 20,6 & 44,2 & 0,7 \\
\hline & rs10805074 & Intron 2 & 4: 71874331 & $\mathrm{C}>\mathrm{T}$ & 93,5 & 6,5 & 0 & 3,3 & 0,9 \\
\hline & rs11544786 & Exon 3 & $4: 71888176$ & $C>T$ & 89,7 & 10,3 & 0 & 5,2 & 0,7 \\
\hline \multirow[t]{14}{*}{$D C T D$} & rs5016499 & $\begin{array}{l}\text { Promotor } \\
-2268\end{array}$ & 4: 183840898 & $\mathrm{C}>\mathrm{A}$ & 49,7 & 40,5 & 9,8 & 30,1 & 0,8 \\
\hline & rs13111117 & Intron 3 & 4: 183825476 & $\mathrm{G}>\mathrm{A}$ & 86,4 & 13,2 & 0,4 & 7.0 & 1 \\
\hline & rs 10016530 & Intron 3 & 4: 183824984 & $T>G$ & 93,0 & 7,0 & 0 & 3,5 & 0,8 \\
\hline & rs10520543 & Intron 3 & 4: 183822229 & $\mathrm{G}>\mathrm{A}$ & 50,7 & 36,4 & 12,9 & 31,1 & 0,05 \\
\hline & rs13148414 & Intron 3 & 4: 183817674 & $C>G$ & 57,3 & 31,5 & 11,2 & 26,9 & 0,003 \\
\hline & rs6834019 & Intron 3 & 4: 183817659 & $\mathrm{C}>\mathrm{A}$ & 88,4 & 11,2 & 0,4 & 6,0 & 1 \\
\hline & rs4742 & Exon 4 & 4: 183815688 & $\mathrm{~T}>\mathrm{C}$ & 49,0 & 38,5 & 12,5 & 31,8 & 0,2 \\
\hline & rs1960207 & Intron 5 & 4: 183813366 & $\mathrm{G}>\mathrm{A}$ & 80,4 & 18,2 & 1,4 & 10,5 & 0,9 \\
\hline & rs2515683 & Intron 5 & $4: 183813147$ & $\mathrm{G}>\mathrm{A}$ & 36,0 & 45,8 & 18,2 & 41,1 & 0,7 \\
\hline & rs10017797 & Intron 5 & 4: 183812883 & $\mathrm{C}>\mathrm{A}$ & 85,3 & 14,3 & 0,4 & 7,5 & 0,9 \\
\hline & rs7278 & 3'UTR & 4: 183811487 & $\mathrm{C}>\mathrm{T}$ & 61,5 & 35,0 & 3,5 & 21,0 & 0,7 \\
\hline & rs3924787 & $\begin{array}{l}\text { upstream } \\
+4340\end{array}$ & 4: 183806904 & $A>G$ & 31,1 & 48,3 & 20,6 & 44,8 & 0,9 \\
\hline & rs4073676 & $\begin{array}{l}\text { upstream } \\
+4679\end{array}$ & $4: 183806565$ & $A>T$ & 88,8 & 10,9 & 0,4 & 6,8 & 1 \\
\hline & rs4073675 & $\begin{array}{l}\text { upstream } \\
+4832\end{array}$ & $4: 183806412$ & $C>T$ & 73,3 & 24,9 & 1,8 & 14,2 & 0,9 \\
\hline \multirow[t]{6}{*}{ NT5C3 } & rs6946062 & Intron 1 & 7: 33083107 & $\mathrm{~T}>\mathrm{C}$ & 33,7 & 49,1 & 17,2 & 41,8 & 1 \\
\hline & rs7795860 & Intron 1 & 7: 33082489 & $A>G$ & 49,7 & 42,8 & 7,6 & 29,0 & 0,8 \\
\hline & rs7792135 & Intron 1 & $7: 33082375$ & $A>G$ & 64,1 & 33,1 & 2,8 & 19,3 & 0,6 \\
\hline & rs 12668520 & Intron 1 & 7: 33075248 & $\mathrm{~T}>\mathrm{C}$ & 64,1 & 31,4 & 4,5 & 20,2 & 0,9 \\
\hline & rs 17170218 & Intron 1 & 7: 33074785 & $A>T$ & 46,6 & 46,2 & 7,2 & 30,3 & 0,3 \\
\hline & rs3750117 & Exon 5 & $7: 33060946$ & $\mathrm{G}>\mathrm{A}$ & 47,4 & 43,9 & 8,7 & 30,6 & 0,8 \\
\hline
\end{tabular}




\begin{tabular}{|c|c|c|c|c|c|c|c|c|c|}
\hline Gen $^{1}$ & SNP & $\begin{array}{l}\text { Genetisches } \\
\text { Element }^{2}\end{array}$ & $\begin{array}{c}\text { Chromosomale } \\
\text { Lokalisation }^{3}\end{array}$ & $\begin{array}{c}\text { Basen- } \\
\text { aus- } \\
\text { tausch }\end{array}$ & $\begin{array}{l}\text { Wt/Wt } \\
4 \quad(\%)\end{array}$ & $\begin{array}{c}\text { Wt/Var } \\
(\%)\end{array}$ & $\begin{array}{c}\operatorname{Var} / \operatorname{Var}^{5} \\
(\%)\end{array}$ & $\begin{array}{c}\text { MAF }^{6} \\
(\%)\end{array}$ & $\begin{array}{c}\text { Chi- } \\
\text { Test } \\
\text { (HWE) }\end{array}$ \\
\hline & rs17170153 & Intron 5 & $7: 33060755$ & $A>C$ & 93,4 & 6,2 & 0,4 & 3,4 & 0,5 \\
\hline & rs4394301 & $\begin{array}{l}\text { upstream } \\
+4158\end{array}$ & 7: 33049584 & $A>G$ & 26,8 & 50,2 & 23,0 & 48,1 & 1 \\
\hline \multirow[t]{11}{*}{$R R M 1$} & rs1561876 & $\begin{array}{l}\text { Promotor } \\
-2529\end{array}$ & $11: 4113395$ & $A>G$ & 77,3 & 21,3 & 1,4 & 12,0 & 1 \\
\hline & rs1465952 & $\begin{array}{l}\text { Promotor } \\
-1385\end{array}$ & $11: 4114539$ & $A>G$ & 85,6 & 14,4 & 0 & 7,2 & 0,4 \\
\hline & rs11030918 & $\begin{array}{l}\text { Promotor } \\
-437\end{array}$ & $11: 4115487$ & $\mathrm{~T}>\mathrm{C}$ & 40,3 & 46,5 & 13,2 & 36,5 & 1 \\
\hline & rs12806698 & 5'UTR & $11: 4115974$ & $\mathrm{C}>\mathrm{A}$ & 51,5 & 41,2 & 7,3 & 27,8 & 0,9 \\
\hline & rs10835613 & Intron 2 & $11: 4124276$ & $C>G$ & 30,6 & 52,2 & 17,2 & 43,3 & 0,6 \\
\hline & rs7932702 & Intron 2 & $11: 4124372$ & $C>T$ & 40,7 & 49,0 & 10,3 & 34,8 & 0,4 \\
\hline & rs10498198 & Intron 2 & 11: 4124731 & $C>G$ & 91,4 & 8,6 & 0 & 4,3 & 0,8 \\
\hline & rs183484 & Exon 9 & $11: 4141132$ & $T>G$ & 25,1 & 52,9 & 22,0 & 48,5 & 0,6 \\
\hline & rs9937 & Exon 19 & $11: 4159457$ & $\mathrm{C}>\mathrm{T}$ & 26,1 & 52,2 & 21,6 & 47,8 & 0,7 \\
\hline & rs1042858 & Exon 19 & $11: 4159466$ & $\mathrm{~T}>\mathrm{C}$ & 84,9 & 14,8 & 0,4 & 7,7 & 0,8 \\
\hline & rs1042919 & 3'UTR & $11: 4159764$ & $\mathrm{~T}>\mathrm{A}$ & 84,9 & 14,8 & 0,4 & 7,7 & 0,8 \\
\hline \multirow[t]{5}{*}{ RRM2 } & rs7574663 & $\begin{array}{l}\text { Promotor } \\
-3368\end{array}$ & 2: 10259327 & $\mathrm{G}>\mathrm{C}$ & 61,2 & 33,7 & 5,2 & 22,0 & 1 \\
\hline & rs1130609 & Exon 1 & 2: 10262920 & $\mathrm{C}>\mathrm{A}$ & 52,6 & 38,8 & 8,6 & 28,0 & 0,8 \\
\hline & rs6741290 & Intron 4 & 2: 10264709 & $C>T$ & 31,3 & 49,8 & 18,9 & 43,8 & 1 \\
\hline & rs4668664 & Intron 7 & 2: 10268798 & $\mathrm{G}>\mathrm{A}$ & 53,3 & 39,9 & 6,9 & 26,8 & 1 \\
\hline & rs1138729 & 3'UTR & $2: 10271196$ & $A>G$ & 69,4 & 26,8 & 3,8 & 17,2 & 0,6 \\
\hline
\end{tabular}

\section{Gemcitabin-Transport}

\begin{tabular}{|c|c|c|c|c|c|c|c|c|c|}
\hline \multirow[t]{10}{*}{ ENT1 } & rs9357436 & $\begin{array}{l}\text { Promotor } \\
-4522\end{array}$ & 6: 44182720 & $\mathrm{C}>\mathrm{T}$ & 66,6 & 30,7 & 2,7 & 18,1 & 0,8 \\
\hline & rs2297393 & $\begin{array}{l}\text { Promotor } \\
-2523\end{array}$ & 6: 44184719 & $A>G$ & 25,3 & 49,7 & 25,0 & 49,8 & 1 \\
\hline & rs3734701 & $\begin{array}{c}\text { Promotor } \\
-1988\end{array}$ & 6: 44185254 & $C>T$ & 62,0 & 34,2 & 3,8 & 20,9 & 0,8 \\
\hline & rs1057985 & $\begin{array}{c}\text { Promotor } \\
-1341\end{array}$ & 6: 44185901 & $C>T$ & 38,9 & 46,2 & 14,9 & 38,0 & 1 \\
\hline & rs66872347 & 5'UTR & 6: 44187386: & $\mathrm{G}>\mathrm{A}$ & 85,4 & 14,6 & 0 & 7,3 & 0,5 \\
\hline & rs67057732 & 5'UTR & 6: 44187403: & $\mathrm{G}>\mathrm{A}$ & 95,1 & 4,9 & 0 & 2,5 & 0,9 \\
\hline & rs6914414 & Intron 1 & 6: 44188277 & $G>A$ & 88,0 & 11,6 & 0,3 & 6,2 & 1 \\
\hline & rs9462977 & Intron 1 & 6: 44188701 & $A>G$ & 27,0 & 53,9 & 19,1 & 46,1 & 0,4 \\
\hline & rs 11274220 & Intron 1 & 6: 44191783 & $\begin{array}{c}\text { Del>Ins } \\
20 \mathrm{bp}\end{array}$ & 62,7 & 33,6 & 3,7 & 20,5 & 0,9 \\
\hline & rs693955 & Intron 1 & 6: 44191920 & $\mathrm{G}>\mathrm{T}$ & 62,5 & 34,1 & 3,4 & 20,5 & 0,7 \\
\hline
\end{tabular}




\begin{tabular}{|c|c|c|c|c|c|c|c|c|c|}
\hline Gen $^{1}$ & SNP & $\begin{array}{c}\text { Genetisches } \\
\text { Element }^{2}\end{array}$ & $\begin{array}{l}\text { Chromosomale } \\
\text { Lokalisation }^{3}\end{array}$ & $\begin{array}{c}\text { Basen- } \\
\text { aus- } \\
\text { tausch }\end{array}$ & $\begin{array}{c}\mathbf{W t} / \mathbf{W t} \mathbf{t}^{5} \\
(\%)\end{array}$ & $\begin{array}{c}\text { Wt/Var } \\
(\%)\end{array}$ & $\begin{array}{c}\operatorname{Var} / \operatorname{Var}^{5} \\
(\%)\end{array}$ & $\begin{array}{c}\text { MAF }^{6} \\
(\%)\end{array}$ & $\begin{array}{l}\text { Chi } \\
\text { Tes } \\
\text { (HW }\end{array}$ \\
\hline & rs1886884 & Intron 1 & 6: 44192158 & $\mathrm{~T}>\mathrm{C}$ & 29,8 & 53,3 & 16,9 & 43,6 & \\
\hline & rs747199 & Intron 1 & 6: 44194345 & $\mathrm{G}>\mathrm{C}$ & 61,1 & 35,9 & 3,0 & 20,9 & \\
\hline & rs9394992 & Intron 2 & 6: 44195992 & $\mathrm{C}>\mathrm{T}$ & 54,4 & 38,9 & 6,7 & 26,2 & \\
\hline & rs324148 & Intron 2 & 6: 44196578 & $\mathrm{G}>\mathrm{A}$ & 51,9 & 40,3 & 7,8 & 28,0 & \\
\hline & rs324149 & Intron 2 & 6: 44196995 & $C>T$ & 54,8 & 38,7 & 6,5 & 25,9 & \\
\hline & $\begin{array}{l}\text { rs } 45573936 \\
=1 l e 216 \mathrm{Thr}\end{array}$ & Exon 7 & 6: 44198362 & $\mathrm{~T}>\mathrm{C}$ & 93,6 & 6,4 & 0 & 3,2 & \\
\hline & rs1128930 & Intron 11 & $6: 44200325$ & $\mathrm{~T}>\mathrm{G}$ & 37,7 & 47,6 & 14,7 & 38,5 & \\
\hline & rs760370 & Intron 12 & $6: 44200953$ & $A>G$ & 33,6 & 48,3 & 18,1 & 42,3 & \\
\hline
\end{tabular}

\section{Hedgehog-Signalweg}

\begin{tabular}{|c|c|c|c|c|c|c|c|c|c|}
\hline \multirow{10}{*}{ PTCH1 } & \multirow{2}{*}{$\begin{array}{l}\text { rs71366293 } \\
\text { rs10512249 }\end{array}$} & 5'UTR & \multirow{2}{*}{$\begin{array}{l}\text { 9: } 98270669 \\
\text { 9: } 98256309\end{array}$} & $\begin{array}{c}\text { Del>Ins } \\
\text { CGG }\end{array}$ & 57,2 & 37,0 & 5,8 & 24,3 & 1 \\
\hline & & Intron 2 & & $\mathrm{C}>\mathrm{T}$ & 80,1 & 18,4 & 1,5 & 10,6 & 0,9 \\
\hline & rs473902 & Intron 2 & 9: 98256235 & $A>C$ & 86,8 & 12,5 & 0,7 & 7,0 & 0,9 \\
\hline & rs574688 & Intron 10 & 9: 98239190 & $G>C$ & 53,5 & 37,3 & 9,2 & 27,8 & 0,7 \\
\hline & rs2066836 & Exon 12 & 9: 98238358 & $C>T$ & 58,7 & 35,0 & 6,3 & 23,8 & 0,9 \\
\hline & rs2236407 & Intron 12 & 9: 98237796 & $A>G$ & 37,8 & 47,6 & 14,7 & 38,5 & 1 \\
\hline & rs357564 & Exon 23 & 9: 98209594 & $G>A$ & 43,4 & 44,1 & 12,6 & 34,6 & 1 \\
\hline & rs357565 & 3'UTR & 9: 98205443 & $G>T$ & 56,9 & 37,2 & 5,9 & 24,5 & 1 \\
\hline & rs16909856 & $\begin{array}{c}\text { upstream } \\
+771\end{array}$ & 9: 98204493 & $C>T$ & 82,4 & 16,2 & 1,4 & 9,5 & 0,8 \\
\hline & rs357563 & $\begin{array}{l}\text { upstream } \\
+1065\end{array}$ & 9: 98204199 & $C>T$ & 42,6 & 46,8 & 10,6 & 34,0 & 0,9 \\
\hline \multirow[t]{7}{*}{ SHH } & rs288746 & $\begin{array}{l}\text { Promotor } \\
-1705\end{array}$ & 7: 155606672 & $\mathrm{~T}>\mathrm{C}$ & 71,8 & 26,8 & 1,4 & 14,8 & 0,8 \\
\hline & rs872723 & $\begin{array}{c}\text { Promotor } \\
-777\end{array}$ & 7: 155605744 & $C>T$ & 67,4 & 29,1 & 3,5 & 18,1 & 1 \\
\hline & rs756884 & Intron 1 & 7: 155604099 & $G>A$ & 82,4 & 16,2 & 1,4 & 9,5 & 0,8 \\
\hline & rs9333596 & Intron 1 & 7: 155603978 & $\mathrm{~T}>\mathrm{C}$ & 68,3 & 28,2 & 3,5 & 17,6 & 0,9 \\
\hline & rs1233556 & Intron 1 & $7: 155600417$ & $G>A$ & 70,4 & 26,1 & 3,5 & 16,5 & 0,8 \\
\hline & rs1233571 & $\begin{array}{c}\text { upstream } \\
+1264\end{array}$ & 7: 155594294 & $\mathrm{G}>\mathrm{A}$ & 71,3 & 25,2 & 3,5 & 16,1 & 0,7 \\
\hline & rs1233560 & $\begin{array}{l}\text { upstream } \\
+2120\end{array}$ & 7: 155593438 & $\mathrm{G}>\mathrm{A}$ & 29,6 & 46,5 & 23,9 & 47,2 & 0,7 \\
\hline \multirow[t]{3}{*}{ SMO } & rs6962740 & $\begin{array}{l}\text { Promotor } \\
-1902\end{array}$ & 7: 128826811 & $\mathrm{C}>\mathrm{G}$ & 57,1 & 36,4 & 6,5 & 24,6 & 1 \\
\hline & rs11762252 & Intron 1 & 7: 128834345 & $C>G$ & 88,7 & 11,3 & 0 & 5,6 & 0,8 \\
\hline & rs2718107 & Intron 1 & 7: 128838659 & $T>G$ & 31,2 & 44,2 & 24,6 & 46,7 & 0,4 \\
\hline
\end{tabular}




\begin{tabular}{|c|c|c|c|c|c|c|c|c|c|}
\hline Gen $^{1}$ & SNP & $\begin{array}{l}\text { Genetisches } \\
\text { Element }^{2}\end{array}$ & $\begin{array}{c}\text { Chromosomale } \\
\text { Lokalisation }^{3}\end{array}$ & $\begin{array}{c}\text { Basen- } \\
\text { aus- } \\
\text { tausch }\end{array}$ & $\begin{array}{c}\mathrm{Wt} / \mathrm{Wt}^{5} \\
(\%)\end{array}$ & $\begin{array}{c}\mathrm{Wt} / \operatorname{Var}^{5} \\
(\%)\end{array}$ & $\begin{array}{c}\operatorname{Var} / \operatorname{Var}^{5} \\
(\%)\end{array}$ & $\begin{array}{c}\text { MAF }^{6} \\
(\%)\end{array}$ & $\begin{array}{l}\text { Chi- } \\
\text { Test }^{7} \\
\text { (HWE) }\end{array}$ \\
\hline & rs4731562 & Intron 1 & $7: 128842573$ & $\mathrm{C}>\mathrm{T}$ & 40,9 & 43,1 & 16,1 & 37,6 & 0,6 \\
\hline & rs2566871 & Intron 1 & 7: 128843169 & $\mathrm{C}>\mathrm{T}$ & 28,6 & 45,7 & 25,7 & 48,6 & 0,6 \\
\hline & rs2228617 & Exon 6 & $7: 128846328$ & $\mathrm{G}>\mathrm{C}$ & 68,3 & 28,2 & 3,5 & 17,6 & 0,9 \\
\hline
\end{tabular}

Tab. 9 Charakteristika untersuchter Genpolymorphismen geordnet nach Genen. Die Analyse der 109 Polymorphismen erfolgte an 142 Proben von Patienten mit Pankreaskarzinom. Zusätzlich habe ich diese Genloci (mit Ausnahme des Hedgehog-Signalwegs) noch an 153 Probanden aus vorangegangenen Studien der Abteilung Klinische Pharmakologie mit isolierten Leukozyten (Preuß 2009; Kuschel 2011) typisiert. Die in der Tabelle genannten Häufigkeitsangaben beziehen sich auf die Gesamtzahl von 295 Proben. ${ }^{1}$ Bei mehreren Transkriptvarianten des Gens beziehen sich die Angaben immer auf die längste Isoform (betrifft CMPK1, DCTD, NT5C3, RRM2, ENT1 und PTCH1). ${ }^{2,3}$ Für jeden Polymorphismus (SNP) sind die rs-Nummer (reference snp number) und die Angaben zur chromosomalen Lokalisation aus der Datenbank dbSNP (Version GRCh37.p2/ http://www.ncbi.nlm.nih.gov/SNP/) des NCBI (National Center of Biotechnology Information) entnommen. Für in der Promotorregion bzw. upstream des Gens gelegenen Varianten sind die Abstände in Relation zum Transkriptionsstart- bzw. -endpunkt angegeben. ${ }^{4}$ Basenaustausch an der jeweiligen polymorphen Stelle. ${ }^{5}$ Häufigkeitsverteilung der beobachteten Genotypkonfigurationen $(\mathrm{Wt} / \mathrm{Wt}=$ homozgot für Wildtyp-Allel; Wt/Var = Wildtyp- und Variantenallel, d.h. Heterozygotie; Var/Var = homozygot für Varianten-Allel). ${ }^{6} \mathrm{MAF}=$ minor allele frequency (Frequenz des selteneren Allels). ${ }^{7}$ Chi-Quadrat-Test zur Abschätzung des Hardy-Weinberg-Equilibriums (HWE).

\subsection{Genpolymorphismen und Gesamtüberleben}

Die Analyse von Genpolymorphismen hinsichtlich ihrer Korrelation zum Gesamtüberleben wurde initial an einer Kohorte von insgesamt 142 Patienten durchgeführt. Aufgrund des maßgeblichen Einflusses des Resektionsstatus auf das Gesamtüberleben (siehe Kapitel 4.2.2) wurden für die spätere Auswertung ausschließlich Patienten mit Resektionstatus R0 und R1 berücksichtigt $(n=97)$. Die Tab. 10 gibt für jeden der 109 Polymorphismen als singuläre unabhängige Variable die mit dem Cox-proportional-hazard-Modell berechneten Hazard Ratios mit Konfidenzintervall sowie die False Discovery Rate (FDR) an. Die angeführten Hazard Ratios (HR) beschreiben in meinen Daten die über die Zeit konstante Sterbewahrscheinlichkeit einer Gruppe von Patienten im Vergleich zur Referenzgruppe, d.h. die Sterbewahrscheinlichkeit in Abhängigkeit der jeweiligen Genotypenkonstellation. Ein HR von 1 bedeutet keinen Unterschied zwischen Variante und Wildtyp. Lag die HR > 1, so war das Risiko zu versterben für die betreffende Gruppe größer als beim Wildtyp. Ein HR $<1$ weist auf ein vermindertes Risiko für die beobachtete Gruppe gegenüber dem Wildtyp hin. 


\subsubsection{Explorative Analyse mit 109 Kandidatengen-Varianten}

Fett gedruckt in Tab. 10 sind die rs-Nummern derjenigen Varianten, die nach Log-rank-Test (linearer Trend entsprechend der Anzahl der Variantenallele angenommen) mit einem $P$ Wert $<$ 0,05 mit der Überlebenszeit assoziiert waren. Dies war für zehn Genvarianten der Fall, welche in Tab. 11 aufgelistet sind.

\begin{tabular}{|c|c|c|c|c|c|}
\hline Gen & SNP & $\begin{array}{l}\text { Het versus Wt } \\
\text { Var versus Wt }\end{array}$ & Hazard Ratio (95\%-KI) & $\boldsymbol{P}$ & FDR \\
\hline \multicolumn{6}{|c|}{ Gemcitabin-Metabolismus } \\
\hline \multirow[t]{22}{*}{$C D A$} & rs540282 & $A G$ versus $A A$ & $1,07(0,63-1,83)$ & 0,8 & 0,9 \\
\hline & & GG versus $A A$ & $2,21(0,30-16,2)$ & 0,4 & 0,8 \\
\hline & rs532545 & $C T$ versus $C C$ & $1,15(0,71-1,87)$ & 0,5 & 0,9 \\
\hline & & $T T$ versus $C C$ & $1,22(0,54-2,75)$ & 0,6 & 0,9 \\
\hline & rs603412 & $G C$ versus $G G$ & $1,24(0,74-2,06)$ & 0,4 & 0,8 \\
\hline & & $C C$ versus $G G$ & $1,38(0,70-2,72)$ & 0,3 & 0,8 \\
\hline & rs602950 & $A G$ versus $A A$ & $1,13(0,70-1,82)$ & 0,6 & 0,9 \\
\hline & & GG versus $A A$ & $1,36(0,60-3,07)$ & 0,5 & 0,8 \\
\hline & rs2072671 & TG versus $T T$ & $1,19(0,74-1,91)$ & 0,5 & 0,8 \\
\hline & & GG versus $T T$ & $0,89(0,35-2,29)$ & 0,8 & 0,9 \\
\hline & rs818202 & $C T$ versus $C C$ & $0,74(0,45-1,23)$ & 0,3 & 0,7 \\
\hline & & $T T$ versus $C C$ & $1,06(0,53-2,11)$ & 0,9 & 0,9 \\
\hline & rs10916824 & $A G$ versus $A A$ & $0,76(0,36-1,58)$ & 0,5 & 0,8 \\
\hline & & GG versus $A A$ & $1,44(0,19-10,5)$ & 0,7 & 0,9 \\
\hline & rs577042 & $T C$ versus $T T$ & $1,16(0,71-1,90)$ & 0,5 & 0,9 \\
\hline & & $C C$ versus $T T$ & $0,74(0,29-1,92)$ & 0,5 & 0,9 \\
\hline & rs818194 & TA versus $T T$ & $1,32(0,81-2,14)$ & 0,3 & 0,7 \\
\hline & & $A A$ versus $T T$ & $1,31(0,55-3,10)$ & 0,5 & 0,9 \\
\hline & rs10916827 & $G A$ versus $G G$ & $0,99(0,58-1,69)$ & 1 & 1 \\
\hline & & $A A$ versus $G G$ & $1,19(0,63-2,23)$ & 0,6 & 0,9 \\
\hline & rs580032 & $A C$ versus $A A$ & $1,27(0,66-2,45)$ & 0,5 & 0,8 \\
\hline & & $C C$ versus $A A$ & $0,20(0,02-1,54)$ & 0,1 & 0,6 \\
\hline
\end{tabular}




\begin{tabular}{|c|c|c|c|c|c|}
\hline Gen & SNP & $\begin{array}{l}\text { Het versus Wt } \\
\text { Var versus Wt }\end{array}$ & Hazard Ratio (95\%-KI) & $P$ & FDR \\
\hline & rs11579252 & TC versus $T T$ & $0,89(0,52-1,52)$ & 0,7 & 0,9 \\
\hline & & CC versus TT & $2,33(0,56-9,69)$ & 0,2 & 0,7 \\
\hline & rs527912 & $G A$ versus $G G$ & $0,92(0,56-1,52)$ & 0,8 & 0,9 \\
\hline & & $A A$ versus $G G$ & $0,84(0,37-1,91)$ & 0,7 & 0,9 \\
\hline & rs1689924 & $T C$ versus $T T$ & $0,95(0,56-1,60)$ & 0,9 & 0,9 \\
\hline & & CC versus $T T$ & $0,89(0,48-1,62)$ & 0,7 & 0,9 \\
\hline & rs12404655 & $T C$ versus $T T$ & $1,14(0,70-1,87)$ & 0,6 & 0,9 \\
\hline & & CC versus $T T$ & $0,60(0,25-1,45)$ & 0,3 & 0,7 \\
\hline & rs12072405 & $A G$ versus $A A$ & $1,06(0,67-1,69)$ & 0,8 & 0,9 \\
\hline & & GG versus $A A$ & $0,73(0,10-5,39)$ & 0,8 & 0,9 \\
\hline & rs1048977 & $G A$ versus $G G$ & $1,28(0,77-2,12)$ & 0,3 & 0,8 \\
\hline & & $A A$ versus $G G$ & $1,09(0,53-2,25)$ & 0,8 & 0,9 \\
\hline & rs1614627 & $C A$ versus $C C$ & $0,80(0,45-1,45)$ & 0,5 & 0,8 \\
\hline & & $A A$ versus $C C$ & $0,19(0,02-1,45)$ & 0,1 & 0,6 \\
\hline \multirow[t]{13}{*}{ CMPK1 } & rs11211517 & $C T$ versus $C C$ & $1,44(0,81-2,56)$ & 0,2 & 0,7 \\
\hline & & TT versus CC & $1,22(0,62-2,43)$ & 0,6 & 0,9 \\
\hline & rs7543016 & $C G$ versus $C C$ & $1,58(0,85-2,95)$ & 0,1 & 0,6 \\
\hline & & GG versus $C C$ & $1,33(0,67-2,64)$ & 0,4 & 0,8 \\
\hline & rs12132521 & $G A$ versus $G G$ & $1,28(0,78-2,07)$ & 0,3 & 0,8 \\
\hline & & $A A$ versus $G G$ & $0,90(0,37-2,19)$ & 0,8 & 0,9 \\
\hline & rs35687416 & GT versus $G G$ & $1,08(0,51-2,26)$ & 0,8 & 0,9 \\
\hline & & $T T$ versus $G G$ & $0,76(0,10-5,52)$ & 0,8 & 0,9 \\
\hline & rs6660321 & $T G$ versus $T T$ & $1,54(0,93-2,55)$ & 0,09 & 0,5 \\
\hline & & GG versus $T T$ & $0,94(0,12-6,89)$ & 1 & 1 \\
\hline & rs7534571 & $A G$ versus $A A$ & $1,20(0,71-2,03)$ & 0,5 & 0,8 \\
\hline & rs12039726 & $G A$ versus $G G$ & $1,54(0,93-2,55)$ & 0,09 & 0,5 \\
\hline & & $A A$ versus $G G$ & $0,94(0,12-6,89)$ & 1 & 1 \\
\hline$D C K$ & rs6446982 & $G A$ versus $G G$ & $0,95(0,38-2,37)$ & 0,9 & 1 \\
\hline
\end{tabular}




\begin{tabular}{|c|c|c|c|c|c|}
\hline Gen & SNP & $\begin{array}{l}\text { Het versus Wt } \\
\text { Var versus Wt }\end{array}$ & Hazard Ratio (95\%-KI) & $\boldsymbol{P}$ & FDR \\
\hline & rs2306744 & $C T$ versus $C C$ & $0,49(0,06-3,57)$ & 0,5 & 0,8 \\
\hline & rs12648166 & $C T$ versus $C C$ & $1,19(0,70-2,02)$ & 0,5 & 0,8 \\
\hline & & $T T$ versus $C C$ & $1,12(0,57-2,22)$ & 0,7 & 0,9 \\
\hline & rs10805074 & $C T$ versus $C C$ & $1,03(0,41-2,57)$ & 0,9 & 1 \\
\hline & rs11544786 & $C T$ versus $C C$ & $0,55(0,24-1,28)$ & 0,2 & 0,6 \\
\hline \multirow[t]{23}{*}{$D C T D$} & rs5016499 & $C A$ versus $C C$ & $2,19(1,33-3,60)$ & 0,002 & 0,2 \\
\hline & & $A A$ versus $C C$ & $1,04(0,36-2,96)$ & 0,9 & 1 \\
\hline & rs13111117 & $G A$ versus $G G$ & $1,47(0,56-3,88)$ & 0,4 & 0,8 \\
\hline & rs10016530 & $T G$ versus $T T$ & $0,58(0,21-1,61)$ & 0,3 & 0,8 \\
\hline & rs10520543 & GA versus $G G$ & $1,28(0,78-2,09)$ & 0,3 & 0,8 \\
\hline & & $A A$ versus $G G$ & $1,47(0,69-3,11)$ & 0,3 & 0,8 \\
\hline & rs13148414 & CG versus $C C$ & $2,01(1,21-3,34)$ & 0,006 & 0,2 \\
\hline & & $G G$ versus $C C$ & $1,59(0,73-3,46)$ & 0,2 & 0,7 \\
\hline & rs6834019 & $C A$ versus $C C$ & $0,64(0,31-1,31)$ & 0,2 & 0,7 \\
\hline & rs4742 & $T C$ versus $T T$ & $1,20(0,73-1,96)$ & 0,5 & 0,8 \\
\hline & & $C C$ versus $T T$ & $1,96(0,92-4,15)$ & 0,08 & 0,5 \\
\hline & rs1960207 & $G A$ versus $G G$ & $1,11(0,60-2,04)$ & 0,7 & 0,9 \\
\hline & & $A A$ versus $G G$ & $1,23(0,29-5,06)$ & 0,8 & 0,9 \\
\hline & rs2515683 & $G A$ versus $G G$ & $1,67(0,99-2,81)$ & 0,05 & 0,4 \\
\hline & & $A A$ versus $G G$ & $1,89(0,94-3,81)$ & 0,07 & 0,5 \\
\hline & rs10017797 & $C A$ versus $C C$ & $0,75(0,40-1,40)$ & 0,4 & 0,8 \\
\hline & & $A A$ versus $C C$ & 3,46 (0-Inf) & 1 & 1 \\
\hline & rs7278 & $C T$ versus $C C$ & $1,81(1,10-3,00)$ & 0,02 & 0,4 \\
\hline & & $T T$ versus $C C$ & $10,8(2,46-48,0)$ & 0,002 & 0,2 \\
\hline & rs3924787 & $A G$ versus $A A$ & $1,67(0,98-2,87)$ & 0,06 & 0,5 \\
\hline & & $G G$ versus $A A$ & $1,45(0,75-2,81)$ & 0,3 & 0,7 \\
\hline & rs4073676 & $A T$ versus $A A$ & $1,46(0,66-3,22)$ & 0,3 & 0,8 \\
\hline & & TT versus $A A$ & $0,57(0,07-4,18)$ & 0,6 & 0,9 \\
\hline
\end{tabular}




\begin{tabular}{|c|c|c|c|c|c|}
\hline Gen & SNP & $\begin{array}{l}\text { Het versus Wt } \\
\text { Var versus Wt }\end{array}$ & Hazard Ratio (95\%-KI) & $P$ & FDR \\
\hline & rs4073675 & $C T$ versus $C C$ & $1,18(0,69-2,00)$ & 0,5 & 0,9 \\
\hline & & $T T$ versus $C C$ & $0,86(0,11-6,32)$ & 0,9 & 1 \\
\hline \multirow[t]{15}{*}{ NT5C3 } & rs6946062 & $T C$ versus $T T$ & $1,48(0,85-2,57)$ & 0,2 & 0,6 \\
\hline & & CC versus $T T$ & $1,64(0,89-3,03)$ & 0,1 & 0,6 \\
\hline & rs7795860 & $A G$ versus $A A$ & $0,82(0,49-1,34)$ & 0,4 & 0,8 \\
\hline & & GG versus $A A$ & $1,17(0,51-2,68)$ & 0,7 & 0,9 \\
\hline & rs7792135 & $A G$ versus $A A$ & $0,56(0,31-0,99)$ & 0,05 & 0,4 \\
\hline & & GG versus $A A$ & $0,64(0,15-2,66)$ & 0,5 & 0,9 \\
\hline & rs12668520 & $T C$ versus $T T$ & $1,32(0,79-2,20)$ & 0,3 & 0,8 \\
\hline & & CC versus $T T$ & $1,08(0,42-2,76)$ & 0,9 & 0,9 \\
\hline & rs17170218 & $A T$ versus $A A$ & $0,65(0,40-1,07)$ & 0,09 & 0,5 \\
\hline & & $T T$ versus $A A$ & $1,33(0,52-3,38)$ & 0,5 & 0,9 \\
\hline & rs3750117 & $G A$ versus $G G$ & $0,81(0,49-1,33)$ & 0,4 & 0,8 \\
\hline & & $A A$ versus $G G$ & $1,26(0,57-2,77)$ & 0,6 & 0,9 \\
\hline & rs17170153 & $A C$ versus $A A$ & $0,51(0,21-1,22)$ & 0,1 & 0,6 \\
\hline & rs4394301 & $A G$ versus $A A$ & $0,69(0,41-1,18)$ & 0,2 & 0,6 \\
\hline & & GG versus $A A$ & $0,84(0,44-1,62)$ & 0,6 & 0,9 \\
\hline \multirow[t]{11}{*}{$R R M 1$} & rs1561876 & $A G$ versus $A A$ & $1,16(0,64-2,10)$ & 0,6 & 0,9 \\
\hline & rs1465952 & $A G$ versus $A A$ & $1,32(0,69-2,53)$ & 0,4 & 0,8 \\
\hline & rs11030918 & $T C$ versus $T T$ & $0,98(0,58-1,66)$ & 1 & 1 \\
\hline & & $C C$ versus $T T$ & $0,96(0,47-1,96)$ & 0,9 & 1 \\
\hline & rs12806698 & $C A$ versus $C C$ & $1,13(0,69-1,84)$ & 0,6 & 0,9 \\
\hline & & $A A$ versus $C C$ & $1,22(0,55-2,67)$ & 0,6 & 0,9 \\
\hline & rs10835613 & $C G$ versus $C C$ & $0,86(0,50-1,48)$ & 0,6 & 0,9 \\
\hline & & $G G$ versus $C C$ & $0,74(0,36-1,53)$ & 0,4 & 0,8 \\
\hline & rs7932702 & $C T$ versus $C C$ & $1,01(0,61-1,68)$ & 0,9 & 1 \\
\hline & & $T T$ versus CC & $0,79(0,34-1,82)$ & 0,6 & 0,9 \\
\hline & rs10498198 & CG versus $C C$ & $1,66(0,59-4,62)$ & 0,3 & 0,8 \\
\hline
\end{tabular}




\begin{tabular}{|c|c|c|c|c|c|}
\hline Gen & SNP & $\begin{array}{l}\text { Het versus Wt } \\
\text { Var versus Wt }\end{array}$ & Hazard Ratio (95\%-KI) & $\boldsymbol{P}$ & FDR \\
\hline & rs183484 & TG versus $T T$ & $0,80(0,46-1,40)$ & 0,4 & 0,8 \\
\hline & & GG versus $T T$ & $0,84(0,43-1,64)$ & 0,6 & 0,9 \\
\hline & rs9937 & $C T$ versus $C C$ & $0,77(0,44-1,33)$ & 0,4 & 0,8 \\
\hline & & $T T$ versus $C C$ & $0,82(0,42-1,59)$ & 0,6 & 0,9 \\
\hline & rs1042858 & $T C$ versus $T T$ & $0,71(0,35-1,44)$ & 0,4 & 0,8 \\
\hline & rs1042919 & TA versus $T T$ & $0,71(0,35-1,44)$ & 0,4 & 0,8 \\
\hline \multirow[t]{10}{*}{ RRM2 } & rs7574663 & $G C$ versus $G G$ & $1,28(0,78-2,10)$ & 0,3 & 0,8 \\
\hline & & $C C$ versus $G G$ & $0,77(0,23-2,62)$ & 0,7 & 0,9 \\
\hline & rs1130609 & $C A$ versus $C C$ & $0,77(0,46-1,26)$ & 0,3 & 0,8 \\
\hline & & $A A$ versus $C C$ & $0,43(0,19-0,97)$ & 0,04 & 0,4 \\
\hline & rs6741290 & $C T$ versus $C C$ & $0,83(0,49-1,41)$ & 0,5 & 0,8 \\
\hline & & $T T$ versus $C C$ & $0,64(0,33-1,22)$ & 0,2 & 0,6 \\
\hline & rs4668664 & $G A$ versus $G G$ & $0,48(0,28-0,81)$ & 0,006 & 0,2 \\
\hline & & $A A$ versus $G G$ & $0,45(0,21-0,94)$ & 0,04 & 0,4 \\
\hline & rs1138729 & $A G$ versus $A A$ & $1,43(0,84-2,43)$ & 0,2 & 0,6 \\
\hline & & GG versus $A A$ & $2,62(0,62-10,9)$ & 0,2 & 0,6 \\
\hline \multicolumn{6}{|c|}{ Gemcitabin-Transport } \\
\hline \multirow[t]{11}{*}{ ENT1 } & rs9357436 & $C T$ versus CC & $0,66(0,40-1,11)$ & 0,1 & 0,6 \\
\hline & & $T T$ versus $C C$ & $0,58(0,08-4,26)$ & 0,6 & 0,9 \\
\hline & rs2297393 & $A G$ versus $A A$ & $0,58(0,32-1,02)$ & 0,06 & 0,5 \\
\hline & & GG versus $A A$ & $0,90(0,47-1,70)$ & 0,7 & 0,9 \\
\hline & rs3734701 & $C T$ versus $C C$ & $0,73(0,45-1,18)$ & 0,2 & 0,7 \\
\hline & & TT versus CC & $0,89(0,27-2,93)$ & 0,8 & 0,9 \\
\hline & rs1057985 & $C T$ versus $C C$ & $0,89(0,55-1,46)$ & 0,7 & 0,9 \\
\hline & & $T T$ versus CC & $0,39(0,18-0,88)$ & 0,02 & 0,4 \\
\hline & rs66872347 & GA versus $G G$ & $1,27(0,48-3,33)$ & 0,6 & 0,9 \\
\hline & rs67057732 & GA versus $G G$ & $2,85(0,66-12,2)$ & 0,2 & 0,6 \\
\hline & rs6914414 & GA versus $G G$ & $0,46(0,19-1,08)$ & 0,08 & 0,5 \\
\hline
\end{tabular}




\begin{tabular}{|c|c|c|c|c|c|}
\hline Gen & SNP & $\begin{array}{l}\text { Het versus Wt } \\
\text { Var versus Wt }\end{array}$ & Hazard Ratio (95\%-KI) & $P$ & FDR \\
\hline & \multirow[t]{2}{*}{ rs9462977 } & $A G$ versus $A A$ & $0,78(0,47-1,30)$ & 0,3 & 0,8 \\
\hline & & $G G$ versus $A A$ & $0,78(0,39-1,53)$ & 0,5 & 0,8 \\
\hline & \multirow[t]{2}{*}{ rs11274220 } & $D I$ versus $D D$ & $0,63(0,38-1,03)$ & 0,07 & 0,5 \\
\hline & & II versus $D D$ & $5,80(1,73-19,4)$ & 0,004 & 0,2 \\
\hline & \multirow[t]{2}{*}{ rs693955 } & GT versus $G G$ & $0,67(0,41-1,09)$ & 0,1 & 0,6 \\
\hline & & $T T$ versus $G G$ & $5,90(1,75-19,8)$ & 0,004 & 0,2 \\
\hline & \multirow[t]{2}{*}{ rs1886884 } & $T C$ versus $T T$ & $0,80(0,48-1,31)$ & 0,4 & 0,8 \\
\hline & & CC versus $T T$ & $0,87(0,44-1,74)$ & 0,7 & 0,9 \\
\hline & \multirow[t]{2}{*}{ rs747199 } & $G C$ versus $G G$ & $0,66(0,40-1,08)$ & 0,1 & 0,5 \\
\hline & & $C C$ versus $G G$ & $2,57(0-\operatorname{Inf})$ & 1 & 1 \\
\hline & \multirow[t]{2}{*}{ rs9394992 } & $C T$ versus $C C$ & $1,05(0,65-1,70)$ & 0,8 & 0,9 \\
\hline & & $T T$ versus $C C$ & $1,32(0,58-3,00)$ & 0,5 & 0,8 \\
\hline & \multirow[t]{2}{*}{ rs324148 } & $G A$ versus $G G$ & $0,59(0,36-0,96)$ & 0,03 & 0,4 \\
\hline & & $A A$ versus $G G$ & $3,61(1,58-8,25)$ & 0,002 & 0,2 \\
\hline & \multirow[t]{2}{*}{ rs324149 } & $C T$ versus $C C$ & $0,60(0,36-1,01)$ & 0,06 & 0,5 \\
\hline & & TT versus CC & $0,92(0,36-2,33)$ & 0,9 & 0,9 \\
\hline & rs45573936 & $T C$ versus $T T$ & $8,79(3,17-24,3)$ & 0,00003 & 0,01 \\
\hline & \multirow[t]{2}{*}{ rs1128930 } & TG versus $T T$ & $0,63(0,38-1,03)$ & 0,07 & 0,5 \\
\hline & & GG versus $T T$ & $1,08(0,54-2,18)$ & 0,8 & 0,9 \\
\hline & \multirow[t]{2}{*}{ rs760370 } & $A G$ versus $A A$ & $0,63(0,38-1,06)$ & 0,08 & 0,5 \\
\hline & & GG versus $A A$ & $0,99(0,52-1,89)$ & 1 & 1 \\
\hline \multicolumn{6}{|c|}{ Hedgehog-Signalweg } \\
\hline \multirow[t]{6}{*}{ PTCH1 } & \multirow[t]{2}{*}{ rs71366293 } & $D /$ versus $D D$ & $1,81(1,10-2,99)$ & 0,02 & 0,4 \\
\hline & & II versus $D D$ & $1,20(0,52-2,74)$ & 0,7 & 0,9 \\
\hline & rs10512249 & $C T$ versus $C C$ & $1,25(0,69-2,26)$ & 0,4 & 0,8 \\
\hline & \multirow[t]{2}{*}{ rs473902 } & $A C$ versus $A A$ & $0,62(0,32-1,23)$ & 0,2 & 0,6 \\
\hline & & $C C$ versus $A A$ & $0,77(0,10-5,61)$ & 0,8 & 0,9 \\
\hline & rs574688 & $G C$ versus $G G$ & $0,85(0,53-1,37)$ & 0,5 & 0,9 \\
\hline
\end{tabular}




\begin{tabular}{|c|c|c|c|c|c|}
\hline Gen & SNP & $\begin{array}{l}\text { Het versus Wt } \\
\text { Var versus Wt }\end{array}$ & Hazard Ratio (95\%-KI) & $P$ & FDR \\
\hline & & $C C$ versus $G G$ & $0,63(0,22-1,77)$ & 0,4 & 0,8 \\
\hline & rs2066836 & $C T$ versus $C C$ & 1,73 (1,06-2,82) & 0,03 & 0,4 \\
\hline & & $T T$ versus $C C$ & $1,13(0,49-2,59)$ & 0,8 & 0,9 \\
\hline & rs2236407 & $A G$ versus $A A$ & $2,19(1,28-3,74)$ & 0,004 & 0,2 \\
\hline & & GG versus $A A$ & $1,66(0,87-3,17)$ & 0,1 & 0,6 \\
\hline & rs357564 & GA versus $G G$ & $1,08(0,65-1,78)$ & 0,8 & 0,9 \\
\hline & & $A A$ versus $G G$ & $1,22(0,62-2,37)$ & 0,6 & 0,9 \\
\hline & rs357565 & GT versus GG & $0,54(0,33-0,89)$ & 0,02 & 0,4 \\
\hline & & $T T$ versus $G G$ & $0,85(0,30-2,40)$ & 0,8 & 0,9 \\
\hline & rs16909856 & $C T$ versus $C C$ & $1,39(0,77-2,51)$ & 0,3 & 0,7 \\
\hline & rs357563 & $C T$ versus $C C$ & $0,60(0,37-0,97)$ & 0,04 & 0,4 \\
\hline & & $T T$ versus $C C$ & $1,12(0,49-2,57)$ & 0,8 & 0,9 \\
\hline \multirow[t]{14}{*}{$S H H$} & rs288746 & $T C$ versus $T T$ & $1,99(1,18-3,36)$ & 0,01 & 0,3 \\
\hline & & CC versus TT & $9,46(0-\operatorname{lnf})$ & 1 & 1 \\
\hline & rs872723 & $C T$ versus $C C$ & $1,51(0,89-2,57)$ & 0,1 & 0,6 \\
\hline & & $T T$ versus $C C$ & $0,56(0,13-2,34)$ & 0,4 & 0,8 \\
\hline & rs756884 & $G A$ versus $G G$ & $1,40(0,71-2,74)$ & 0,3 & 0,8 \\
\hline & & $A A$ versus $G G$ & $9,40(1,20-73,3)$ & 0,03 & 0,4 \\
\hline & rs9333596 & $T C$ versus $T T$ & $1,47(0,85-2,52)$ & 0,2 & 0,6 \\
\hline & & CC versus TT & $0,91(0,28-2,95)$ & 0,9 & 1 \\
\hline & rs1233556 & $G A$ versus $G G$ & $1,21(0,72-2,01)$ & 0,5 & 0,8 \\
\hline & & $A A$ versus $G G$ & $0,67(0,16-2,77)$ & 0,6 & 0,9 \\
\hline & rs1233571 & $G A$ versus $G G$ & $0,73(0,43-1,23)$ & 0,2 & 0,7 \\
\hline & & $A A$ versus $G G$ & $1,43(0,51-4,00)$ & 0,5 & 0,8 \\
\hline & rs1233560 & $G A$ versus $G G$ & $0,91(0,54-1,52)$ & 0,7 & 0,9 \\
\hline & & $A A$ versus $G G$ & $1,33(0,70-2,54)$ & 0,4 & 0,8 \\
\hline \multirow[t]{2}{*}{ SMO } & rs6962740 & $C G$ versus $C C$ & $0,70(0,41-1,18)$ & 0,2 & 0,6 \\
\hline & & $G G$ versus $C C$ & $0,76(0,35-1,63)$ & 0,5 & 0,8 \\
\hline
\end{tabular}




\begin{tabular}{lllccc}
\hline Gen & SNP & $\begin{array}{l}\text { Het versus Wt } \\
\text { Var versus Wt }\end{array}$ & Hazard Ratio (95\%-KI) & $\boldsymbol{P}$ & FDR \\
\hline rs11762252 & CG versus CC & $1,53(0,65-3,60)$ & 0,3 & 0,8 \\
rs2718107 & TG versus TT & $1,30(0,75-2,26)$ & 0,3 & 0,8 \\
& GG versus TT & $0,81(0,43-1,51)$ & 0,5 & 0,9 \\
rs4731562 & CT versus CC & $0,93(0,55-1,57)$ & 0,8 & 0,9 \\
& TT versus CC & $1,02(0,53-1,96)$ & 0,9 & 1 \\
& rs2566871 & CT versus CC & $1,60(0,93-2,74)$ & 0,09 & 0,5 \\
& TT versus CC & $1,24(0,64-2,41)$ & 0,5 & 0,9 \\
& GS2228617 versus GG & $0,60(0,34-1,07)$ & 0,09 & 0,5 \\
& CC versus GG & $1,26(0,45-3,51)$ & 0,7 & 0,9 \\
\hline
\end{tabular}

Tab. 10 Genpolymorphismen und Gesamtüberleben. Dargestellt sind Hazard Ratios (HR) mit 95\% Konfidenzintervall (KI) und P-Wert sowie die False Discovery Rate (FDR) für jeden Genpolymorphismus als singuläre unabhängige Variable in Bezug zum Gesamtüberleben entsprechend einem Coxproportional-hazard-Modell. Im Falle von drei Genotypenkonfigurationen sind der heterozygote Genotyp (Het) und der homozygote Variantenallelstatus (Var) jeweils auf die Wildtyp-Konfiguration (Wt) bezogen, bei nur zwei Genotypenkonfigurationen nur der Het-Status auf den Wildtyp. Fett gedruckt sind diejenigen Polymorphismen, die im Log-rank-Test unter Berücksichtigung eines von der Alleldosis abhängigen linearen Trends einen $P$-Wert von $<0,05$ zeigten. Die Angabe „Inf“ im Konfidenzintervall (KI) steht für ,infinity“ und trat dann auf, wenn in einer Genotypkonfiguration nur eine Person vorhanden war; das KI ist dann nicht bestimmbar. FDR gibt ein Maß für die Wahrscheinlichkeit falsch positiver Assoziationen an und ist üblicherweise bei einem Wert > 0,2 gegeben, d.h. die statistische Evidenz für derartige Befunde ist auch bei einem $P$-Wert $<0,05$ schwach. 


\subsubsection{Adjustierung auf nicht-genetische Faktoren}

Die nach Log-rank-Test mit einem P-Wert $<0,05$ identifizierten und in Tab. 10 durch Fettschrift hervorgehobenen Varianten sind nachstehend in Tab. 11 aufgelistet. Für diese wurde jeweils mit einer Cox-Regression geprüft, ob die beobachtete Assoziation von Grading, Alter, Geschlecht und Resektionsgrad (R0 versus R1) beeinflusst wird. Nach dieser Adjustierung verlieben noch sieben Polymorphismen mit einer nominalen statistischen Signifikanz von $P<0,05$.

\begin{tabular}{llcc}
\hline Gen & SNP & $\begin{array}{c}\boldsymbol{P} \\
\text { (Log-rank-Test) }\end{array}$ & $\begin{array}{c}\boldsymbol{P} \\
\text { (Cox-Regression) }\end{array}$ \\
\hline Gemcitabin-Metabolismus & & \\
DCTD & rs7278 & 0,003 & 0,009 \\
& rs13148414 & 0,03 & 0,2 \\
RRM2 & rs2515683 & 0,03 & 0,1 \\
& rs4668664 & 0,006 & 0,004 \\
Gemcitabin-Transport & rs1130609 & 0,03 & 0,04 \\
ENT1 & rs45573936 & & \\
& rs1057985 & 0,00003 & 0,0005 \\
Hedgehog-Signalweg & 0,04 & 0,01 \\
PTCH1 & rs2236407 & & 0,01 \\
SHH & rs357565 & 0,04 & 0,2 \\
\hline
\end{tabular}

Tab. 11 Zusammenstellung der mit dem Gesamtiiberleben assoziierten SNPs. Betrachtet wurden hier zunächst alle SNPs mit $P<0,05$ im Log-rank-Test. Diese wurden dann jeweils einer CoxRegressionsanalyse mit den Faktoren Alter, Geschlecht, Grading und Resektionsgrad (R0 versus R1) als potenzielle Confounder unterzogen. Dabei wurde in SPSS die Methode „Enter“ verwendet, wobei die unabhängigen Variablen mit Ausnahme des Alters als kategoriell klassifiziert wurden. Varianten mit daraus resultierenden P-Werten $<\mathbf{0 , 0 5}$ sind durch Fettschrift hervorgehoben.

\subsubsection{Kombiniertes SNP-Modell}

Diejenigen sieben SNPs, die auch nach Adjustierung auf nicht-genetische Faktoren eine nominale statistische Signifikanz mit $P<0,05$ zeigten (siehe Tab. 11 in vorigem Kapitel 4.4.2), wurden nun zusammen in einem Cox-Modell analysiert. Dies ist unter Angabe der HR mit dem 95\%-KI und P-Werten in Tab. 12 aufgeführt. Dabei blieben drei Polymorphismen unterhalb des Signifikanzniveaus von $P<0,05$. Diese sind in Tab. 12 durch Fettschrift hervorgehoben (rs1057985 hatte einen $P$-Wert von exakt 0,049). 


\begin{tabular}{|c|c|c|c|}
\hline Gen & SNP & Hazard Ratio (95\%-KI) & $\boldsymbol{P}$ \\
\hline \multicolumn{4}{|c|}{ Gemcitabin-Metabolismus } \\
\hline$D C T D$ & rs7278 & $1,60(0,98-2,66)$ & 0,06 \\
\hline \multirow[t]{2}{*}{ RRM2 } & rs4668664 & $0,69(0,41-1,16)$ & 0,2 \\
\hline & rs1130609 & $1,02(0,62-1,67)$ & 0,9 \\
\hline \multicolumn{4}{|c|}{ Gemcitabin-Transport } \\
\hline \multirow[t]{2}{*}{ ENT1 } & rs45573936 & $9,24(2,95-28,9)$ & 0,0001 \\
\hline & rs1057985 & $0,68(0,47-1,00)$ & 0,05 \\
\hline \multicolumn{4}{|c|}{ Hedgehog-Signalweg } \\
\hline $\mathrm{PTCH} 1$ & rs2236407 & $1,25(0,93-1,70)$ & 0,1 \\
\hline $\mathrm{SHH}$ & rs288746 & $2,08(1,20-3,62)$ & 0,01 \\
\hline
\end{tabular}

Tab. 12 Kombiniertes Cox-Modell der am stärksten mit dem Überleben assoziierten SNPs. Betrachtet wurden hier zunächst die sieben SNPs mit $P<0,05$ in der Cox-Regressionsanalyse nach Adjustierung auf nicht-genetische Faktoren (Tab. 11). Fett hervorgehoben sind diejenigen SNPs, die im kombinierten Modell einen $P$-Wert $<0,05$ aufwiesen.

\subsubsection{Adjustierung auf multiples Testen}

Nun wurde eine Adjustierung auf multiples Testen vorgenommen, indem für die oben genannten SNP-Assoziationen eine FDR unter Berücksichtigung der Zahl der insgesamt untersuchten Genvarianten berechnet wurde. Nach dieser Prozedur verblieb nur der Effekt der ENT1-Aminosäurevariante rs45573936 statistisch signifikant mit $P=0,004$. Dieser Beziehung wurde daher die stärkste Bedeutung eingeräumt. Die nachfolgenden Darstellungen konzentrieren sich somit zunächst auf diese Variante. Weiterhin werden noch die SNPs dargestellt, welche sowohl nach Adjustierung auf nicht-genetische Faktoren (Kapitel 4.4.2) als auch im kombinierten Cox-Modell (Kapitel 4.4.3) mit $P<0,05$ mit der Überlebenszeit assoziiert waren, auch wenn nach Korrektur auf multiples Testen hier keine statistische Signifikanz mehr vorlag.

\subsubsection{Stärkste Effekte für Varianten im Bereich des ENT1-Gens}

Die stärkste Assoziation mit der Überlebenszeit zeigte sich für den SNP rs45573936, der zum Aminosäureaustausch Ile216Thr im Nukleosid-Transporter ENT1 (SLC29A1) führt. Das Variantenallel hat dabei in der Allgemeinbevölkerung nur eine Häufigkeit von ca. 1\%. In dem ausgewerteten Kollektiv (Resektionsstatus R0 und R1, $n=97$ ) waren fünf Patienten mit heterozygoter Allelausprägung enthalten; Homozygotie für die Variante (Thr216) fand sich nicht. Der Effekt dieser Variante auf das Überleben ist in Abb. 10 anhand eines Kaplan-MeierPlots grafisch veranschaulicht. Das Hazard Ratio für Patienten mit heterozygoter Allelausprägung im Vergleich zu Patienten mit Wildtyp-Konfiguration wurde mit 8,8 (95\%KI 3,2 - 24,3; siehe Tab. 10 oben) ermittelt. Das bedeutet, die Variantenträger hatten über die Zeit konstant ein 8,8-fach erhöhtes Sterberisiko. Der Einfluss dieser Variante war sowohl nach 
Adjustierung auf nicht-genetische Parameter $(P=0,0005$; siehe Tab. 11 oben und im Detail nachstehend in Tab. 13) als auch nach Korrektur auf multiples Testen $(P=0,004$; Kapitel 4.4.4) statistisch signifikant.

\begin{tabular}{ll}
\hline Parameter & Statistische Signifikanz (P-Wert) \\
\hline ENT1 rs45573936 & 0,0005 \\
Grading & 0,04 \\
Resektionsgrad (0 vs 1) & 0,2 \\
Geschlecht & 0,4 \\
Alter bei Therapiebeginn & 0,8 \\
\hline
\end{tabular}

Tab. 13 Cox-Regressionsanalyse zur Assoziation von ENT1 rs45573936 und Überleben. Die Angaben beziehen sich auf 97 Patienten mit adenoduktalem Pankreaskarzinom und R0- bzw. R1-Resektion.

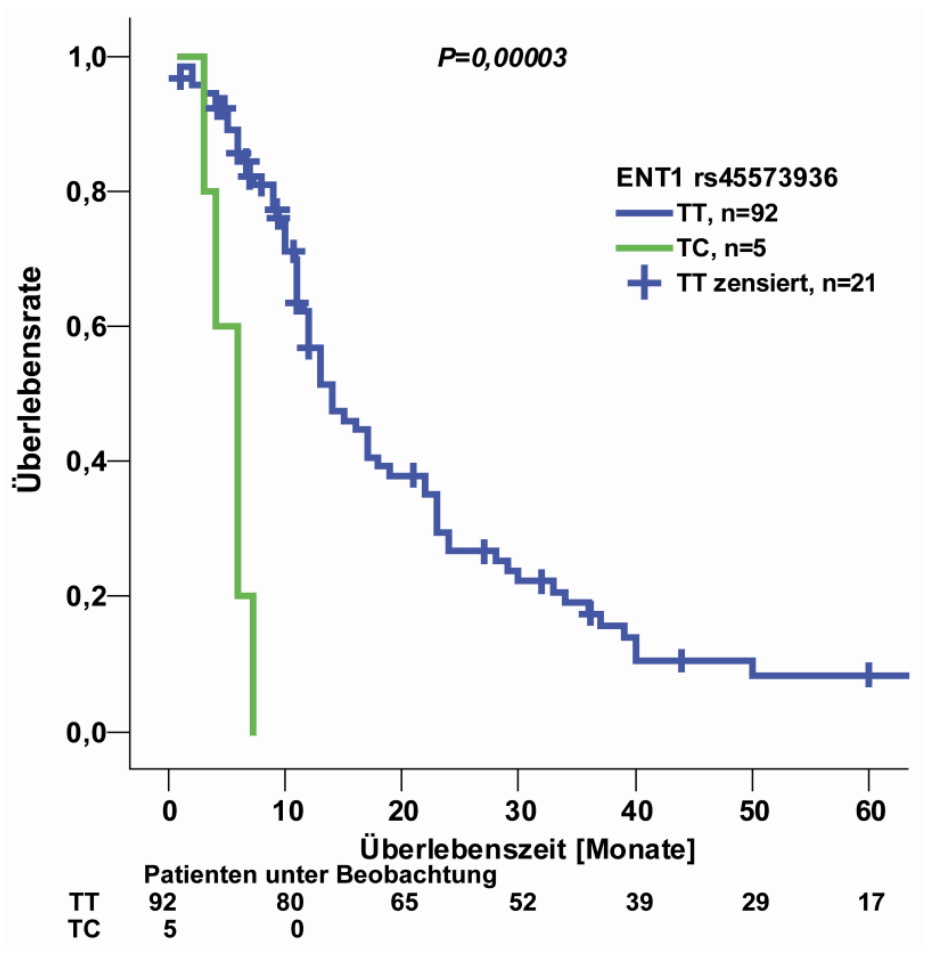

Abb. 10 Überlebenskurven in Abhängigkeit des ENT1-SNPs rs45573936 (Ile216Thr). Es sind für die zwei Genotypenkonfigurationen Wildtyp (TT) und Heterozygotie (TC) die Überlebensraten ab Beginn der Gemcitabin-Therapie veranschaulicht. Die Überprüfung der statistischen Signifikanz erfolgte mit dem Log-rankTest

Da sich in der initialen Kohorte von 142 Patienten (einschließlich R2 und nicht operable) elf mit Heterozygotie für rs45573936 fanden, wurde geprüft, ob eventuell ein Einfluss dieser Variante auf die Ausbreitung des Pankreas-Karzinoms zum Operationszeitpunkt vorliegt. Dazu wurde die Genotypverteilung dieser Variante in den drei Gruppen „R2/Inoperabilität““, „R0/R1“ und „Gesunde“ jeweils paarweise verglichen. Zwischen „R0/R1“ und „Gesunden“ war keinerlei Unterschied festzustellen. In der Gruppe „R2/Inoperabilität“ war ein Trend zu einem häufigeren Vorkommen des heterozygoten Status gegenüber „R0/R1“ $(P=0,09)$ und gegenüber „Gesunden“ $(P=0,07)$ festzustellen.

Eine weitere Variante des ENT1-Gens, für die sich ein Einfluss auf die Gesamtüberlebenszeit in Abhängigkeit seiner Allelausprägung feststellen ließ, war rs1057985. Dieser SNP ist im 
Promotorbereich des ENT1, 1341 Basenpaare vor der längsten mRNA-Transkriptvariante des Gens, lokalisiert (Abb. 11). Mit einer beobachteten Allelfrequenz von 38\% trat das Variantenallel relativ häufig innerhalb der Patientenkohorte auf, was zu den Daten zur Verteilung innerhalb der kaukasischen Bevölkerung (33\% nach Datenbank dbSNP) passt. Wie aus Abb. 11 ersichtlich, sind rs1057985 und die oben beschriebene Aminosäurevariante rs45573936 nicht im Kopplungsungleichgewicht $\left(r^{2}=0,03\right)$, d.h. sie sind voneinander unabhängig.

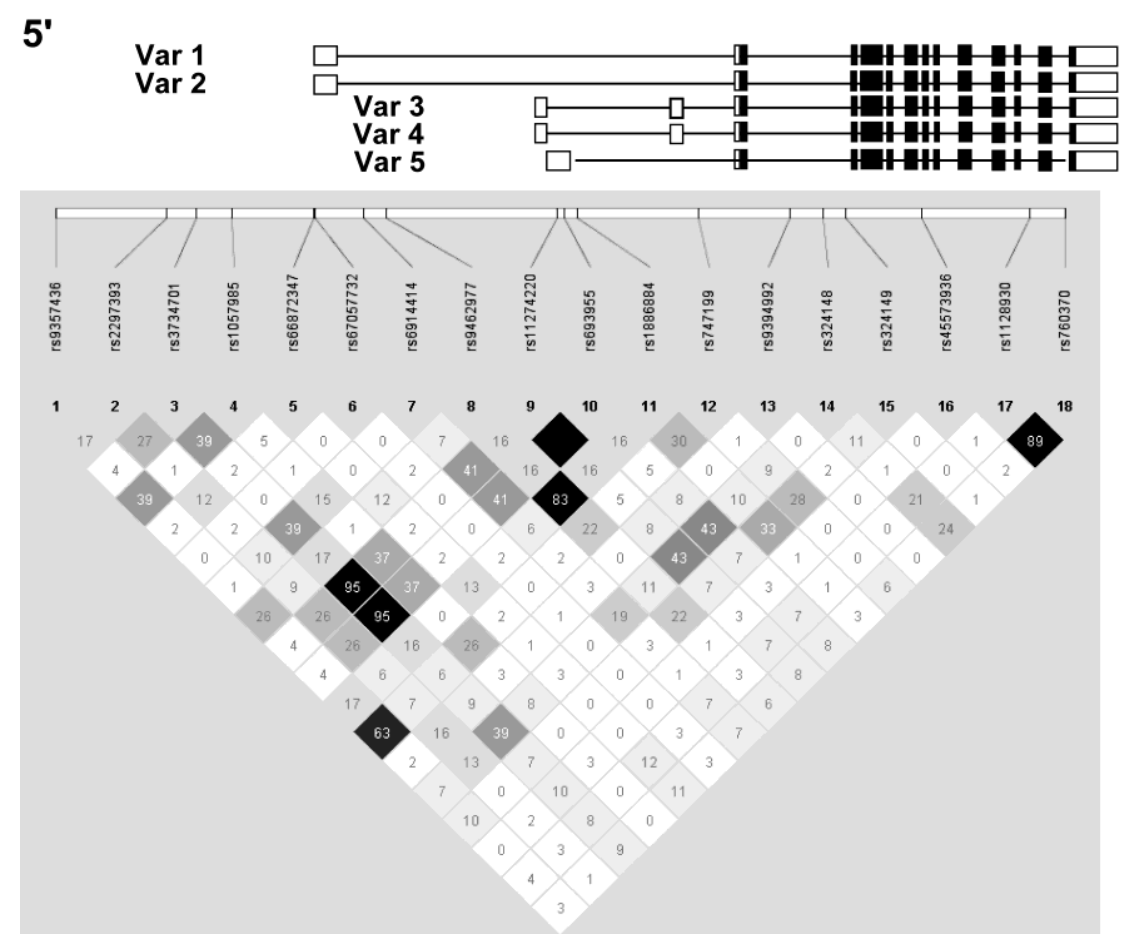

3'

Abb. 11 Architektur des ENT1-Gens und Kopplungsplot der analysierten Varianten. Die Abbildung ist einer Vorarbeit der Abteilung Klinische Pharmakologie (Kuschel 2011) entnommen. Die 18 SNPs sind von 5'- nach 3'-Richtung aufsteigend nummeriert. Rs1057985 ist SNP „4“", rs45573936 SNP „16“. Im oberen Teil der Abbildung finden sich die fünf Transkriptvarianten des ENT1-Gens in Relation zu den untersuchten Polymorphismen. Im unteren Teil der Abbildung sind paarweise die Kopplungsungleichgewichte (linkage disequilibrium, $L D$ ) der Genvarianten als Plot dargestellt. Anhand der Zahlen und Farbgebung innerhalb der Rauten kann auf die Stärke des $L D$ geschlossen werden. Ein hohes $L D$ wird durch einen hohen Zahlenwert und dunkle Farbe signalisiert. Starke genetische Kopplung spricht für häufige gemeinsame Vererbung der beiden Genvarianten. Ein dunkel-schwarzes Feld ohne Zahlenwert zeigt ein LD von $100 \%$ an.

Univariat zeigte der SNP rs1057985 als singuläre unabhängige Variable sowohl im Log-rankTest und der Cox-Regressionsanalyse einen Effekt auf die Überlebenszeit mit $P=0,04$. Grafisch ist dies in Abb. 12 illustriert. Dabei ist klar erkennbar, dass Träger der Variante AA bedeutend länger überlebten als Wildtypträger (HR 0,39; 95\%-KI 0,18-0,88; siehe Tab. 10 oben). Dies besagt, dass homozygote Träger des Variantenallels gegenüber der WildtypKonfiguration eine um fast $2 / 3$ reduzierte Wahrscheinlichkeit haben, in einem bestimmten Zeitintervall unter Gemcitabin zu versterben. Für Träger heterozygoter Allelausprägung waren diese Befunde nicht nachweisbar (HR 0,89; 95\%-KI 0,55 - 1,46). 


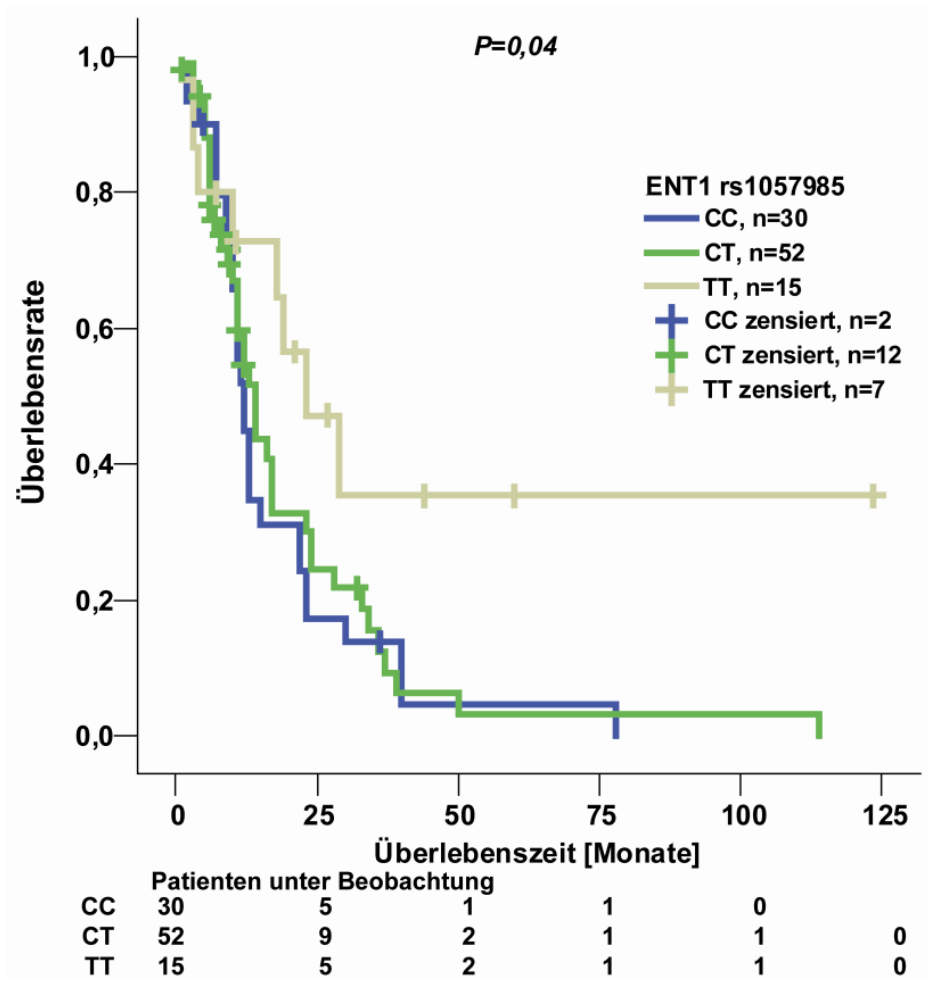

Abb. 12 Einfluss von rs1057985 auf die Überlebenszeit. Es sind für die drei Genotypenkonfigurationen Wildtyp (CC), Heterozygotie (CT) und Variante (TT) die Überlebensraten für die 97 Patienten mit R0- bzw. R1Resektionsstatus gezeigt. Die Darstellung entspricht Abb. 6 und Abb. 7

Wurden wie zuvor nicht-genetische Faktoren im Cox-Modell berücksichtigt, nahm die statistische Signifikanz dieser Variante noch leicht zu (siehe Tab. 14). Nach Korrektur auf multiples Testen wurde ein $P$-Wert von 0,5 bestimmt, so dass die Nullhypothese eines falschpositiven Befundes gegenwärtig nicht verworfen werden kann.

\begin{tabular}{ll}
\hline Parameter & Statistische Signifikanz (P-Wert) \\
\hline ENT1 rs1057985 & 0,01 \\
Grading & 0,006 \\
Resektionsgrad (0 vs 1) & 0,3 \\
Alter bei Therapiebeginn & 0,8 \\
Geschlecht & 0,9 \\
\hline
\end{tabular}

Tab. 14 ENT1 rs1057985 und nicht-genetische Faktoren im Cox-Modell bezogen auf Gesamtüberleben. Betrachtet wurden 97 Patienten mit Pankreaskarzinom und R0- bzw. R1-Resektionsstatus.

\subsubsection{SNP in SHH mit tendenzieller Beeinflussung der Überlebenszeit}

Die Genvariante rs288746 ist im Promotorbereich des SHH-Gens, 1705 Basenpaare vor Beginn des RNA-Transkripts, lokalisiert. Das SHH-Gen selbst befindet sich auf Chromosom 7. Innerhalb der kaukasischen Normalbevölkerung hat das Variantenallel dieses Polymorphismus eine Häufigkeit von 10,5\% (in meiner Studie 14,8\%). Die Variante war bei den 97 analysierten Patienten mit Pankreaskarzinom und Resektionsstatus R0 bzw. R1 mit $P=0,02$ nach Log-rank-Test mit dem Gesamtüberleben assoziiert. Das HR wurde mit 1,99 (95\%-KI: 1,18 - 3,36) bestimmt, d.h. Patienten mit heterozygoter Allelausprägung hatten 
verglichen mit Trägern des Wildtypes ein 2-fach erhöhtes Risiko, unter Gemcitabin-Therapie zu versterben $(P=0,01)$. Eine Kaplan-Meier-Grafik in Abb. 13 verdeutlicht diesen Befund.

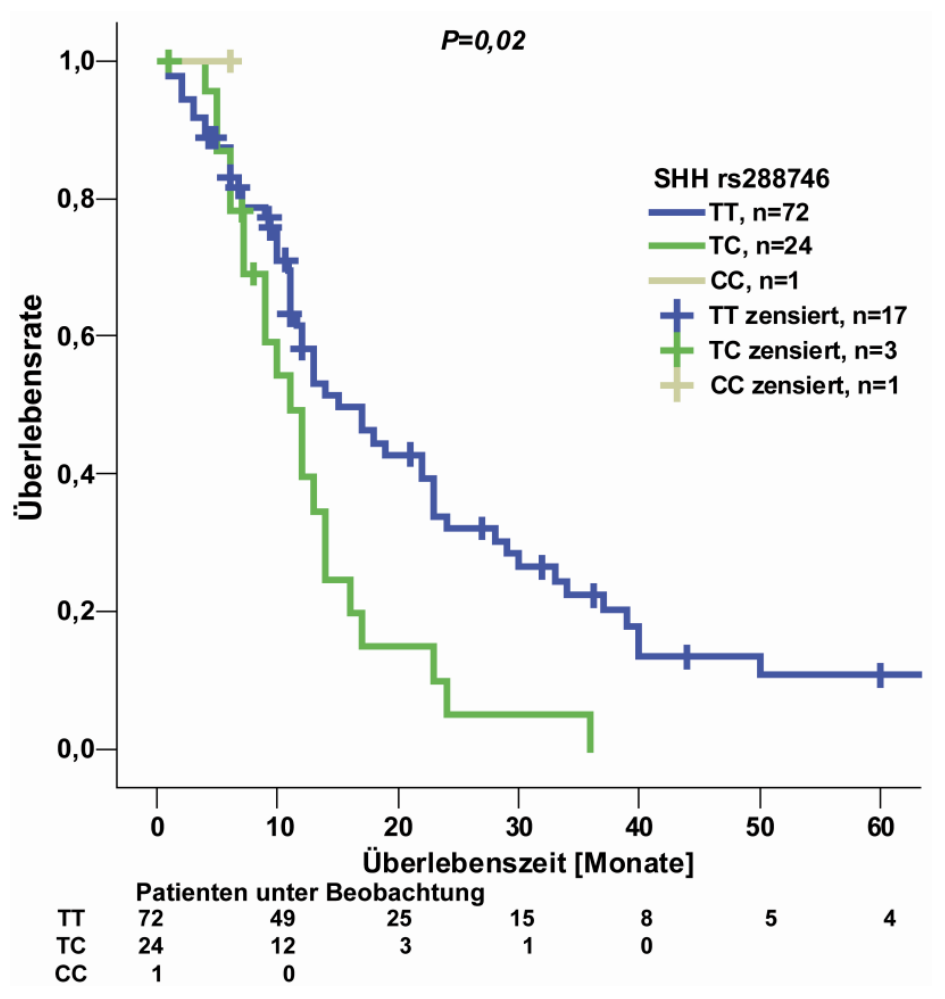

Abb. 13 Überlebenszeit in Abhängigkeit von $\mathrm{SHH}$-SNP rs288746. Die Darstellung erfolgte analog zu Abb. 6 und Abb. 7

Auch nach Adjustierung auf nicht-genetische Faktoren war in einem Cox-Regressionsmodell ein Einfluss dieser Variante in ähnlicher Größenordnung wie das Grading erkennbar $(P=0,05 ;$ Tab. 15).

\begin{tabular}{ll}
\hline Parameter & Statistische Signifikanz (P-Wert) \\
\hline SHH rs288746 & 0,05 \\
Grading & 0,05 \\
Resektionsgrad (0 vs 1) & 0,2 \\
Geschlecht & 0,5 \\
Alter bei Therapiebeginn & 0,7 \\
\hline
\end{tabular}

Tab. 15 Einfluss von $S H H$ rs288746 und nicht-genetischer Faktoren auf Gesamtüberleben. Im CoxModell analysiert, wurden Daten von 97 Patienten mit Pankreaskarzinom mit R0- oder R1Resektionsstatus zugrunde gelegt. 


\subsection{Hämatotoxizität unter Gemcitabin-Therapie}

\subsubsection{Deskriptiver Verlauf von Leukozyten und Thrombozyten}

Für die Bewertung der sekundären Zielgröße „Hämatotoxizität unter Gemcitabin-Therapie“ wurde wieder die ursprüngliche Patientenzahl von 142 ungeachtet des Resektionsstatus zu Grunde gelegt. Für 116 von diesen gelang eine lückenlose Darstellung der Verläufe von Leukozyten- und Thrombozytenzahlen während der ersten 42 Tage der Therapie. Bedingung war die erstmalige Gabe von Gemcitabin. Bei dem zumeist angewandten 3/4-Takt (d.h. drei Gaben von 1000 mg Gemcitabin/m² KOF im wöchentlichen Abstand gefolgt von einer Woche Pause) sind in diesem 42-Tage-Intervall zwei komplette Gemcitabin-Zyklen enthalten. Von den 116 Patienten mit auswertbaren Blutbilddaten erhielten 71 einen solchen 3/4-Takt, 23 einen 2/3-Takt, 16 Patienten einen 6/8-Takt und 6 eine andere Taktung der Chemotherapie.

Die Charakteristika der Hämatotoxizitätsdaten sind in Tab. 16 und Tab. 17 zusammengefasst. Der tiefste Wert für Leukozyten und Thrombozytenzahl innerhalb des Beobachtungsintervalls von 42 Tagen wurde als Nadir festgelegt. Der Nadir von Leukozyten betrug im Median

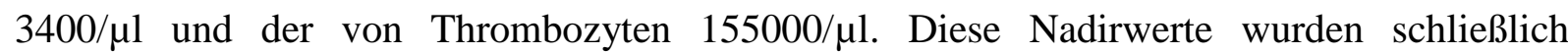
Zytotoxizitätskriterien, den sogenannten Common Terminology Criteria for Adverse Events (CTC, Version 4.0, 2010) des National Cancer Instituts (NCI), zugeordnet. Diese Kriterien beschreiben den Grad der (Hämato-) Toxizität einer Therapie auf einer Skala von Grad 1 (leicht) bis Grad 4 (schwer).

\begin{tabular}{|c|c|}
\hline \multicolumn{2}{|l|}{ Nadir Leukozyten [1000/ul] bzw. in \% zu Tag $0^{1}$} \\
\hline Median (\%) & $3,4(51)$ \\
\hline Interquartilabstand (\%) & $2,6-4,9(39-67)$ \\
\hline Range (\%) & $0,7-10,6(11-102)$ \\
\hline \multicolumn{2}{|l|}{$\mathrm{NCl}$ - CTC [Zahl der Patienten] ${ }^{2}$} \\
\hline G0:>4000 Leukozyten/ $\mu$ l (Untergrenze Normbereich) & 48 \\
\hline G1:3000 - 4000 Leukozyten/ $\mu$ l & 26 \\
\hline G2:2000 - 3000 Leukozyten/ $\mu$ l & 26 \\
\hline G3:1000 - 2000 Leukozyten/ $\mu$ l & 15 \\
\hline 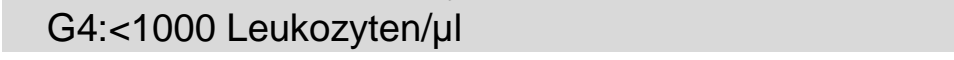 & 1 \\
\hline \multicolumn{2}{|l|}{ Zeit bis Nadir Leukozyten [Tage] } \\
\hline Median & 14 \\
\hline Interquartilabstand & $7-28$ \\
\hline Range & $3-42$ \\
\hline \multicolumn{2}{|c|}{ Gemcitabin-Intensität bei Leukozytennadir [Zahl der Patienten] ${ }^{3}$} \\
\hline$<1000 \mathrm{mg} / \mathrm{m}^{2} \mathrm{KOF}$ & 49 \\
\hline $1000-2000 \mathrm{mg} / \mathrm{m}^{2} \mathrm{KOF}$ & 46 \\
\hline $2000-3000 \mathrm{mg} / \mathrm{m}^{2} \mathrm{KOF}$ & 21 \\
\hline \multicolumn{2}{|l|}{ 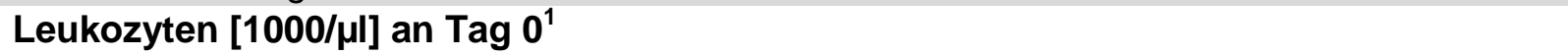 } \\
\hline Median & 7 \\
\hline Interquartilabstand & $5,7-8,6$ \\
\hline
\end{tabular}


Range

Leukozyten [1000/ $\mu l]$ an Tag 7 der Gemcitabin-Therapie

Median

Interquartilabstand

Range

\% Leukozyten Tag 7 zu Tag 0

Median

Interquartilabstand

Range
$3-12,4$

$$
4,5
$$

$3,4-5,7$

$1,2-11,4$

64,3

$50,0-83,3$

$29,1-186,0$

Tab. 16 Verlaufsdaten für Leukozyten während der ersten 42 Tage Gemcitabin-Therapie. ${ }^{1}$ Die Werte von Tag 0 beziehen sich in der Regel auf eine unmittelbar vor der ersten Gemcitabin-Gabe abgenommene Blutprobe, in einzelnen Fällen bis zu maximal zwei Tage davor. ${ }^{2} \mathrm{NCI}$ (National Cancer Institute) - CTC (Common Terminology Criteria for Adverse Events) beschreibt den Grad der Toxizität einer durchgeführten Therapie, hier diejenige von Gemcitabin auf Leukozyten und bezieht sich auf die gemessenen Nadir-Werte. Die Einteilung erfolgte entsprechend den Kriterien der CTC-Version 4.0 (2010). G0 entspricht dem Normbereich und bedeutet keine Toxizität. ${ }^{3}$ Die Gemcitabin-Intensität bei Nadir beschreibt die kumulative Gesamtdosis Gemcitabin, welche innerhalb von 3 Wochen (21 Tage) vor Eintritt des Nadir verabreicht wurde.

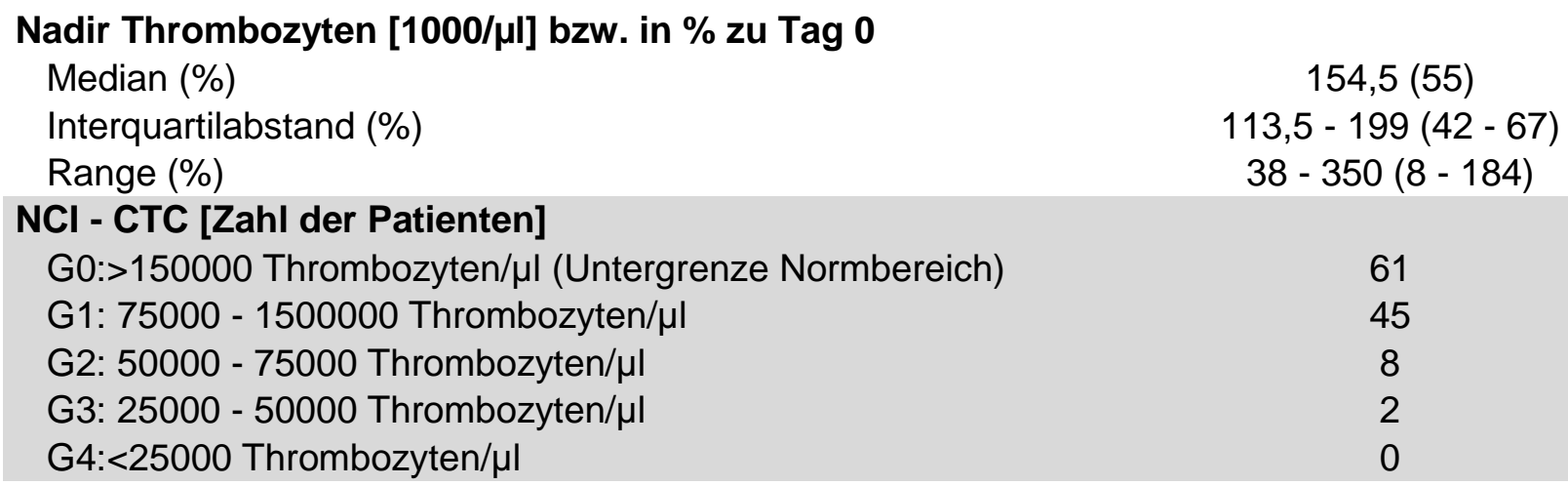

Zeit bis Nadir Thrombozyten [Tage]

Median

Interquartilabstand

$8-28,3$

Range

$2-43$

$\begin{array}{ll}\text { Gemcitabin-Intensität bei Thrombozytennadir [Zahl der Patienten] } & \\ <1000 \mathrm{mg} / \mathrm{m}^{2} \mathrm{KOF} & 37 \\ 1000-2000 \mathrm{mg} / \mathrm{m}^{2} \mathrm{KOF} & 64 \\ 2000-3000 \mathrm{mg} / \mathrm{m}^{2} \mathrm{KOF} & 16\end{array}$

Thrombozyten [Tsd./ $\mu \mathrm{l}]$ an Tag 0 der Gemcitabin-Therapie

Median

Interquartilabstand

Range

$102-705$

Thrombozyten [Tsd./ $\mu$ l] an Tag 7 der Gemcitabin-Therapie

Median

196

Interquartilabstand

$158-255,5$

Range

$42-708$

\% Thrombozyten Tag 7 zu Tag 0

Median

70,6

Interquartilabstand

$60,1-82,9$

Range

$31,6-197,8$

Tab. 17 Verlaufsdaten für Thrombozyten in den ersten 42 Tagen der Gemcitabin-Therapie. Die Darstellungsweise ist wie in Tab. 16 für Leukozyten beschrieben. 


\subsubsection{Variabilität in Ausprägung und Zeitdauer des Nadir-Eintritts}

Die Häufigkeitsverteilung der Nadire entsprechend der CTC-Skala und die Zeitdauer bis zu deren Eintreten ist für Leukozyten in Abb. 14 und für Thrombozyten in Abb. 15 veranschaulicht. Von 116 Patienten entwickelten 16 (14\%) eine schwere Leukozytopenie mit Grad 3 odere 4. Demgegenüber zeigten 48 (41\%) keine nennenswerte Leukozytotoxizität. Schwere Thrombozytopenien waren wesentlich seltener zu verzeichnen (2 Fälle). Für beide Zellreihen traten die Nadire bei etwa 2/3 der Patienten innerhalb der ersten 21 Tage auf (Median 14 Tage). Zwischen der Ausprägung des Nadirs (in absoluten Zahlen) und der Zeitdauer bis zu dessen Eintreten bestand keinerlei Korrelation, weder bei den Leukozyten noch bei den Thrombozyten (Spearman rho $=-0,07, P=0,5$ bzw. rho $=-0,14, P=0,2$ ).
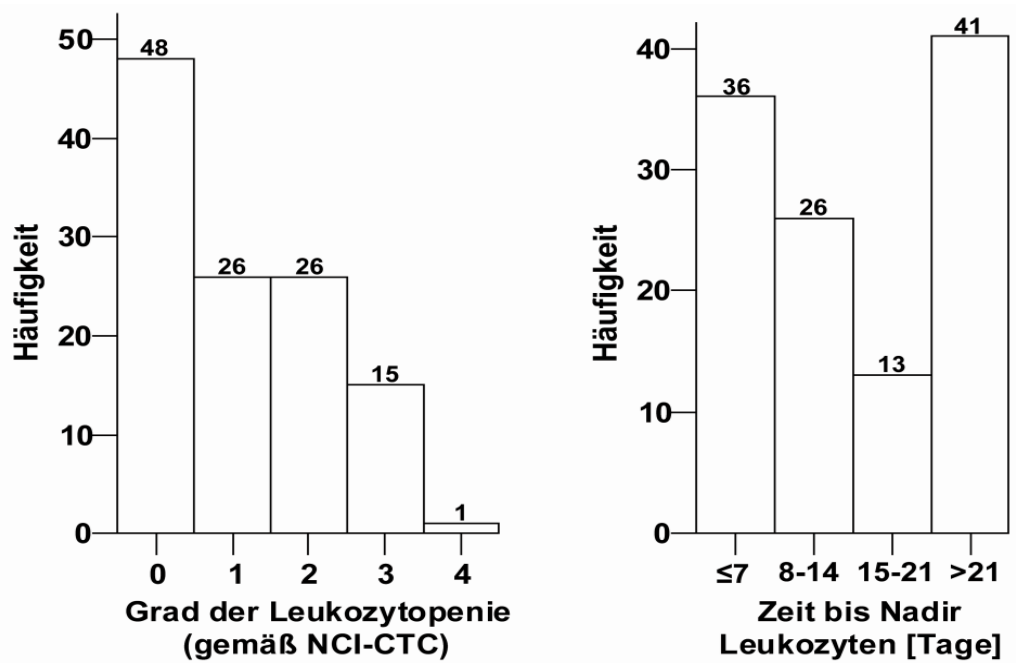

Abb. 14 Häufigkeitsverteilung des Leukozytopeniegrades und des Zeitintervalls bis Nadireintritt. Betrachtet wurden insgesamt 116 Patienten während der ersten 42 Tage einer Gemcitabin-Therapie. Die Gradeinteilung der Leukozytopenie wurde anhand der der Common Terminology Criteria for Adverse Events (CTC) des National Cancer Institute (NCI) vorgenommen. Grad 0 entspricht dem Normbereich und stellt keine Toxizität dar.
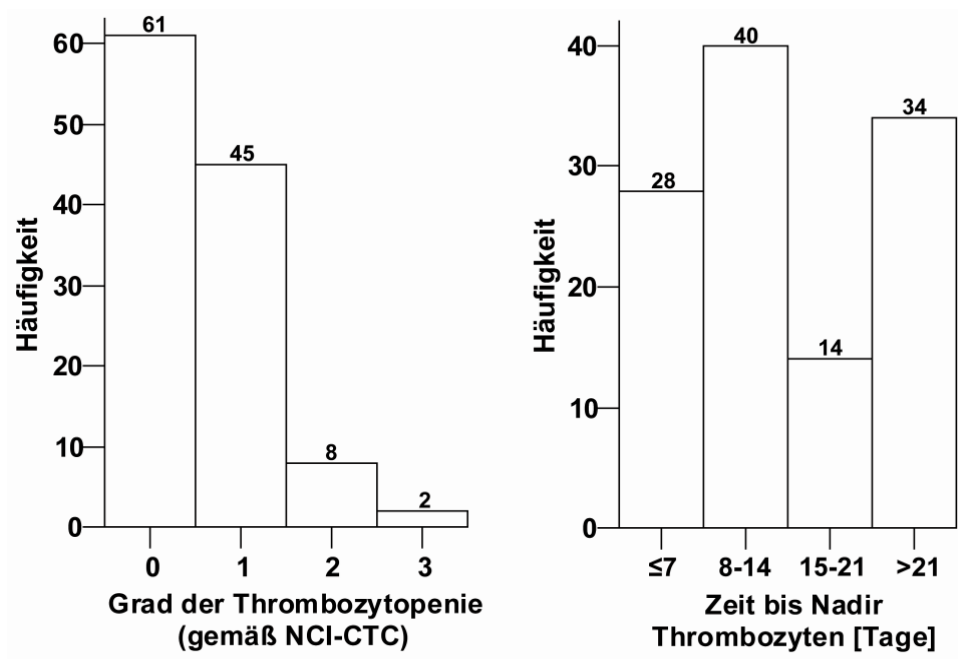

Abb. 15 Häufigkeitsverteilung des Thrombozytopeniegrades und des Zeitintervalls bis Nadireintritt. Darstellungsweise analog zu Abb. 14. 
Es ist denkbar, dass die Intensität der Gemcitabin-Therapie (im Median aller Patienten $2000 \mathrm{mg} / \mathrm{m}^{2} \mathrm{KOF}$ ) die Nadirwerte von Leukozyten und Thrombozyten beeinflusst. Dies wurde in einer nicht-parametrischen Korrelationsanalyse für die in einem Zeitraum von 21 Tagen vor Auftreten des Nadirs verabreichte kumulative Gemcitabin-Dosis geprüft. Ein Zusammenhang fand sich nur für die Zeit bis zum Eintreten des Leukozytennadirs (rho = 0,61, $P<0,001$ ), was jedoch nicht erstaunlich ist, da einem ,späteren“ Nadir in der Regel auch eine höhere Gemcitabin-Dosis voranging. Mit der Schwere des Nadirs war die Gemcitabin-Intensität dagegen überhaupt nicht korreliert, weder bei Leukozyten (rho $=-0,01, P=0,9$ ) noch bei Thrombozyten $($ rho $=0,01, P=0,9)$.

\subsubsection{Zytotoxizität nach singulärer Gemcitabin-Gabe}

Als weiterer Parameter zum Vergleich der Zytotoxizität bei den einzelnen Patienten wurden die Veränderungen der Hämatotoxizitätswerte über ein konstantes Zeitintervall betrachtet. Es wurden dafür die ersten sieben Tage gewählt, da zu Beginn der Therapie in der Regel noch keine Dosisanpassungen erfolgten und fast alle Patienten initial 1000 mg/m² KOF Gemcitabin erhielten. Außerdem werden bei allen angewandten Regimen unabhängig des GemcitabinTakts nach einer Woche routinemäßig Blutbilddaten vor der nächsten Gabe erhoben. Bezogen auf den prätherapeutischen Ausgangswert waren die Leukozyten nach sieben Tagen im Median auf 64,3\% und die Thrombozyten auf 70,6\% abgefallen. Für eine diesbezüglich auswertbare Subgruppe von 93 Patienten ist die Verteilung der absoluten Leukozyten- und Thrombozyten-Werte für Tag 0 und Tag 7 in Abb. 16 dargestellt.
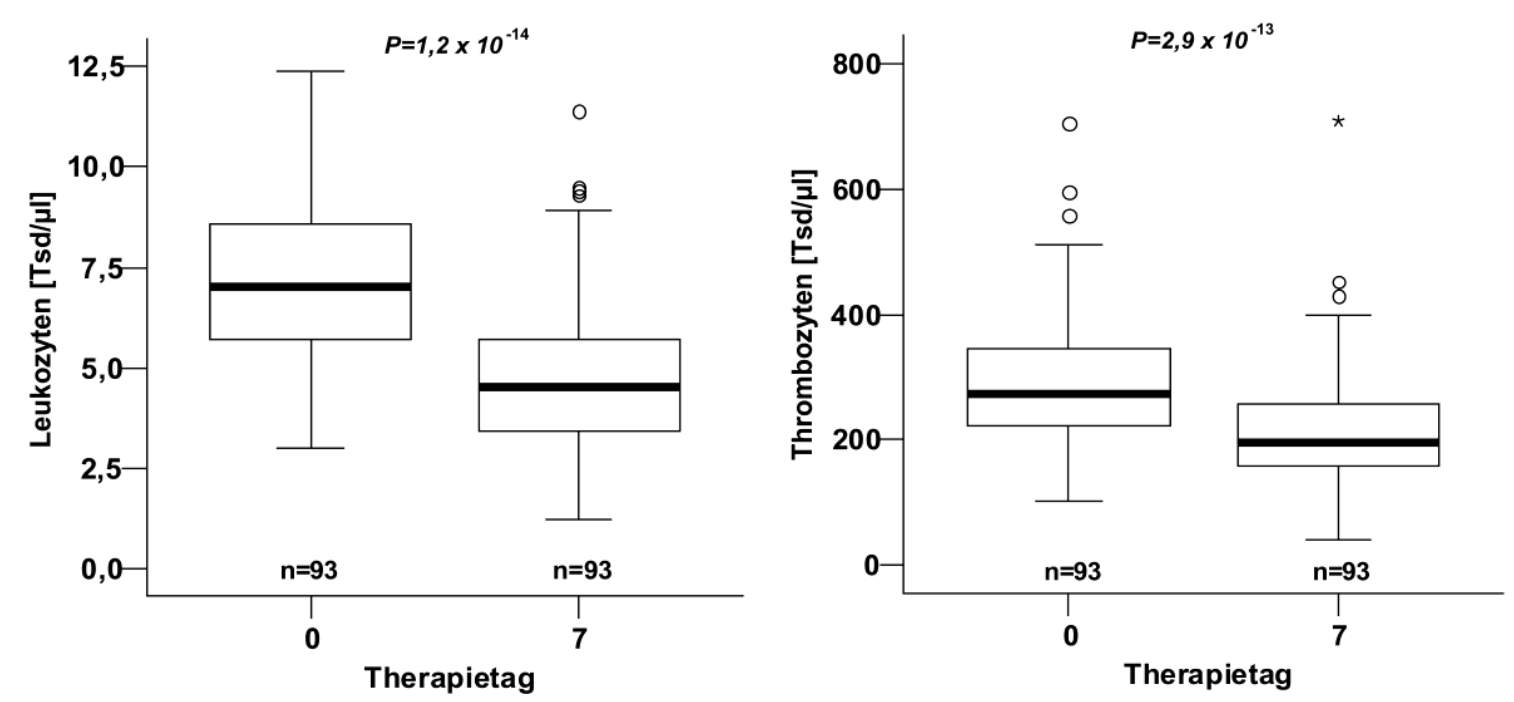

Abb. 16 Verlauf von Leukozyten (links) und Thrombozyten (rechts) innerhalb der ersten sieben Tage. Alle betrachteten 93 Patienten hatten, der prätherapeutischen Blutentnahme an Tag 0 folgend, eine einmalige Gabe von $1000 \mathrm{mg}$ Gemcitabin $/ \mathrm{m}^{2} \mathrm{KOF}$ erhalten. Die statistische Signifikanz der Veränderungen der Leukozyten- und Thrombozytenwerte zwischen den beiden Messpunkten wurde mit dem gepaarten Rangsummentest nach Wilcoxon geprüft und ist als $P$-Wert angegeben. 


\subsubsection{Einfluss von Varianten in Gemcitabin-Kandidatengenen auf Nadir sowie Zytotoxizität nach singulärer Gemcitabin-Gabe}

Denkbar ist, dass Polymorphismen in Kandidatengenen für die Wirksamkeit von Gemcitabin nicht nur den Erfolg, sondern auch die Nebenwirkungen einer Therapie beeinflussen können. Daher wurden 86 der 109 in Kapitel 4.3 gelisteten Genvarianten hinsichtlich möglicher Assoziationen zur Hämatotoxizität während einer Gemcitabin-Therapie überprüft. Keine Berücksichtigung fanden hier die 23 Varianten der Gene des Hedgehog-Signalwegs (PTCH1, $S H H$ und $S M O$ ), da die Bedeutung dieser Signalkaskade vor allem im Tumor-induzierten Bindegewebswachstum zu sehen ist. Als Phänotypen wurden - wie oben beschrieben (siehe Kapitel 4.5.2 und 4.5.3) - für Leukozyten und Thrombozyten die Zeitdauer (in Tagen) bis zum Nadir während der ersten 42 Tage der Gemcitabin-Therapie sowie die Veränderungen beider Blutzelllinien während der ersten sieben Therapietage analysiert. Insgesamt zeigten 14 Genvarianten einen Einfluss auf mindestens einen der genannten phänotypischen Parameter mit $P<0,05$. Eine Zusammenstellung dieser Ergebnisse ist in Tab. 18 aufgeführt. Unter Berücksichtigung multiplen Testens war jedoch keine dieser Assoziationen statistisch signifikant. Eine medizinische Bedeutung einer dieser Varianten wäre plausibler, wenn weitere Hinweise für eine Funktionalität vorlägen. Aus diesem Grund wurden hier zusätzlich die Effekte der 14 Polymorphismen auf die Überlebenszeit der Patienten betrachtet (siehe ebenfalls Tab. 18) und den Assoziationen mit Hämatotoxizitätsdaten gegenüber gestellt. In diesem Zusammenhang fand sich für den ENT1-SNP rs747199 eine konsistente Beeinflussung von Überleben und der Wirkung von Gemcitabin auf den Thrombozytenverlauf innerhalb der ersten sieben Therapietage. 


\begin{tabular}{llllc|cc}
\hline \multirow{2}{*}{ Gen } & SNP & $\begin{array}{l}\text { Parameter } \\
\text { klinischer Hämatotoxizität }\end{array}$ & $\boldsymbol{P}$ & $\begin{array}{l}\text { Gemcitabin } \\
\text { Sensitivität }\end{array}$ & \multicolumn{2}{c}{ Überleben } \\
\cline { 6 - 7 } & & & & Tendenz & $\begin{array}{c}\boldsymbol{P} \\
\text { (Log-rank) }\end{array}$ \\
\hline CDA & rs12404655 & Thrombozyten Therapietag 7 & 0,04 & $\uparrow$ & $\leftrightarrow$ & 0,5 \\
CMPK1 & rs12039726 & Zeit bis Nadir Leukozyten & 0,02 & $\uparrow$ & $\leftrightarrow$ & 0,2 \\
CMPK1 & rs35687416 & Leukozyten Therapietag 7 & 0,02 & $\uparrow$ & $\leftrightarrow$ & 1,0 \\
CMPK1 & rs6660321 & Zeit bis Nadir Leukozyten & 0,02 & $\uparrow$ & $\leftrightarrow$ & 0,2 \\
DCTD & rs1960207 & Thrombozyten Therapietag 7 & 0,02 & $\downarrow$ & $\leftrightarrow$ & 0,7 \\
& rs4073675 & Thrombozyten Therapietag 7 & 0,003 & $\downarrow$ & $\leftrightarrow$ & 0,7 \\
& & Zeit bis Nadir Leukozyten & 0,01 & $\downarrow$ & & \\
DCTD & rs7278 & Zeit bis Nadir Leukozyten & 0,01 & $\uparrow$ & $\downarrow$ & 0,003 \\
ENT1 & rs1128930 & Thrombozyten Therapietag 7 & 0,01 & $\uparrow$ & $\leftrightarrow$ & 0,6 \\
& rs747199 & Thrombozyten Therapietag 7 & 0,007 & $\uparrow$ & $\uparrow$ & 0,07 \\
& rs760370 & Thrombozyten Therapietag 7 & 0,01 & $\uparrow$ & $\leftrightarrow$ & 0,6 \\
NT5C3 & rs7795860 & Zeit bis Nadir Thrombozyten & 0,01 & $\downarrow$ & $\leftrightarrow$ & 0,9 \\
RRM1 & rs7932702 & Leukozyten Therapietag 7 & 0,02 & $\downarrow$ & $\leftrightarrow$ & 0,7 \\
& rs9937 & Leukozyten Therapietag 7 & 0,04 & $\uparrow$ & $\leftrightarrow$ & 0,6 \\
RRM2 & rs1138729 & Zeit bis Nadir Leukozyten & 0,02 & $\uparrow$ & & 0,09 \\
\hline
\end{tabular}

Tab. 18 SNPs mit Einfluss auf Hämatotoxizität. Klinische Parameter waren für Leukozyten sowie Thrombozyten die Zeit bis Eintritt des Nadir innerhalb der ersten 42 Tage der Gemcitabin-Therapie und die Veränderung der Zellzahlen von Tag 7 der Therapie bezogen auf Tag 0 (in \%). Assoziationen mit $P<0,05$ sind aufgelistet. Die Prüfung auf statistische Signifikanz erfolgte mit Mann-Whitney-U-Test (zwei Genotyp-Konfigurationen) bzw. Jonkheere-Terpstra-Test (drei Genotypen-Ausprägungen mit je mindestens fünf Patienten). Entsprechend der biochemischen Funktionsweise eines Gens wurden die Effekte des Variantenallels eines Polymorphismus hinsichtlich der Sensitivität auf Gemcitabin bewertet ( $\uparrow$ = gesteigerte,$\downarrow=$ reduzierte $\quad$ Empfindlichkeit). Zum Vergleich ist der Einfluss dieser Genpolymorphismen auf die Überlebenszeit gegenüber gestellt, wobei , $\uparrow “$ eine Verängerung, , $\downarrow$ “ eine Verkürzung und „↔ $\leftrightarrow$ " kein Effekt des Variantenallels bedeutet.

\subsubsection{Rs747199 beeinflusst gleichsinnig Überleben und Hämatotoxizität}

Historisch zunächst dem Promotorbereich zugerechnet (traditionelle Nomenklatur:-706G>C), wird rs747199 heute auf Intron 1 des ENT1-Gens, 7103 Basenpaare hinter dem Transkriptionsstart der längsten mRNA-Isoform, lokalisiert (siehe oben Abb. 11). Laut dbSNP-Datenbank besteht eine Häufigkeit des selteneren Allels von 16\% bei Kaukasiern. Die Überprüfung der Auswirkungen dieses SNPs auf die untersuchten Hämatotoxizitätsparameter zeigte eine Assoziation mit $P=0,007$ mit den Veränderungen der Thrombozytenzahlen innerhalb der ersten Therapiewoche. Für Patienten mit Variantenallel war an Tag sieben der Therapie bezogen auf den prätherapeutischen Wert eine verstärkte Thrombozytopenie zu verzeichnen (siehe Abb. 17, links). In Gegenwart des Variantenallels $C$ zeigte sich zudem eine Tendenz zu längerem Gesamtüberleben. Ein Kaplan-Meier-Plot in Abb. 17 rechts illustriert diese Beobachtung. 

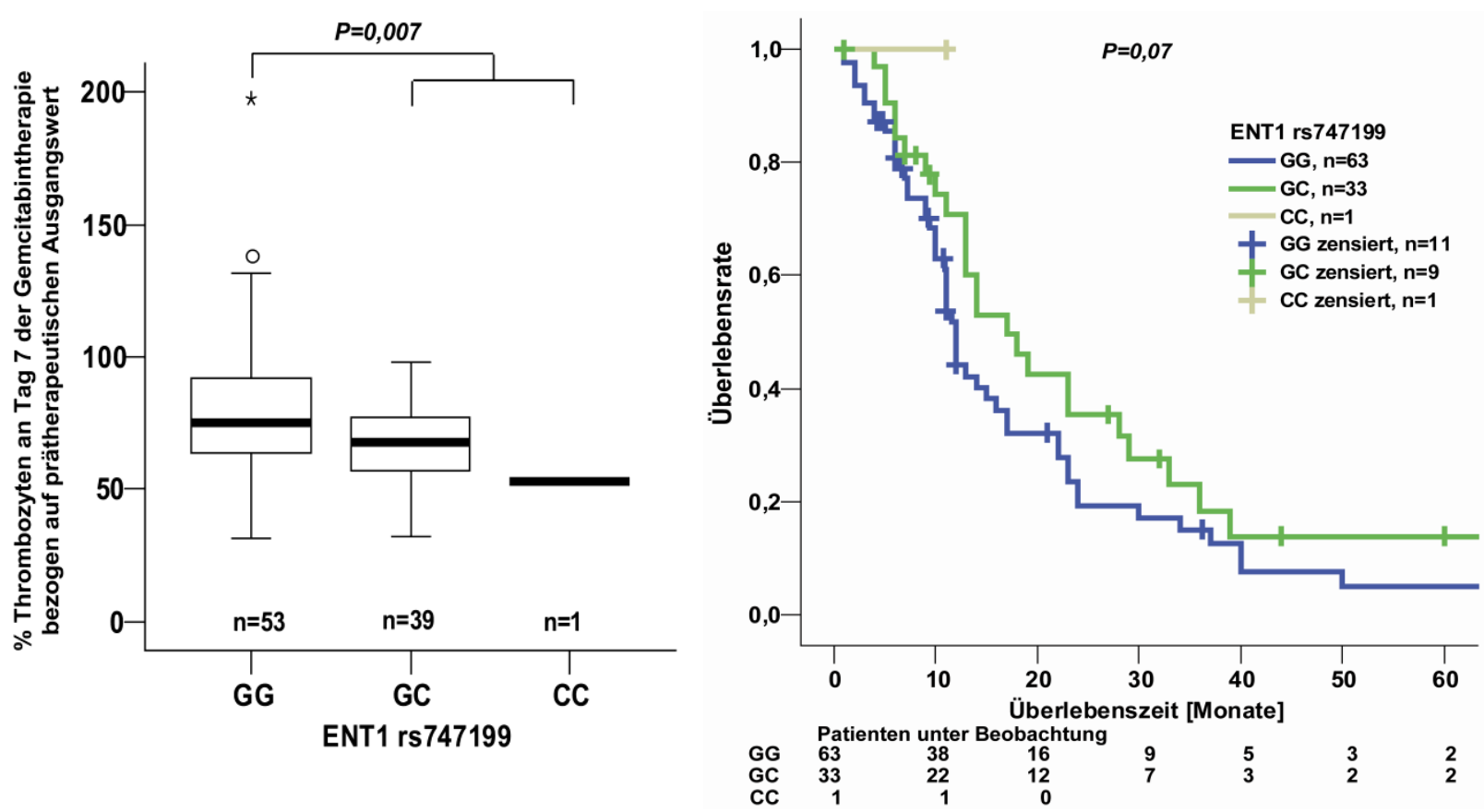

Abb. 17 Effekte von rs747199 auf Hämatotoxizität (links) und Gesamtüberleben (rechts). Links ist der Anteil Thrombozyten an Therapietag 7 bezogen auf Therapietag 0 in Abhängigkeit von rs747199 dargestellt. Die statistische Prüfung erfolgte hier mit dem Mann-Whitney-U-Test, wobei der heterozygote und homozygote Variantenallel-Status zusammengefasst wurden. Rechts ist der Einfluss dieser Genvariante auf das Gesamtüberleben veranschaulicht und mit Hilfe des Log-rank-Tests statistisch bewertet. 


\section{Diskussion}

Der Einfluss des Resektionsgrades und des histopathologischen Gradings auf die Überlebenszeit von Patienten mit Pankreaskarzinom ist bekannt. Als möglicher neuer Marker für das Überleben mit Gemcitabin therapierter Patienten konnte in meiner Arbeit eine Aminosäurevariante im Nukleosidtransporter ENT1 identifiziert werden. Diese (rs45573936) zeigte sich auch unter Berücksichtigung nicht-genetischer Faktoren und nach Korrektur auf multiples Testen statistisch signifikant mit dem Überleben verknüpft. Zwei weitere Varianten im Promotorbereich bzw. im Intron 1 des ENT1-Gens, rs1057985 bzw. rs747199, zeigten ebenfalls einen Bezug zum Gesamtüberleben. Letztgenannte war gleichzeitig auch mit dem Grad der Thrombozytotoxizität verbunden. Das Zeitintervall bis zum Auftreten des Nadirs für Thrombozyten bzw. Leukozyten stand in keinem Zusammenhang mit dessen Intensität. In den Genen DCTD, RRM2, PTCH1 und SHH konnten fünf weitere Genvarianten mit einer Beeinflussung der Überlebenszeit identifiziert werden. Unter Berücksichtigung multiplen Testens kann jedoch nur der Zusammenhang zwischen Überlebenszeit und der Aminosäurevariante rs45573936 als statistisch signifikant betrachtet werden. Nachfolgend werden diese Befunde - beginnend mit rs45573936 als stärkstem - diskutiert und mit der aktuellen Literaturlage in Beziehung gesetzt.

\subsection{ENT1-Aminosäurevariante lle216Thr (rs45573936)}

Die Aminosäurevariante rs45573936 des ENT1-Gens zeigte einen starken Effekt auf die Gesamtüberlebenszeit der untersuchten Patienten mit Pankreaskarzinom. Heterozygote Patienten verstarben deutlich früher als Patienten mit Homozygotie für den Wildtyp. Homozygote Träger des Variantenallels wurden nicht beobachtet. Auch nach Adjustierung auf nicht-genetische Faktoren sowie auf multiples Testen erwies sich die Assoziation als statistisch signifikant. Die Thr216-Variante dieses biallelischen Polymorphismus findet sich in der deutschen Bevölkerung mit einer Frequenz von etwa 2,5\%.

Der ENT1-Transporter enthält elf transmembranäre Domänen (Sundaram et al. 2001). In der sechsten dieser Domänen befindet sich der Aminosäureaustausch Ile216Thr (siehe Abb. 18). Klare Beweise für die Funktionalität der Variante liegen noch nicht vor. In der Literatur existieren hierzu bislang nur zwei Arbeiten. In Thr216-überexprimierenden Hefezellen wurde die kompetitive Hemmung des $\left[{ }^{3} \mathrm{H}\right]$-Inosin-Transports durch die Nukleosid-Analoga Gemcitabin, Cytarabin und Ribavirin analysiert (Osato et al. 2003). Es konnte dabei für keines der drei Medikamente eine relevante Modifikation des Transports durch das Thr216-Allel nachgewiesen werden. Diese Messungen wurden über einen Zeitraum von 20 min 
durchgeführt. Dabei wurde der einwärts gerichtete Transport, jedoch kaum derjenige in die Gegenrichtung erfasst. Es ist durchaus denkbar, dass sich Thr216 bei einem von intra- nach extrazellulär gerichteten Gradienten auswirkt. Weiterhin ist in Bezug auf die zitierte Arbeit anzumerken, dass Gemcitabin und die beiden anderen Nukleosid-Analoga (da nicht radioaktiv markiert) lediglich als Inhibitoren des Transports von $\left[{ }^{3} \mathrm{H}\right]$-Inosin, nicht jedoch als direkte Substrate des ENT1 gemessen wurden. Diese Unterscheidung sollte gleichwohl nicht außer Acht gelassen werden. Dass Thr216 tatsächlich die Aufnahme von Nukleosiden modulieren kann, wurde kürzlich in einer Studie für Adenosin gezeigt (Kim et al. 2011).

$$
\text { extrazellulär }
$$

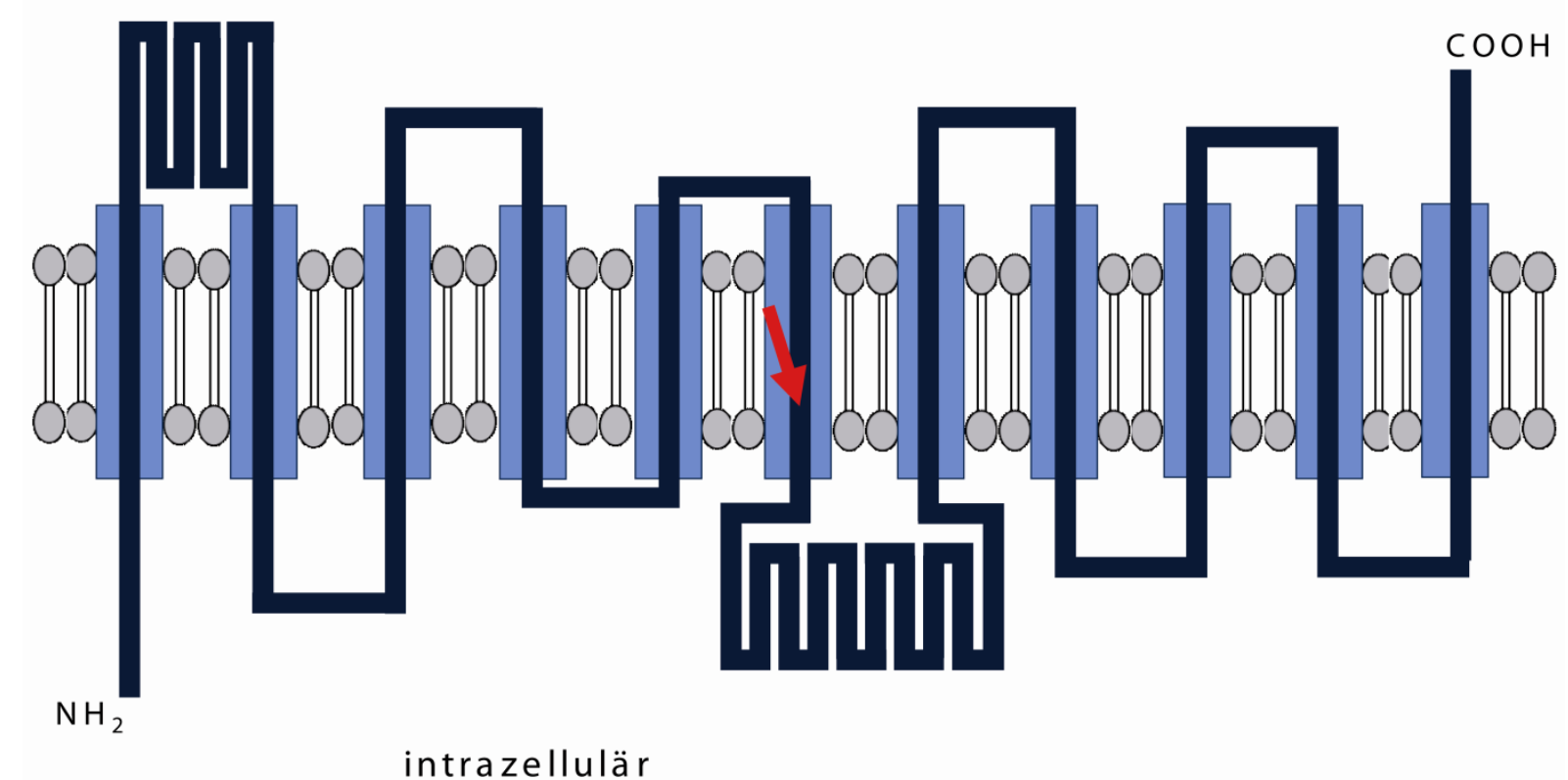

Abb. 18 Sekundärstruktur des ENT1-Transporters. Der rote Pfeil zeigt die Lokalisation von Ile216Thr an.

Einen weiteren Hinweis auf eine Funktionalität dieser Variante erbrachte eine frühere Studie der Abteilung Klinische Pharmakologie (Kuschel 2011). Dabei fand sich in vitro eine nahezu komplette Resistenz auf Gemcitabin in Gegenwart von Thr216 (siehe Abb. 19). Leukozyten wurden $6 \mathrm{~h}$ mit Gemcitabin inkubiert, danach das Zytostatikum durch gründliches Waschen entfernt und nach weiteren $42 \mathrm{~h}$ die Apoptoserate in Bezug auf eine unbehandelte Kontrolle durchflusszytometrisch gemessen. Somit scheint es sich hier im Wesentlichen um eine Wirkung auf den Efflux von Gemcitabin zu handeln, der bei der homogeneren Zellpopulation der T-Lymphozyten besonders zu Tage trat. In Parallelansätzen, die während der gesamten Inkubationszeit von $48 \mathrm{~h}$ Gemcitabin exponiert waren, war dies so nicht zu sehen. Diese Beobachtung zusammen mit der Tatsache, dass der starke Effekt bereits im heterozygoten Zustand von Ile216Thr bewirkt wurde, lässt die Hypothese zu, dass es sich bei Thr216 um ein 
gain-of-function-Allel handeln könnte. Möglicherweise beruht dies auf einer Phosphorylierung des Thr-Restes. In einem weiteren Schritt sollte zunächst untersucht werden, ob dies in Anbetracht der Lokalisation dieser Aminosäure in der ENT1-Proteinkette prinzipiell denkbar ist. Ausgeschlossen hingegen wurde bereits ein Einfluss von rs45573936 auf die Transkription und Translation des ENT1-Gens (Kim et al. 2011). Demzufolge werden bei Heterozygotie das Ile- und das Thr-Allel gleichberechtigt exprimiert, was ein weiterer Grund für die Annahme ist, dass ein Thr-bedingter Effekt mutmaßlich hyperfunktionell ist.
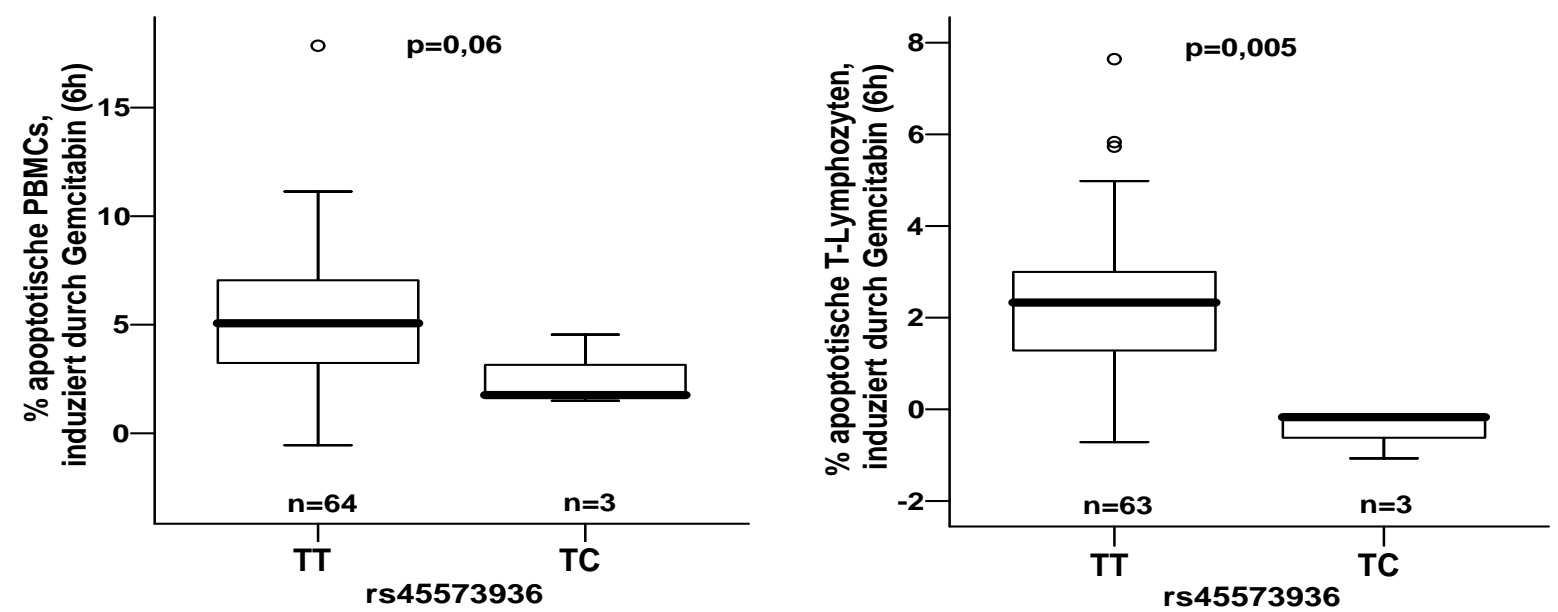

\begin{abstract}
Abb. 19 Gemcitabin-Toxizität in Abhängigkeit von rs45573936 (Ile216Thr). Die Abbildung ist einer Vorarbeit der Abteilung Klinische Pharmakologie (Kuschel 2011) entnommen. Aus venösem Blut von 67 gesunden Spendern wurden PBMCs (Peripheral Blood Mononuclear Cells) isoliert, über $6 \mathrm{~h}$ bei $37^{\circ} \mathrm{C}$ mit $10 \mu \mathrm{g} / \mathrm{ml}$ Gemcitabin behandelt und danach so gewaschen, dass Gemcitabin im Kulturmedium um mindestens Faktor 1000 verdünnt wurde. Nach $42 \mathrm{~h}$ Weiterkultivierung bei $37^{\circ} \mathrm{C}$ (insgesamt 48 seit Beginn der Gemcitabin-Zugabe) erfolgte die Bestimmung der Apoptoserate mittels Durchflusszytometrie. Es wurde jeweils eine Probe ohne jegliche Gemcitabin-Behandlung als Kontrolle mitgeführt. Dargestellt sind die Effekte von rs45573936 auf die mit Gemcitabin exponierten Proben in Relation zur jeweiligen Kontrolle, und zwar für die Gesamtpopulation der PBMCs (links) sowie für die mit einem spezifischen Antikörper markierte Subpopulation der T-Lymphozyten (rechts). Die statistische Testung erfolgte mit dem Mann-Whitney-U-Test.
\end{abstract}

\title{
5.2 Varianten in Promotorregion und Intron 1 von ENT1
}

Zwei weitere Varianten im ENT1 hatten einen günstigen Einfluss auf das Gesamtüberleben, wenngleich diese Befunde unter Berücksichtigung multiplen Testens zum jetzigen Zeitpunkt nicht als statistisch signifikant bezeichnet werden können.

Zum Polymorphismus rs1057985 ist in der Literatur noch nichts bekannt. Auf Grund seiner Lokalisation (siehe oben Abb. 11) sind Allel-spezifische Effekte auf die Transkription vorstellbar. Möglicherweise werden die beiden längeren Transkripte nur in Gegenwart eines Allels gebildet (mutmaßlich desjenigen mit einem effizienteren Transport von Gemcitabin und einem somit besseren Ansprechen). Für diese Überlegungen sprechen Daten aus einer 
früheren Arbeit der Abteilung Klinische Pharmakologie (Preuß 2009). Dort waren, bezogen auf Genvarianten, Expressionsanalysen an isolierten PBMCs gesunder Probanden durchgeführt worden (siehe Abb. 20). Im Basalzustand ohne weitere Medikamentenzugabe lagen in Anwesenheit des Variantenallels deutlich höhere Transkriptkonzentrationen vor. Bei homozygotem Vorkommen des Variantenallels zeigte sich nahezu einer Verdopplung der ENT1-Transkripte.
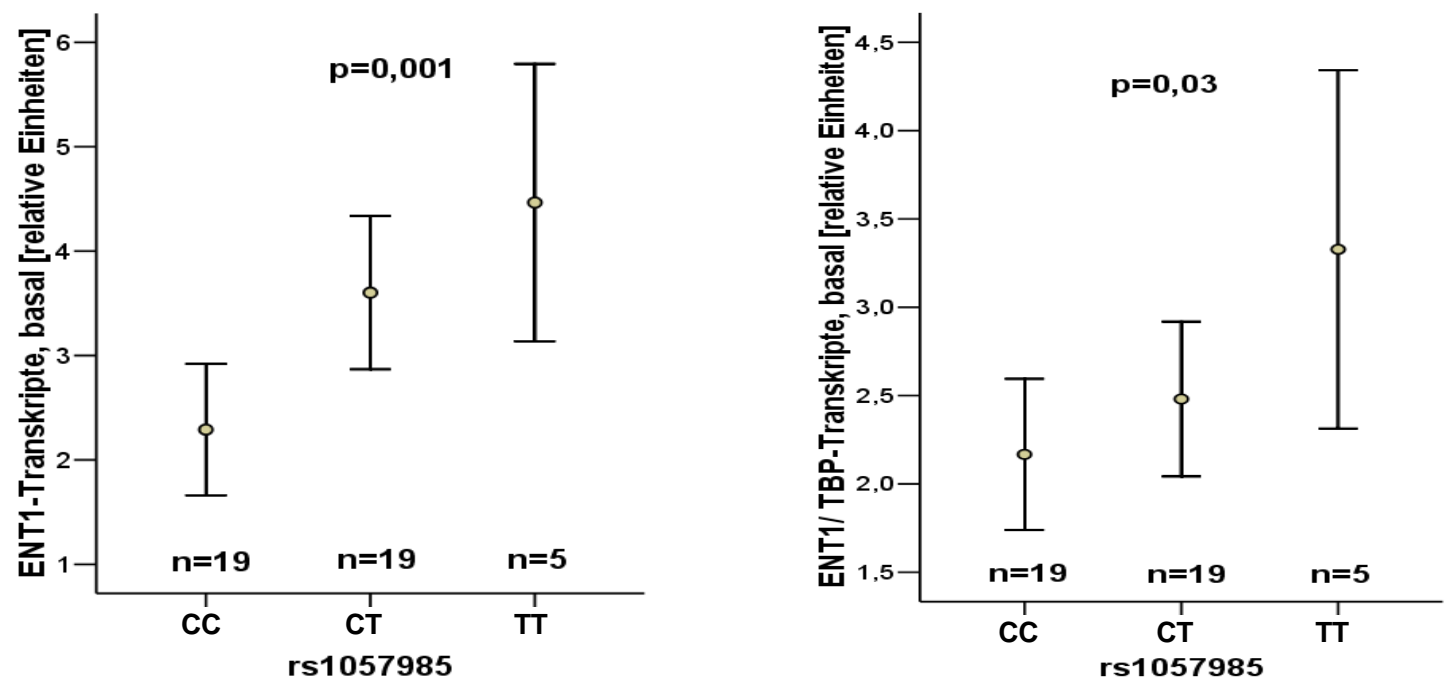

Abb. 20 Einfluss des Promotor-SNPs rs1057985 auf die basale ENT1-Transkription. Die Abbildung ist einer früheren Dissertation der Abteilung Klinische Pharmakologie entnommen (Preuß 2009). Dort war mittels quantitativer Real time-PCR die basale Transkription des ENT1-Gens 6 h nach Gewinnung von PBMCs aus venösem Blut gesunder Spender analysiert worden. Links ist für jede der drei GenotypKonfigurationen der Mittelwert ( \pm SEM, standard error of the mean) der gemessenen ENT1-Transkripte dargestellt, rechts mit Bezug auf TBP (tata box-binding protein) als Referenzgen. Die angegebenen $P$ Werte wurden mittels linearer Regression ermittelt.

Der zweite ENT1-Polymorphismus, dessen Variantenallel das Überleben in der von mir untersuchten Patientenkohorte günstig beeinflusste, ist rs747199. Diese Variante war vor Entdeckung der längeren Transkriptformen dem Promotor des ENT1-Gens zugeordnet worden (traditionelle Nomenklatur:-706G>C), wird aber heute als Intron 1-Variante geführt. Neben einer tendenziell günstigeren Prognose ging das Variantenallel auch mit einem verstärkten Abfall der Thrombozyten während der ersten sieben Therapietage mit Gemcitabin einher. Dies lässt vermuten, dass es sich hierbei um ein den ENT1-vermittelten Transport steigerndes Allel handelt. Zu dieser Auffassung gelangten auch die Autoren einer Studie, welche basierend auf bioinformatischen Analysen zu Transkriptionsfaktor-Bindestellen Konstrukte mit Genvarianten im 5'-Bereich des ENT1 herstellten und damit Reportergenanalysen durchführten. Eine Kombination dreier Genvarianten mit dem Variantenallel von rs747199 ging in diesen Untersuchungen mit einer erhöhten Transkriptrate einher (Myers et al. 2006). 


\subsection{Weltweite Verteilung der ENT1-Varianten}

Auf Basis genomweiter Daten des „1000 humane genome-Projekts“ (http://www.1000genomes.org/) können Häufigkeiten einzelner Genvarianten zwischen unterschiedlichen Ethnizitäten verglichen werden. Für die ENT1-SNPs rs1057985, rs747199 und rs45573936 ist dies in Tab. 19 aufgelistet.

Dabei fällt auf, dass die in meiner Studie so stark mit dem Sterberisiko bei Pankreaskarzinom unter Gemcitabin-Therapie verbundene Genvariante rs45573936 (Ile216Thr) weltweit selten ist, am häufigsten jedoch bei Kaukasiern mit einer Frequenz von 1,9\% für das Thr216-Allel auftritt. Bei gesunden in Göttingen rekrutierten Probanden deutscher Abstammung belief sich dieses Vorkommen sogar auf 2,6\% und war damit ähnlich häufig wie bei der Subpopulation von Briten innerhalb der Kaukasier (2,8\%). Bei Finnen und Italienern (Toskana) kommt diese Variante mit etwa $1,5 \%$ vor. Noch seltener ist sie bei Afrikanern $(0,6 \%)$ und in Lateinamerika $(0,3 \%)$. Gar nicht vorhanden scheint sie bei Asiaten (Chinesen und Japaner) zu sein.

Auch bei den anderen beiden betrachteten ENTI-Varianten waren deutliche Unterschiede zwischen den ethnischen Gruppen festzustellen. Das Allel von rs1058985, welches in meiner Studie eine bessere Prognose unter der durchgeführten Therapie bedingte, kommt am häufigsten bei Asiaten, am seltensten bei Afrikanern vor. Auch das Variantenallel von SNP rs747199 scheint meinen Daten zufolge mit einer tendenziell längeren Überlebenszeit einherzugehen und ein Bezug zu einer stärkeren ENT1-Transkription wurde beschrieben (Myers et al. 2006, siehe oben in Abschnitt 5.2). Dieses Allel ist bei Afrikanern sehr selten, während es bei den anderen Bevölkerungsgruppen eine gleichmäßige Verteilung von etwa $20 \%$ hat. Sollte sich die Assoziationen für diese Genvarianten in weiteren klinischen Studien bestätigen, könnten die ethnisch bedingten Disparitäten eine therapeutische Relevanz haben. Asiaten scheinen für die Prognose eines Gemcitabin-therapierten Pankreaskarzinoms die günstigste genetische Konstellation in Bezug auf ENT1-Genpolymorphismen zu haben. 


\begin{tabular}{lcccc}
\hline Population & $\begin{array}{c}\text { Anzahl } \\
\text { Personen }\end{array}$ & $\begin{array}{c}\text { rs1057985 } \\
\text { C>T (T in \%) }\end{array}$ & $\begin{array}{c}\text { rs747199 } \\
\text { G>C (C in \%) }\end{array}$ & $\begin{array}{c}\text { rs45573936 } \\
\text { Ile216Thr } \\
\text { T>C (C in \%) }\end{array}$ \\
\hline Afrikaner & 246 & 26,0 & 0,8 & 0,6 \\
Asiaten & 288 & 54,3 & 22,6 & 0,0 \\
Kaukasier & 434 & 37,0 & 21,1 & 1,9 \\
Lateinamerikaner & 179 & 46,9 & 20,4 & 0,3 \\
\hline
\end{tabular}

Tab. 19 Häufigkeit der ENTI-Varianten rs1057985, rs747199 und rs45573936 bezogen auf Ethnizitäten. Die Angaben basieren auf Daten des 1000 human genome-Projekts (http://www.1000genomes.org/) und beziehen sich stets auf das in dieser Arbeit als ,seltener auftretend“ identifizierte Allel, dessen Vorkommen in \% angegeben ist. Unter „Afrikaner“ wurden Afroamerikaner der amerikanischen Südstaaten, Yoruba aus Nigeria und Luhya aus Kenia zusammengefasst. Als „Asiaten“ zählten die Gruppen der Chinesen (Peking und Südchina) und Japaner. Unter „Kaukasier“ wurden Amerikaner europäischer Abstammung, Briten, Iberer, Toskaner, Finnen und Deutsche subsumiert. Letztere entsprechen 153 Probanden aus Vorstudien der Abteilung Klinische Pharmakologie der Universitätsmedizin Göttingen (Preuß 2009 und Kuschel 2011). Die Gruppe der Lateinamerikaner umfasste Kolumbianer, Puertoricaner und Mexikaner.

\subsection{Weitere Genvarianten als mögliche Biomarker für Therapieansprechen}

Außerhalb des ENT1-Gens zeigten noch einige weitere Varianten einen Einfluss auf die Überlebenszeit unter Gemcitabin bei Pankreaskarzinom. Es werden hier nur diejenigen kurz diskutiert, die auch nach Adjustierung auf die nicht-genetischen Faktoren Alter, Geschlecht, Resektionsstatus (R0 versus R1) und Grading eine Assoziation von $P<0,05$ aufwiesen. Unter Berücksichtigung multiplen Testens zeigte sich jedoch keine statistische Signifikanz $(P>0,05$ unter Anwendung der False Discovery Rate). Für die Varianten DCTD rs7278, RRM2 rs4668664 und RRM2 rs1130609 ist in der Literatur funktionell noch nichts beschrieben. Rs7278 befindet sich in der 3'-UTR von DCTD und könnte die Transkriptstabilität (z.B. durch differenzielle Bindung von microRNAs) modulieren. Dies könnte weiter untersucht werden, indem man die RNA-Neusynthese mit Actinomycin D hemmt und somit die biologische Halbwertszeit der DCTD-Transkripte in Abhängigkeit von rs7278 bestimmt. Die beiden genannten RRM2-SNPs stehen in starkem genetischen Kopplungsungleichgewicht $\left(\mathrm{r}^{2}=0,72\right)$ und sind somit nicht als unabhängig voneinander zu betrachten. Rs1130609 liegt in Exon 1, repräsentiert den Aminosäureaustausch Ser59Ala und könnte somit die Proteinfunktion verändern.

Für die PTCH1-Variante rs2236407 zeichnete sich ab, dass Träger des Variantenallels tendenziell früher verstarben als solche mit Homozygotie für das Wildtyp-Allel. Dieser Polymorphismus wurde im Zusammenhang mit dem Risiko der Entwicklung von LippenKiefer-Gaumenspalten bei menschlichen Neugeborenen beschrieben (Letra et al. 2010). Der SNP befindet sich auf Intron 12 des PTCHI-Gens (Chromosom 9). Auswirkungen des 
Hedgehog-Signalwegs auf das Therapieansprechen von Patienten mit Pankreaskarzinom sind bereits bekannt (Olive et al. 2009): Im Mausmodell führte eine Hemmung dieses Signalwegs zu einer erhöhten Sensitivität von Pankreaskarzinomen auf Gemcitabin. Inwiefern rs2236407 als Genvariante die Expression und/oder Aktivität dieses Signalwegs beeinflusst, bedarf detaillierter funktioneller Untersuchungen. Zuvor sollte aber die in meinen Daten beobachtete klinische Assoziation in einer weiteren Studie mit vergleichbaren Bedingungen bestätigt werden.

Ein weiterer Polymorphismus des Hedgehog-Signalwegs mit Assoziation zum Gesamtüberleben war rs288746 des SHH-Gens (Chromosom 7). Rs288746 wird dem Promotorbereich des Gens zugerechnet. Patienten mit heterozygoter Allelausprägung besaßen verglichen mit Trägern des Wildtyps ein erhöhtes Risiko unter Gemcitabin-Therapie zu versterben (Homozygotie für die Variante lag nur in einem Fall vor). Basierend auf genomweiten Analysen wurde eine Bedeutung von SHH-SNPs, einschließlich rs288746 für das Risiko der Entwicklung eines Pankreaskarzinoms postuliert (Amundadottir et al. 2009). Diese Publikation beinhaltete eine schnelle Replikationsstudie, in der sich die initial beobachtete Assoziation zu einem höheren Erkrankungsrisiko für Träger des Variantenallels von rs288746 nicht bestätigte. In Anbetracht der Lokalisation dieses SNPs im Promotorbereich des $\mathrm{SH} H$-Gens wäre am ehesten ein Einfluss auf die Transkription plausibel. Dies könnte z.B. durch Reportergenuntersuchungen mit entsprechenden Allel-spezifischen Konstrukten überprüft werden.

\subsection{Determinanten der Hämatotoxizität unter Gemcitabin}

Eine Abnahme um mehr als 20\% gegenüber dem Ausgangswert fand sich während der ersten 42 Therapietage mit Gemcitabin bei 92 (von 104) bzw. bei 97 (107) Patienten hinsichtlich der Leukozyten bzw. Thrombozyten. Ein Zusammenhang zwischen dem Ausmaß der Hämatotoxizität und der Zeit bis zu deren Eintreten konnte nicht ausgemacht werden. Ebenso wenig war eine Korrelation zwischen dem Nadir für Leukozyten bzw. Thrombozyten und der während 21 Tage unmittelbar zuvor verabreichten Gemcitabindosis zu erkennen. Umso wichtiger erscheinen Biomarker, mit denen sich schwere Blutbildveränderungen im Therapieverlauf vorhersagen lassen. Solche Marker könnten nicht nur schwere Nebenwirkungen vermeiden helfen, sondern auch bei Patienten mit geringer Sensitivität eine Dosiseskalation erlauben. Von den analysierten 86 genetischen Markern in potenziellen Kandidatengenen für die Hämatotoxizität von Gemcitabin (ENT1-Transporter, metabolisierende und katabolisierende Enzyme) zeigten sich für 14 SNPs tendenzielle 
Assoziationen mit den in-vivo-Parametern für Leuko- und Thrombozytotoxizität. Unter Anwendung der Kriterien für multiples Testen waren diese Befunde jedoch nicht belastbar und bedürfen weiterer Überprüfung.

Weiterhin konnten für die Hypothese, dass im Rahmen einer Zytostatikatherapie häufig diejenigen Patienten profitieren, die besonders schwere Nebenwirkungen erfahren, in meiner Studie keine Belege gefunden werden. Auch bei den nominal signifikanten Assoziationen fanden sich - mit Ausnahme von rs747199 - keine Genvarianten, welche im Hinblick auf eine postulierte Modulation der Gemcitabinempfindlichkeit in gleicher Weise mit Überlebenszeit und Hämatotoxizität verbunden waren. Daher kann vermutet werden, dass Therapieansprechen und Nebenwirkungen einer Gemcitabin-Therapie durch unterschiedliche Biomarker beeinflusst werden.

\subsection{Kritische Betrachtung}

Für den wesentlichen Befund meiner Arbeit, der Identifizierung von Ile216Thr als möglichen Biomarker für die Prognose eines mit Gemcitabin behandelten Pankreaskarzinoms, ist eine Beziehung zu Gemcitabin auf Grund der Lokalisation dieser Genvariante im NukleosidTransporter ENT1 naheliegend. Eine Aussage darüber, ob der beobachtete klinische Effekt tatsächlich in ursächlichem Zusammenhang mit Gemcitabin steht, kann endgültig jedoch nicht getroffen werden. Denkbar wäre eine Beeinflussung des natürlichen Verlaufs der Erkrankung durch diese Genvariante, da für diese Arbeit keine Vergleichsgruppe ohne GemcitabinBehandlung (d.h. mit Placebo) zur Verfügung stand. Eine Studie mit Placebo muss aus ethischen Gründen ausgeschlossen werden. Ohnehin erscheint die Frage, ob der Effekt dieser Aminosäurevariante in direkter Beziehung zu Gemcitabin steht, eher theoretischer Natur, da Gemcitabin als Standardtherapie bei Pankreaskarzinom etabliert ist. Neuere Strategien sind typischerweise Add-on-Therapien, d.h. es wird der Zusatz weiterer Substanzen, zumeist Tyrosinkinase-Inhibitoren, zu Gemcitabin erprobt. Für einen direkten Zusammenhang mit Gemcitabin sprechen die ex-vivo-Daten einer praktisch kompletten Resistenz von Leukozyten auf dieses Medikament in Gegenwart von Thr216 (Kuschel 2011).

Kritisch zu sehen ist insbesondere, dass der beobachtete Effekt von Thr216 letztlich auf nur fünf Patienten beruht. Dies ist aber der niedrigen Allelfrequenz geschuldet. Angemerkt sei hier noch, dass auch in der initial betrachteten Kohorte von 142 Patienten insgesamt elf das Thr216-Allel aufwiesen und auch hier ein deutlicher Effekt auf das Gesamtüberleben erkennbar war. Eine grundsätzliche Schwierigkeit bei klinischen Assoziationsstudien besteht in der Erfordernis eines möglichst homogenen Patientenkollektivs. Aus dem Patientenpool 
von 552 Patienten, die wegen des Verdachts auf einen malignen Pankreasprozesses zwischen 2003 und 2010 am Uniklinikum Göttingen behandelt wurden, kam der Großteil für meine Analysen letztlich nicht in Frage. Festzuhalten bleibt, dass trotz der geringen Fallzahl die Assoziation dieser Genvariante so stark war, dass die statistische Signifikanz auch nach Adjustierung auf multiples Testen Bestand hatte.

In letztgenannter Hinsicht mussten Assoziationen sechs weiterer Genvarianten, die nach Korrektur auf nicht-genetische Faktoren eine nominale Signifikanz mit $P<0,05$ zeigten, kritisch bewertet werden. Hierzu bedarf es zunächst einer klinischen Bestätigung, um die medizinische Relevanz besser einschätzen zu können und ggf. dann weitergehende molekularbiologische Untersuchungen anzustrengen.

\subsection{Ausblick}

Auf Grund der starken klinischen (auch nach Korrektur auf multiples Testen) sowie der funktionellen Assoziation von Ile216Thr (in Leukozyten) sollten nun weiterführende Analysen klären, ob sich diese Genvariante tatsächlich auf die Gemcitabin-Empfindlichkeit auswirkt. Um einen eindeutigen Beweis für die Funktionalität von Ile216Thr zu führen, müssen Allel-spezifische Konstrukte, eines mit Ile216 und eines mit Thr216, bei ansonsten identischem genetischem Hintergrund hergestellt werden. Nach Transfektion dieser Konstrukte in Modellzellen könnten vergleichende Toxizitätsversuche durchgeführt werden. Weiterhin wären Prüfungen der Transporterfunktion in Abhängigkeit der Allelkonfiguration denkbar. Wegen der Hypothese eines Effekts auf den Efflux von ENT1 könnten die Zellen mit radioaktiv-markiertem Gemcitabin inkubiert, gewaschen, in Gemcitabin-freiem Medium weiterkultiviert und die intrazelluläre Konzentration des Pharmakons für Ile216 mit Thr216 verglichen werden. Entscheidend im Hinblick auf eine mögliche klinische Anwendung wäre die Initiierung einer prospektiven Studie zu Ile216Thr als biologischem Marker. Hierbei müssten Patienten mit Pankreaskarzinom, die sich für eine Gemcitabin-Therapie entscheiden, prätherapeutisch genotypisiert werden. Die Gesamtüberlebenszeit und das progressionsfreie Überleben könnten Studienendpunkte im Sinne des Therapieansprechens sein. In Deutschland findet sich das seltenere Allel Thr216 mit einer Frequenz von 2,5\%. Dies lässt von 5\% heterozygoten Allelträgern ausgehen. Bei 13000 neuerkrankten Patienten mit Pankreaskarzinom pro Jahr in Deutschland entspricht das etwa 650 Personen. Variantenbedingt hätten diese Patienten per se keinen Benefit von einer Gemcitabin-Chemotherapie zu erwarten. Ihnen könnte stattdessen eine alternative Therapie angeboten werden. Wichtig wäre weiterhin zu überprüfen, ob Thr216 auch die Wirksamkeit von Gemcitabin bei anderen 
Tumorentitäten beeinflusst. Zunächst könnten Patientenkohorten mit nicht-kleinzelligem Bronchialkarzinom oder Mammakarzinom retrospektiv dahingehend analysiert werden.

Die Befunde für die anderen Genvarianten mit nominal signifikantem Bezug zum Gesamtüberleben sind im Rahmen dieser Arbeit als explorativ einzuordnen. Für diese Varianten ist eine gezielte Replikation der Befunde an einem vergleichbaren Patientensatz erforderlich. Im positiven Falle wären auch dann weitergehende funktionelle Charakterisierungen anzustellen.

Darüber hinaus liefern die aufwändig erhobenen Nachsorgedaten eine hervorragende Basis zur Prüfung einer Assoziation mit weiteren Genvarianten. Solche Kandidaten könnten z.B. aus Experimenten mit Genom-weit sequenzierten Zellen gewonnen werden, in welchen die Empfindlichkeit auf Gemcitabin bestimmt wird. 


\section{Zusammenfassung}

Jährlich erkranken etwa 13000 Personen in Deutschland an einem Pankreaskarzinom. Therapiestandard ist die Resektion des Tumors und die Gemcitabin-basierte Chemotherapie in adjuvanter und palliativer Intention. Auch unter adäquater Therapie zählt das Pankreaskarzinom mit einer durchschnittlichen Überlebenszeit von weniger als einem Jahr zu den Tumorentitäten mit der schlechtesten Prognose überhaupt. Einige Patienten leben jedoch verhältnismäßig lange, ohne dass man die Gründe dafür kennt. Unter anderem wird ein Einfluss genetischer Varianten vermutet, insbesondere in Genen, welche für die Wirksamkeit von Gemcitabin wichtig sind. Dabei handelt es sich üblicherweise nicht um somatische Tumormutationen, sondern um Keimbahn-Varianten. Letztere kommen in der Allgemeinbevölkerung in unterschiedlicher Häufigkeit vor und haben meist keinen Krankheitswert. Ziel meiner Arbeit war es, den Einfluss solcher Keimbahn-Polymorphismen in Genen für Transport (extrazellulär Hedgehog-Signalweg und transmembranäre Nukleosidtransporter) sowie Metabolismus von Gemcitabin auf Ansprechen und Nebenwirkung (Hämatotoxizität) von Patienten mit Pankreaskarzinom zu prüfen.

Aus 552 Patienten, die zwischen 2003 und 2011 in der Abteilung Allgemein- und Viszeralchirurgie der Universitätsmedizin Göttingen wegen einer Pankreaserkrankung behandelt wurden, kamen für meine Studie letztlich 142 in Betracht. Kriterien waren ein histologisch gesichertes adenoduktales Pankreaskarzinom, eine Gemcitabin-haltige Chemotherapie und die Verfügbarkeit von Überlebensdaten. Dazu wurden PathologieBerichte und Arztbriefe ausgewertet, sowie Kontakte zu ambulanten Onkologen und Hausärzten hergestellt. Dabei wurden auch die Blutbildverläufe unter Therapie dokumentiert. Aus peripherem Blut dieser Patienten konnten genomische DNA isoliert und daran 109 Polymorphismen in elf Genen mit dem Primerextensions-Verfahren analysiert werden.

Das mediane Gesamtüberleben aller 142 Patienten betrug elf Monate und variierte im Bereich von einem bis 114 Monaten. Ein deutlicher Einfluss auf das Überleben konnte für den Resektionsstatus und das histopathologische Grading des Tumors nachgewiesen werden. Die Genanalysen erfolgten daraufhin an 97 Patienten mit R0/R1-Resektionsstatus. Ein Signifikanzniveau von $P<0,05$ mit dem Gesamtüberleben erreichten zunächst in univariater Analyse zehn Varianten in DCTD, RRM2, ENT1, PTCH1 und SHH. Nach Adjustierung auf nicht-genetische Faktoren durch Cox-Regressionsanalyse verblieben davon noch sieben. Wurden diese dann zusammen in einem kombinierten Modell betrachtet, waren es noch drei: Eine Promotorvariante (rs1057985) und eine Aminosäurevariante (rs45573936, Ile216Thr) in ENT1 sowie ein SNP im Promotorbereich von SHH. Nach Adjustierung auf multiples Testen 
war ausschließlich die ENT1-Aminosäurevariante Ile216Thr statistisch signifikant mit Gesamtüberleben verbunden $(P=0,004)$. Heterozygote Träger von Thr216 wiesen eine um Faktor 8,8 erhöhte Sterbewahrscheinlichkeit auf. In der deutschen Bevölkerung tragen etwa $5 \%$ dieses Allel, d.h. bezogen auf die jährliche Pankreaskarzinom-Inzidenz betrifft dies ca. 650 Personen. Homozygotie für Thr216 fand sich weder in meiner Patientenkohorte noch in den ca. 2000 Individuen des weltweiten Genom-Resequenzierungsprojekts. Frühere in der Abteilung Klinische Pharmakologie der Universitätsmedizin Göttingen durchgeführte Studien ex vivo mit Gemcitabin behandelter Leukozyten zeigten in Gegenwart von Thr216 eine massiv verminderte Empfindlichkeit auf das Zytostatikum. Das Variantenallel des ENT1SNPs rs1057985 in der Promotorregion des Gens ging mit einer verlängerten Überlebenszeit während der Gemcitabin-Therapie einher. Funktionelle Untersuchungen deuten auf eine verstärkte ENT1-Transkription in Gegenwart dieses Allels hin. Dies fügt sich in die durch die Literatur gut belegte Hypothese, dass die Expressionsstärke des ENT1 eine wichtige Determinante für das Ansprechen auf Gemcitabin ist. Auch der Effekt des SNPs rs288746 im Hedgehog-Liganden $S H H$ auf die Überlebenszeit könnte infolge der Lokalisation im Promotorbereich auf einer transkriptionellen Beeinflussung beruhen; hierzu gibt es jedoch noch keine funktionellen Daten. Im Hinblick auf die Hämatotoxizität von Gemcitabin ließ sich keine Korrelation zwischen den Nadirwerten der Leuko- und Thrombozyten und der Zeitdauer bis zu deren Eintreten innerhalb der ersten 42 Therapietage nachweisen. Eine klare Assoziation der Hämatotoxizität mit den untersuchten Genpolymorphismen zeigte sich nicht. Am kohärentesten stellte sich in diesem Zusammenhang der ENT1-SNP rs747199 dar. Träger des Variantenallels tendierten in meiner Kohorte zu mehr Hämatotoxizität unter Gemcitabin und sprachen gleichzeitig etwas besser auf die Therapie an.

Die Bestätigung der Effekte von Ile216Thr in einer prospektiven Studie und den Nachweis einer direkten Funktionalität mittels Allel-spezifischer molekular-genetischer Konstrukte vorausgesetzt, wäre in Zukunft der Einsatz dieser Genvariante als möglicher Biomarker für eine Gemcitabin-basierte Chemotherapie bei Pankreaskarzinom denkbar. Den Patienten mit Thr216 könnten, in Annahme der Wirkungslosigkeit der Therapie, bereits initial alternative Therapiemodalitäten vorgeschlagen werden. Über einen Beitrag zur personalisierten Tumortherapie hinaus können die Ergebnisse meiner Dissertation weitere Forschungsanstrengungen zu einem besseren Verständnis der molekularen Zusammenhänge bei der Gemcitabin-Therapie stimulieren. Dies würde dann zukünftig weitere Optionen der Therapieverbesserung eröffnen. 


\section{Literaturverzeichnis}

Abbruzzese JL, Grunewald R, Weeks EA, Gravel D, Adams T, Nowak B, Mineishi S, Tarassoff P, Satterlee W, Raber MN et al. (1991): A phase I clinical, plasma, and cellular pharmacology study of gemcitabine. J Clin Oncol 9 (3), 491-498

Achiwa H, Oguri T, Sato S, Maeda H, Niimi T, Ueda R (2004): Determinants of sensitivity and resistance to gemcitabine: the roles of human equilibrative nucleoside transporter 1 and deoxycytidine kinase in non-small cell lung cancer. Cancer Sci 95 (9), 753-757

Aksoy P, Zhu MJ, Kalari KR, Moon I, Pelleymounter LL, Eckloff BW, Wieben ED, Yee VC, Weinshilboum RM, Wang L (2009): Cytosolic 5'-nucleotidase III (NT5C3): gene sequence variation and functional genomics. Pharmacogenet Genomics 19 (8), 567-576

Albain KS, Nag SM, Calderillo-Ruiz G, Jordaan JP, Llombart AC, Pluzanska A, Rolski J, Melemed AS, Reyes-Vidal JM, Sekhon JS et al. (2008): Gemcitabine plus Paclitaxel versus Paclitaxel monotherapy in patients with metastatic breast cancer and prior anthracycline treatment. J Clin Oncol 26(24), 3950-3957

Amundadottir L, Kraft P, Stolzenberg-Solomon RZ, Fuchs CS, Petersen GM, Arslan AA, Bueno-deMesquita HB, Gross M, Helzlsouer K, Jacobs EJ et al. (2009): Genome-wide association study identifies variants in the $\mathrm{ABO}$ locus associated with susceptibility to pancreatic cancer. Nat Genet $\underline{41}$ $\underline{(9)}, 986-990$

Bailey JM, Swanson BJ, Hamada T, Eggers JP, Singh PK, Caffery T, Ouellette MM, Hollingsworth MA (2008): Sonic hedgehog promotes desmoplasia in pancreatic cancer. Clin Cancer Res 14 (19), 5995-6004

Baldwin SA, Mackey JR, Cass CE, Young JD (1999): Nucleoside transporters: molecular biology and implications for therapeutic development. Mol Med Today 5 (5), 216-224

Baldwin SA, Beal PR, Yao SY, King AE, Cass CE, Young JD (2004): The equilibrative nucleoside transporter family, SLC29. Pflugers Arch 447 (5), 735-743

Berman DM, Karhadkar SS, Maitra A, Montes De Oca R, Gerstenblith MR, Briggs K, Parker AR, Shimada Y, Eshleman JR, Watkins DN et al. (2003): Widespread requirement for Hedgehog ligand stimulation in growth of digestive tract tumours. Nature $\underline{425(6960)}, 846-851$

Braakhuis BJ, van Dongen GA, Vermorken JB, Snow GB (1991): Preclinical in vivo activity of 2',2'difluorodeoxycytidine (Gemcitabine) against human head and neck cancer. Cancer Res 51 (1), 211214

Burris HA, 3rd, Moore MJ, Andersen J, Green MR, Rothenberg ML, Modiano MR, Cripps MC, Portenoy RK, Storniolo AM, Tarassoff P et al. (1997): Improvements in survival and clinical benefit with gemcitabine as first-line therapy for patients with advanced pancreas cancer: a randomized trial. $J$ Clin Oncol 15 (6), 2403-2413

Conroy T, Desseigne F, Ychou M, Bouche O, Guimbaud R, Becouarn Y, Adenis A, Raoul JL, Gourgou-Bourgade S, de la Fouchardiere C et al. (2011): FOLFIRINOX versus gemcitabine for metastatic pancreatic cancer. $N$ Engl J Med $\underline{364(19)}, 1817-1825$

Cunningham D, Chau I, Stocken DD, Valle JW, Smith D, Steward W, Harper PG, Dunn J, TudurSmith C, West J et al. (2009): Phase III randomized comparison of gemcitabine versus gemcitabine plus capecitabine in patients with advanced pancreatic cancer. J Clin Oncol 27 (33), 5513-5518 
Dong S, Guo AL, Chen ZH, Wang Z, Zhang XC, Huang Y, Xie Z, Yan HH, Cheng H, Wu YL (2010): RRM1 single nucleotide polymorphism -37C-->A correlates with progression-free survival in NSCLC patients after gemcitabine-based chemotherapy. J Hematol Oncol $\underline{3} 10$

Farrell JJ, Elsaleh H, Garcia M, Lai R, Ammar A, Regine WF, Abrams R, Benson AB, Macdonald J, Cass CE et al. (2009): Human equilibrative nucleoside transporter 1 levels predict response to gemcitabine in patients with pancreatic cancer. Gastroenterology 136 (1), 187-195

Farrell JJ, Bae K, Wong J, Guha C, Dicker AP, Elsaleh H (2011): Cytidine deaminase singlenucleotide polymorphism is predictive of toxicity from gemcitabine in patients with pancreatic cancer: RTOG 9704. Pharmacogenomics J. Epub 2011 May 31. http://www.nature.com/tpj/index.html. DOI: $10.1038 /$ tpj.2011.22

Ferlay J, Shin HR, Bray F, Forman D, Mathers C, Parkin DM (2010): Estimates of worldwide burden of cancer in 2008: GLOBOCAN 2008. Int J Cancer 127 (12), 2893-2917

Gandhi V, Plunkett W (1990): Modulatory activity of 2',2'-difluorodeoxycytidine on the phosphorylation and cytotoxicity of arabinosyl nucleosides. Cancer Res 50 (12), 3675-3680

Garcia-Manteiga J, Molina-Arcas M, Casado FJ, Mazo A, Pastor-Anglada M (2003): Nucleoside transporter profiles in human pancreatic cancer cells: role of hCNT1 in 2',2'-difluorodeoxycytidineinduced cytotoxicity. Clin Cancer Res 9 (13), 5000-5008

Gilbert JA, Salavaggione OE, Ji Y, Pelleymounter LL, Eckloff BW, Wieben ED, Ames MM, Weinshilboum RM (2006): Gemcitabine pharmacogenomics: cytidine deaminase and deoxycytidylate deaminase gene resequencing and functional genomics. Clin Cancer Res 12 (6), 1794-1803

Gillen S, Schuster T, Meyer Zum Buschenfelde C, Friess H, Kleeff J (2010): Preoperative/neoadjuvant therapy in pancreatic cancer: a systematic review and meta-analysis of response and resection percentages. PLoS Med 7 (4), e 1000267

Giovannetti E, Del Tacca M, Mey V, Funel N, Nannizzi S, Ricci S, Orlandini C, Boggi U, Campani D, Del Chiaro M et al. (2006): Transcription analysis of human equilibrative nucleoside transporter-1 predicts survival in pancreas cancer patients treated with gemcitabine. Cancer Res 66 (7), 3928-3935

Giovannetti E, Laan AC, Vasile E, Tibaldi C, Nannizzi S, Ricciardi S, Falcone A, Danesi R, Peters GJ (2008): Correlation between cytidine deaminase genotype and gemcitabine deamination in blood samples. Nucleosides Nucleotides Nucleic Acids 27 (6), 720-725

Gray JH, Owen RP, Giacomini KM (2004): The concentrative nucleoside transporter family, SLC28. Pflugers Arch $\underline{477(5)}, 728-734$

Griffiths M, Beaumont N, Yao SY, Sundaram M, Boumah CE, Davies A, Kwong FY, Coe I, Cass CE, Young JD et al. (1997): Cloning of a human nucleoside transporter implicated in the cellular uptake of adenosine and chemotherapeutic drugs. Nat Med 3 (1), 89-93

Hamilton SR, Yao SY, Ingram JC, Hadden DA, Ritzel MW, Gallagher MP, Henderson PJ, Cass CE, Young JD, Baldwin SA (2001): Subcellular distribution and membrane topology of the mammalian concentrative Na+-nucleoside cotransporter rCNT1. J Biol Chem 276 (30), 27981-27988

Hart AR, Kennedy H, Harvey I (2008): Pancreatic cancer: a review of the evidence on causation. Clin Gastroenterol Hepatol $\underline{6 \text { (3), 275-282 }}$

Hassan MM, Bondy ML, Wolff RA, Abbruzzese JL, Vauthey JN, Pisters PW, Evans DB, Khan R, Chou TH, Lenzi R et al. (2007): Risk factors for pancreatic cancer: case-control study. Am J

Gastroenterol 102 (12), 2696-2707 
Heinemann V, Xu YZ, Chubb S, Sen A, Hertel LW, Grindey GB, Plunkett W (1990): Inhibition of ribonucleotide reduction in CCRF-CEM cells by 2',2'-difluorodeoxycytidine. Mol Pharmacol 38 (4), 567-572

Heinemann V, Xu YZ, Chubb S, Sen A, Hertel LW, Grindey GB, Plunkett W (1992): Cellular elimination of 2',2'-difluorodeoxycytidine 5'-triphosphate: a mechanism of self-potentiation. Cancer Res 52 (3), 533-539

Heinemann V, Quietzsch D, Gieseler F, Gonnermann M, Schonekas H, Rost A, Neuhaus H, Haag C, Clemens M, Heinrich B et al. (2006): Randomized phase III trial of gemcitabine plus cisplatin compared with gemcitabine alone in advanced pancreatic cancer. J Clin Oncol 24 (24), 3946-3952

Hertel LW, Boder GB, Kroin JS, Rinzel SM, Poore GA, Todd GC, Grindey GB (1990): Evaluation of the antitumor activity of gemcitabine (2',2'-difluoro-2'-deoxycytidine). Cancer Res 50 (14), 4417-4422

Huang P, Plunkett W (1995): Induction of apoptosis by gemcitabine. Semin Oncol 22 (4 Suppl 11), $19-25$

Huang P, Chubb S, Hertel LW, Grindey GB, Plunkett W (1991): Action of 2',2'-difluorodeoxycytidine on DNA synthesis. Cancer Res 51 (22), 6110-6117

Humbert M, Casteran N, Letard S, Hanssens K, Iovanna J, Finetti P, Bertucci F, Bader T, Mansfield $\mathrm{CD}$, Moussy A et al. (2010): Masitinib combined with standard gemcitabine chemotherapy: in vitro and in vivo studies in human pancreatic tumour cell lines and ectopic mouse model. PLoS One 5 (3), e9430

Innocenti F, Owzar K, Cox NL, Evans P, Kubo M, Zembutsu H, Jiang C, Hollis D, Mushiroda T, Li L et al. (2012): A Genome-Wide Association Study of Overall Survival in Pancreatic Cancer Patients Treated with Gemcitabine in CALGB 80303. Clin Cancer Res 18 (2), 577-584

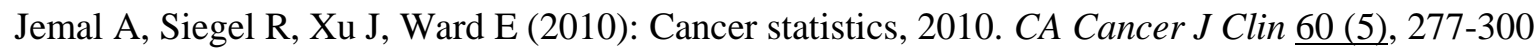

Jones S, Zhang X, Parsons DW, Lin JC, Leary RJ, Angenendt P, Mankoo P, Carter H, Kamiyama H, Jimeno A et al. (2008): Core signaling pathways in human pancreatic cancers revealed by global

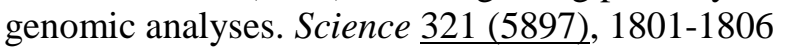

Kim JH, Karpyak VM, Biernacka JM, Nam HW, Lee MR, Preuss UW, Zill P, Yoon G, Colby C, Mrazek DA et al. (2011): Functional role of the polymorphic 647 T/C variant of ENT1 (SLC29A1) and its association with alcohol withdrawal seizures. PLoS One 6 (1), e16331

Kindler HL, Niedzwiecki D, Hollis D, Sutherland S, Schrag D, Hurwitz H, Innocenti F, Mulcahy MF, O'Reilly E, Wozniak TF et al. (2010): Gemcitabine plus bevacizumab compared with gemcitabine plus placebo in patients with advanced pancreatic cancer: phase III trial of the Cancer and Leukemia Group B (CALGB 80303). J Clin Oncol 28 (22), 3617-3622

Kuschel C: Funktionelle und genetische Variabilität bei der zytotoxischen Wirkung von NukleosidAnaloga. Untersuchung in menschlichen Leukozyten und lymphoblastoiden Zelllinien. Medizinische Dissertation Göttingen 2011

Lamba JK, Crews K, Pounds S, Schuetz EG, Gresham J, Gandhi V, Plunkett W, Rubnitz J, Ribeiro R (2007): Pharmacogenetics of deoxycytidine kinase: identification and characterization of novel genetic variants. J Pharmacol Exp Ther 323 (3), 935-945 
Leabman MK, Huang CC, DeYoung J, Carlson EJ, Taylor TR, de la Cruz M, Johns SJ, Stryke D, Kawamoto M, Urban TJ et al. (2003): Natural variation in human membrane transporter genes reveals evolutionary and functional constraints. Proc Natl Acad Sci U S A 100 (10), 5896-5901

Letra A, Menezes R, Govil M, Fonseca RF, McHenry T, Granjeiro JM, Castilla EE, Orioli IM, Marazita ML, Vieira AR (2010): Follow-up association studies of chromosome region 9q and nonsyndromic cleft lip/palate. Am J Med Genet A 152A (7), 1701-1710

Li L, Schaid DJ, Fridley BL, Kalari KR, Jenkins GD, Abo RP, Batzler A, Moon I, Pelleymounter L, Eckloff BW et al. (2012): Gemcitabine metabolic pathway genetic polymorphisms and response in patients with non-small cell lung cancer. Pharmacogenet Genomics 22 (2), 105-116

Mackey JR, Mani RS, Selner M, Mowles D, Young JD, Belt JA, Crawford CR, Cass CE (1998): Functional nucleoside transporters are required for gemcitabine influx and manifestation of toxicity in cancer cell lines. Cancer Res 58 (19), 4349-4357

Mackey JR, Yao SY, Smith KM, Karpinski E, Baldwin SA, Cass CE, Young JD (1999): Gemcitabine transport in xenopus oocytes expressing recombinant plasma membrane mammalian nucleoside transporters. J Natl Cancer Inst 91 (21), 1876-1881

Mangravite LM, Lipschutz JH, Mostov KE, Giacomini KM (2001): Localization of GFP-tagged concentrative nucleoside transporters in a renal polarized epithelial cell line. Am J Physiol Renal Physiol 280 (5), F879-885

Moore MJ, Goldstein D, Hamm J, Figer A, Hecht JR, Gallinger S, Au HJ, Murawa P, Walde D, Wolff RA et al. (2007): Erlotinib plus gemcitabine compared with gemcitabine alone in patients with advanced pancreatic cancer: a phase III trial of the National Cancer Institute of Canada Clinical Trials Group. J Clin Oncol 25 (15), 1960-1966

Morinaga S, Nakamura Y, Watanabe T, Mikayama H, Tamagawa H, Yamamoto N, Shiozawa M, Akaike M, Ohkawa S, Kameda Y et al. (2011): Immunohistochemical Analysis of Human Equilibrative Nucleoside Transporter-1 (hENT1) Predicts Survival in Resected Pancreatic Cancer Patients Treated with Adjuvant Gemcitabine Monotherapy. Ann Surg Oncol. Epub 2011 Sept 13. http://www.annsurgoncol.org. DOI: 10.1245/s10434-011-2054-z

Myers SN, Goyal RK, Roy JD, Fairfull LD, Wilson JW, Ferrell RE (2006): Functional single nucleotide polymorphism haplotypes in the human equilibrative nucleoside transporter 1.

Pharmacogenet Genomics 16(5), 315-320

Neoptolemos JP, Stocken DD, Bassi C, Ghaneh P, Cunningham D, Goldstein D, Padbury R, Moore MJ, Gallinger S, Mariette C et al. (2010): Adjuvant chemotherapy with fluorouracil plus folinic acid vs gemcitabine following pancreatic cancer resection: a randomized controlled trial. The Journal of the American Medical Association (Jama) 304 (10), 1073-1081

Nusslein-Volhard C, Wieschaus E (1980): Mutations affecting segment number and polarity in Drosophila. Nature 287 (5785), 795-801

Nybakken K, Perrimon N (2002): Hedgehog signal transduction: recent findings. Curr Opin Genet Dev 12(5), 503-511

Oettle H, Post S, Neuhaus P, Gellert K, Langrehr J, Ridwelski K, Schramm H, Fahlke J, Zuelke C, Burkart C et al. (2007): Adjuvant chemotherapy with gemcitabine vs observation in patients undergoing curative-intent resection of pancreatic cancer: a randomized controlled trial. The Journal of the American Medical Association (Jama) 297 (3), 267-277 
Oguri T, Achiwa H, Muramatsu H, Ozasa H, Sato S, Shimizu S, Yamazaki H, Eimoto T, Ueda R (2007): The absence of human equilibrative nucleoside transporter 1 expression predicts nonresponse to gemcitabine-containing chemotherapy in non-small cell lung cancer. Cancer Lett 256 (1), 112-119

Okazaki T, Javle M, Tanaka M, Abbruzzese JL, Li D (2010): Single nucleotide polymorphisms of gemcitabine metabolic genes and pancreatic cancer survival and drug toxicity. Clin Cancer Res 16 (1), 320-329

Olive KP, Jacobetz MA, Davidson CJ, Gopinathan A, McIntyre D, Honess D, Madhu B, Goldgraben MA, Caldwell ME, Allard D et al. (2009): Inhibition of Hedgehog signaling enhances delivery of

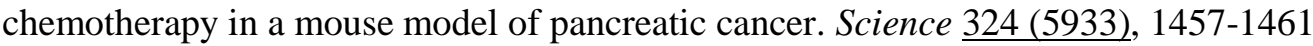

Osato DH, Huang CC, Kawamoto M, Johns SJ, Stryke D, Wang J, Ferrin TE, Herskowitz I, Giacomini KM (2003): Functional characterization in yeast of genetic variants in the human equilibrative nucleoside transporter, ENT1. Pharmacogenetics 13 (5), 297-301

Plunkett W, Huang P, Xu YZ, Heinemann V, Grunewald R, Gandhi V (1995): Gemcitabine: metabolism, mechanisms of action, and self-potentiation. Semin Oncol 22 (4 Suppl 11), 3-10

Plunkett W, Huang P, Searcy CE, Gandhi V (1996): Gemcitabine: preclinical pharmacology and mechanisms of action. Semin Oncol 23 (5 Suppl 10), 3-15

Preuß A: Funktionelle und genetische Variabilität in Nukleosidtransportern für die Wirksamkeit von Gemcitabin: Retrospektive und prospektive Patientenstudie bei Pankreaskarzinom sowie in-vitroUntersuchungen an Blutzellen gesunder Spender. Medizinische Dissertation Göttingen 2009

Raimondi S, Lowenfels AB, Morselli-Labate AM, Maisonneuve P, Pezzilli R (2010): Pancreatic cancer in chronic pancreatitis; aetiology, incidence, and early detection. Best Pract Res Clin Gastroenterol 24 (3), 349-358

Rha SY, Jeung HC, Choi YH, Yang WI, Yoo JH, Kim BS, Roh JK, Chung HC (2007): An association between RRM1 haplotype and gemcitabine-induced neutropenia in breast cancer patients. Oncologist $12(6), 622-630$

Ritzel MW, Ng AM, Yao SY, Graham K, Loewen SK, Smith KM, Hyde RJ, Karpinski E, Cass CE, Baldwin SA et al. (2001): Recent molecular advances in studies of the concentrative Na+-dependent nucleoside transporter (CNT) family: identification and characterization of novel human and mouse proteins (hCNT3 and mCNT3) broadly selective for purine and pyrimidine nucleosides (system cib). Mol Membr Biol 18 (1), 65-72

Robbins DJ, Nybakken KE, Kobayashi R, Sisson JC, Bishop JM, Therond PP (1997): Hedgehog elicits signal transduction by means of a large complex containing the kinesin-related protein costal2. Cell 90 (2), 225-234

Robert Koch-Institut (Hrsg): Krebs in Deutschland 2005/2006. Häufigkeiten und Trends.7. Ausgabe. Robert Koch-Institut (Hrsg) und die Gesellschaft der epidemiologischen Krebsregister in Deutschland e. V. (Hrsg). Berlin, 2010a

Robert Koch-Institut (Hrsg.): Verbreitung von Krebserkrankungen in Deutschland. Entwicklung der Prävalenzen zwischen 1990 und 2010. Beiträge zur Gesundheitsberichterstattung des Bundes. RKI, Berlin, 2010b

Robert Koch-Institut (2011): Datenbankabfrage www.rki.de vom 28.08.2011 
Ryu JS, Shin ES, Nam HS, Yi HG, Cho JH, Kim CS, Kim HJ, Lee JE (2011): Differential effect of polymorphisms of CMPK1 and RRM1 on survival in advanced non-small cell lung cancer patients treated with gemcitabine or taxane/cisplatinum. J Thorac Oncol $\underline{6(8)}$, 1320-1329

Saif MW (2008): Translational research in pancreatic cancer. Highlights from the "44th ASCO Annual Meeting". Chicago, IL, USA. May 30 - June 3, 2008. Journal of the Pancreas (Jop) 9 (4), 398-402

Sandler AB, Nemunaitis J, Denham C, von Pawel J, Cormier Y, Gatzemeier U, Mattson K, Manegold C, Palmer MC, Gregor A et al. (2000): Phase III trial of gemcitabine plus cisplatin versus cisplatin alone in patients with locally advanced or metastatic non-small-cell lung cancer. J Clin Oncol 18 (1), $122-130$

Santini D, Perrone G, Vincenzi B, Lai R, Cass C, Alloni R, Rabitti C, Antinori A, Vecchio F, Morini S et al. (2008): Human equilibrative nucleoside transporter 1 (hENT1) protein is associated with short survival in resected ampullary cancer. Ann Oncol 19 (4), 724-728

Santini D, Vincenzi B, Fratto ME, Perrone G, Lai R, Catalano V, Cass C, Ruffini PA, Spoto C, Muretto P et al. (2010): Prognostic role of human equilibrative transporter 1 (hENT1) in patients with resected gastric cancer. J Cell Physiol 223 (2), 384-388

Shewach DS, Reynolds KK, Hertel L (1992): Nucleotide specificity of human deoxycytidine kinase. Mol Pharmacol 42 (3), 518-524

Shi JY, Shi ZZ, Zhang SJ, Zhu YM, Gu BW, Li G, Bai XT, Gao XD, Hu J, Jin W et al. (2004): Association between single nucleotide polymorphisms in deoxycytidine kinase and treatment response among acute myeloid leukaemia patients. Pharmacogenetics 14 (11), 759-768

Spratlin J, Sangha R, Glubrecht D, Dabbagh L, Young JD, Dumontet C, Cass C, Lai R, Mackey JR (2004): The absence of human equilibrative nucleoside transporter 1 is associated with reduced survival in patients with gemcitabine-treated pancreas adenocarcinoma. Clin Cancer Res 10 (20), 6956-6961

Stecca B, Mas C, Clement V, Zbinden M, Correa R, Piguet V, Beermann F, Ruiz IAA (2007): Melanomas require HEDGEHOG-GLI signaling regulated by interactions between GLI1 and the RAS-MEK/AKT pathways. Proc Natl Acad Sci U S A 104 (14), 5895-5900

Storniolo AM, Allerheiligen SR, Pearce HL (1997): Preclinical, pharmacologic, and phase I studies of gemcitabine. Semin Oncol 24 (2 Suppl 7), S7-2-S7-7

Sugiyama E, Kaniwa N, Kim SR, Kikura-Hanajiri R, Hasegawa R, Maekawa K, Saito Y, Ozawa S, Sawada J, Kamatani N et al. (2007): Pharmacokinetics of gemcitabine in Japanese cancer patients: the impact of a cytidine deaminase polymorphism. J Clin Oncol $\underline{25(1)}, 32-42$

Sundaram M, Yao SY, Ng AM, Cass CE, Baldwin SA, Young JD (2001): Equilibrative nucleoside transporters: mapping regions of interaction for the substrate analogue nitrobenzylthioinosine (NBMPR) using rat chimeric proteins. Biochemistry 40 (27), 8146-8151

Tanaka M, Javle M, Dong X, Eng C, Abbruzzese JL, Li D (2010): Gemcitabine metabolic and transporter gene polymorphisms are associated with drug toxicity and efficacy in patients with locally advanced pancreatic cancer. Cancer $116(22), 5325-5335$

Thayer SP, di Magliano MP, Heiser PW, Nielsen CM, Roberts DJ, Lauwers GY, Qi YP, Gysin S, Fernandez-del Castillo C, Yajnik V et al. (2003): Hedgehog is an early and late mediator of pancreatic cancer tumorigenesis. Nature $\underline{425(6960)}, 851-856$ 
Turati F, Galeone C, Edefonti V, Ferraroni M, Lagiou P, La Vecchia C, Tavani A (2012): A metaanalysis of coffee consumption and pancreatic cancer. Ann Oncol 23 (2), 311-318

Vincent A, Herman J, Schulick R, Hruban RH, Goggins M (2011): Pancreatic cancer. Lancet 378 (9791), 607-620

von der Maase H, Hansen SW, Roberts JT, Dogliotti L, Oliver T, Moore MJ, Bodrogi I, Albers P, Knuth A, Lippert CM et al. (2000): Gemcitabine and cisplatin versus methotrexate, vinblastine, doxorubicin, and cisplatin in advanced or metastatic bladder cancer: results of a large, randomized, multinational, multicenter, phase III study. J Clin Oncol 18 (17), 3068-3077

Wagner M, Redaelli C, Lietz M, Seiler CA, Friess H, Buchler MW (2004): Curative resection is the single most important factor determining outcome in patients with pancreatic adenocarcinoma. $\mathrm{Br} J$ Surg $91(5), 586-594$

Wolpin BM, Kraft P, Gross M, Helzlsouer K, Bueno-de-Mesquita HB, Steplowski E, StolzenbergSolomon RZ, Arslan AA, Jacobs EJ, Lacroix A et al. (2010): Pancreatic cancer risk and ABO blood group alleles: results from the pancreatic cancer cohort consortium. Cancer Res $\underline{70}$ (3), 1015-1023

Xu X, Strimpakos AS, Saif MW (2011): Biomarkers and pharmacogenetics in pancreatic cancer. Highlights from the "2011 ASCO Annual Meeting". Chicago, IL, USA; June 3-7, 2011. Journal of the Pancreas (Jop) 12 (4), 325-329

Yuan Z, Goetz JA, Singh S, Ogden SK, Petty WJ, Black CC, Memoli VA, Dmitrovsky E, Robbins DJ (2007): Frequent requirement of hedgehog signaling in non-small cell lung carcinoma. Oncogene $\underline{26}$ (7), 1046-1055 


\section{Danksagung}

Herrn Prof. Dr. med. J. Brockmöller danke ich für das entgegengebrachte Vertrauen bei der Überlassung dieses spannenden Themas sowie für die Ermöglichung meiner Dissertation und wissenschaftlichen Tätigkeit in seiner Abteilung.

Herrn Prof. Dr. med. B. M. Ghadimi danke ich für die Förderung dieser Arbeit und die Ermöglichung, auf ein solch umfassendes Patientenkollektiv zurückgreifen zu können.

Mein besonderer Dank gilt Herrn Dr. med M. Schirmer für seine kompetente und intensive Betreuung während der gesamten Arbeit. Danke für die stete, tatkräftige Unterstützung, die wertvollen Hilfestellungen bei der Erstellung der vorliegenden Dissertationsschrift und die vielen investierten Stunden.

Ich möchte zudem allen Mitarbeiterinnen und Mitarbeitern der Abteilung Klinische Pharmakologie der Universitätsmedizin Göttingen für Hilfe und Beratung bei meiner experimentellen Tätigkeit danken, hier v.a. meinen Mitdoktoranden Herrn C. Zimmer und Herrn S.Roppel.

Weiterhin gilt den Mitarbeiterinnen und Mitarbeitern der Abteilung Allgemein- und Viszeralchirurgie der Universitätsmedizin Göttingen, insbesondere Herrn Dr. med J. Gaedcke sowie aus der Abteilung Pathologie der Universitätsmedizin Göttingen Frau Dr. med J. Kitz mein Dank für die konstruktive Zusammenarbeit.

Darüber hinaus bedanke ich mich für die gute Kooperation und Hilfe bei der Patientennachsorge bei allen beteiligten Arztpraxen und Ambulanzen im Raum Südniedersachsen / Nordhessen, v.a. bei den Mitarbeiterinnen und Mitarbeitern der Interdisziplinären Kurzzeitonkologie (IKO) der Universitätsmedizin Göttingen.

Einen besonderen Dank möchte ich an Frau Dr. med. R. Montag richten, die mir bei der Erarbeitung dieser Dissertationsschrift vertrauensvoll mit Rat und Tat zur Seite gestanden hat. 


\section{Lebenslauf}

Ich wurde am 21.04.1983 als einziger Sohn der Eheleute Dr. med. Esther Schaudinn (geb. Ullmann) und Dipl. Ing. Siegfried Schaudinn in Erfurt geboren.

Von 1989 bis 1993 besuchte ich die Grundschule Am Schwemmbach in Erfurt. Danach wechselte ich auf das Heinrich-Mann-Gymnasium in Erfurt. Während der Gymnasialzeit verbrachte ich ein Schuljahr an der Caprock Highschool in Amarillo/Texas, USA. 2002 legte ich das Abitur ab.

Anschließend absolvierte ich den Zivildienst im Helios Klinikum Erfurt.

Von Herbst 2003 bis Frühjahr 2004 verfolgte ich das Studium der Kulturwissenschaften an der Europa-Universität Viadrina in Frankfurt an der Oder.

Im April 2004 begann ich mit dem Studium der Humanmedizin an der Georg-AugustUniversität Göttingen. Im Jahr 2006 bestand ich erfolgreich das Physikum. Ein Jahr des klinischen Studienabschnitts absolvierte ich an der Universidad Autonoma in Barcelona. Nach zehn Semestern beendete ich den theoretischen Teil des Studiums. Im Anschluss begann ich mit den Arbeiten zu meiner Dissertation als Stipendiat des Graduiertenkollegs 1034 der Universität Göttingen. Von Februar 2009 bis Januar 2010 war ich als PJ-Student in den Abteilungen Neurologie der Universitätsmedizin Göttingen, Innere des Klinikums Bremen Mitte und Chirurgie des Hospital Aleman in Buenos Aires, Argentinien (Lehrkrankenhaus der Universität Buenos Aires) tätig. Das Medizinstudium schloss ich im April 2010 mit dem Staatsexamen an der Universität Göttingen erfolgreich ab und erhielt meine Approbation als Arzt.

Seither arbeitete ich weiter an meiner Dissertationsschrift. 